\title{
COMPARATIVE EFFICACY OF THREE ANTISEPTICS AS SURGICAL SKIN PREPARATIONS IN DOGS
}

\author{
by \\ Charles Boucher \\ Submitted in partial fulfilment of the requirements for the degree of

\section{MMedVet (Surgery)(Small Animals)}

Companion Animal Clinical Studies

Faculty of Veterinary Science

University of Pretoria

Pretoria, April 2017 


\section{Dissertation}

Comparative efficacy of three antiseptics as surgical skin preparations in dogs

\section{Charles Boucher}

97099245

Supervisor: $\quad$ Prof Marthinus J. Hartman

Co-supervisor: Dr Maryke M. Henton

Department: $\quad$ Companion Animal Clinical Studies

Faculty of Veterinary Science

University: University of Pretoria 
I, Charles Boucher, student number 97099245 hereby declare that this dissertation, "Comparative efficacy of three antiseptics as surgical skin preparations in dogs", is submitted in accordance with the requirements for the Master in Veterinary Medicine degree at University of Pretoria, is my own original work and has not previously been submitted to any other institution of higher learning. All sources cited or quoted in this research paper are indicated and acknowledged with a comprehensive list of references.

Signature:

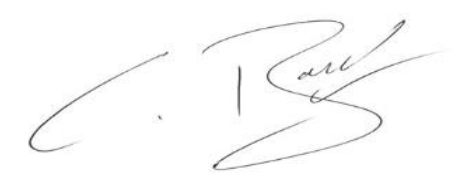

Dr Charles Boucher

Date: $\quad 31$ March 2017 
I dedicate this research to my loving wife, Christie, and our two children Charlie and Celeste, for their unconditional love and support in my pursuit of a lifelong dream.

Quote by Sir Thomas Clifford Allbutt, about Lord Joseph Lister (English surgeon, medical scientist and pioneer of aseptic surgery):

"Lister saw the vast importance of the discoveries of Pasteur. He saw it because he was watching on the heights, and he was watching there alone." 
My sincere appreciation and grateful thanks to the following people for their contributions in helping me to complete this research project:

- Professor Marthinus Hartman, acted as my research supervisor. His open door approach (at work and at his home), his contagious and positive attitude towards research and his ability to take a problem and turn it into a challenge sustained me through this project.

- Dr Maryke Henton, for acting as my research co-supervisor, for her expert opinion, the late nights and the weekends that she sacrificed to help me in the development of this dissertation.

- Mrs Zelda Coetzer kindly assisted me in the editing of this dissertation.

- Professor Robert Kirberger, provided valuable advice during the planning of the research protocol and gave me continued moral support and encouragement to expedite this research project.

- Professor Piet Becker guided me through the many pitfalls with the statistical analyses of project data.

- My parents, Charlie and Thea, for their endless years of support and providing me with a good education, life skills and principles that allowed me to follow my dream.

- Sisters Jana Stander and Adéle Rossouw assisted me with the patient preparations the the collection of samples.

- Charmaine Vermeulen and Sister Michelle Schutte provided the photographic record.

- Debbie Landman, Erick Kapp, Hailey Bunge and Johan Gouws from the Department of Tropical Diseases for performing the bacteriological work. 


\section{SUMMARY}

\section{Aim and Objective}

To determine the difference in antimicrobial efficacy between the combination of $2 \%$ chlorhexidine and $70 \%$ ethanol $(\mathrm{CG}+\mathrm{A}), \mathrm{F} 10^{\circledR}$ Skin Prep Solution $(\mathrm{F} 10)$ and electrochemically activated water (EAW) when used as a surgical preparation in canine patients.

\section{Study design}

Prospective randomised clinical study.

\section{Sample population}

One hundred and seventeen dogs.

\section{Materials and methods}

Skin samples using replicating organism detection and counting plates were taken at four different perioperative sites and time intervals. The first sample of each dog was taken after skin preparation, using a neutral detergent, from the caudal and central aspect of the surgical field. The second sample was taken from the umbilical area following antisepsis with one of the three chosen antiseptics. The third sample was taken from the cranial surgical field two hours after the second sample and the fourth sample was taken from the right para-median aspect of the surgical field, halfway along the incision site at the end of surgery. The colony forming unit (CFU) counts from each sample were quantified according to the level of bacterial contamination. No contamination was defined as zero CFU's. Low contamination was defined as between 1-12 CFU's and high contamination was defined as greater than or equal to $13 \mathrm{CFU}$ 's. The three antiseptics were compared with respect to the level of contamination. The manufacturers' directions for use were not followed for any of the skin preparation solutions used in this research project. 


\section{Results}

There was no significant difference in the level of contamination between the antiseptics at the first sampling time $(P=.454)$. However, the level of contamination for $\mathrm{CG}+\mathrm{A}$ was significantly lower compared to $\mathrm{F} 10$ and $\mathrm{EAW}$ at the second, third and fourth sampling times $(P=.001, P=.01, P=.02)$.

Relative to $\mathrm{CG}+\mathrm{A}$, EAW had a 7 fold increased risk for bacterial contamination $(P=.001)$ and similarly $\mathrm{F} 10^{\circledR}$ showed a 10 fold increased risk $(P=.001)$ at the second sampling time for a clean ( 0 CFU's) or contaminated ( $\geq 1$ CFU's) outcome. Similar results were obtained at the third and fourth sampling times when EAW had a 3 and 4 fold increased risk for bacterial contamination $(P=.015)$ respectively and F10 showed a 5 and 4 fold increased risk $(P=.001)$.

\section{Conclusion}

The combination of $2 \%$ chlorhexidine and $70 \%$ alcohol was a statistically significant more effective skin antiseptic at achieving a zero CFU count and low levels of contamination when compared to F10 and EAW for surgical preparation in dogs undergoing ovariohysterectomy. 


\section{TABLE OF CONTENTS}

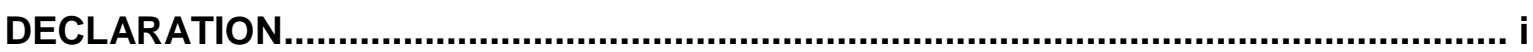

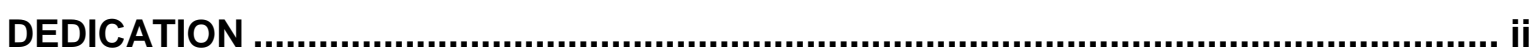

ACKNOWLEDGEMENTS.............................................................................................ii

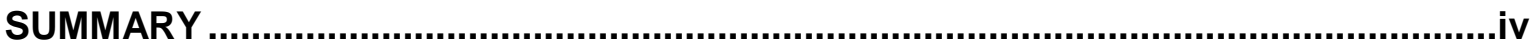

TABLE OF CONTENTS …..........................................................................................

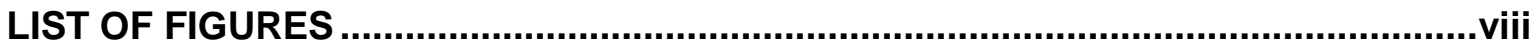

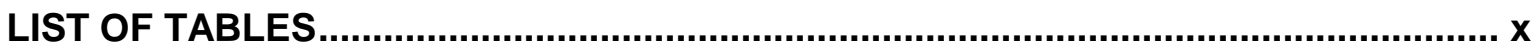

LIST OF ABBREVIATIONS.....................................................................................

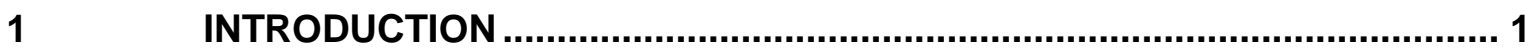

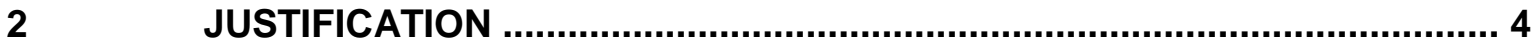

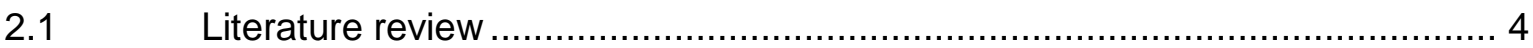

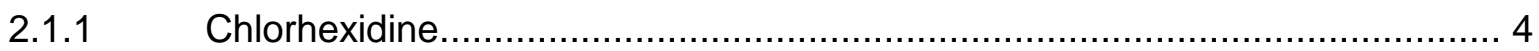

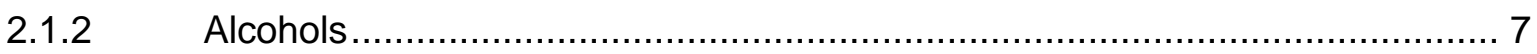

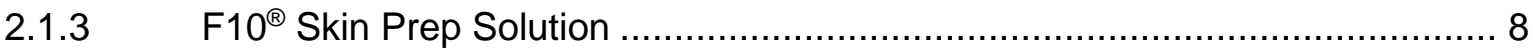

2.1.4 Electrochemically activated water ....................................................... 10

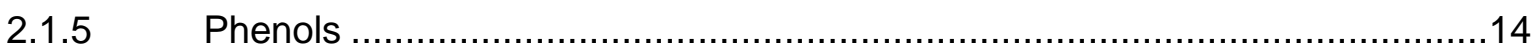

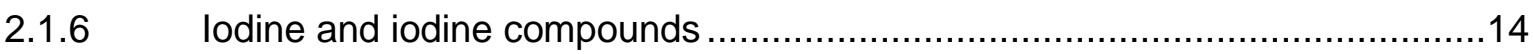

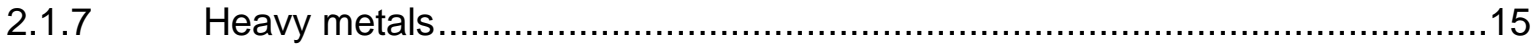

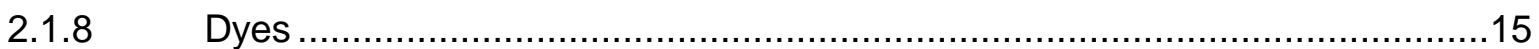

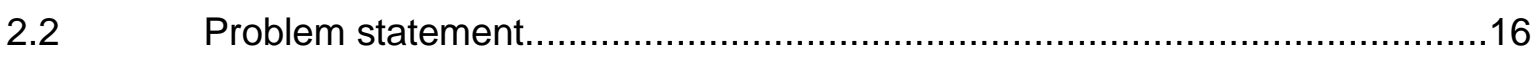

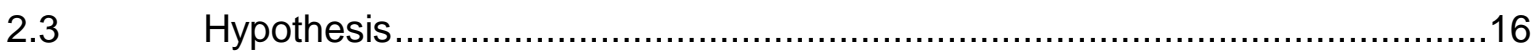

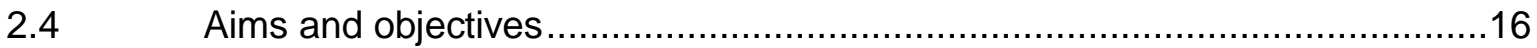

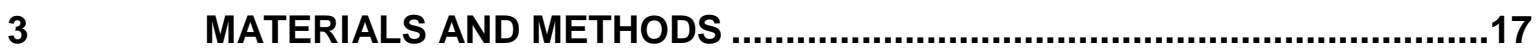

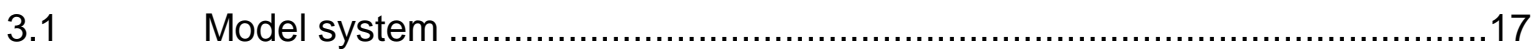

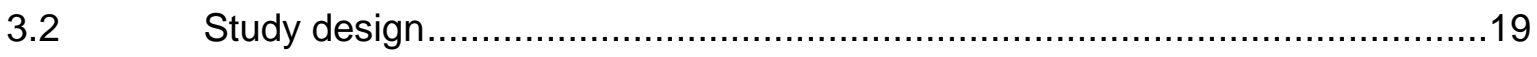

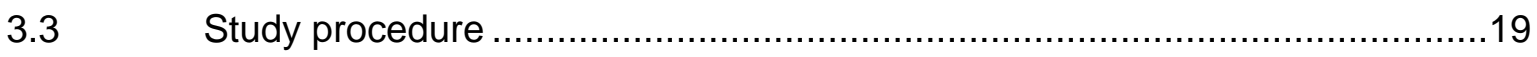

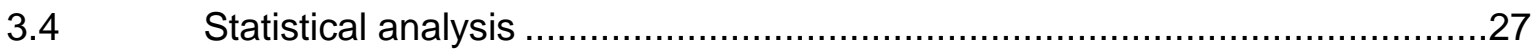

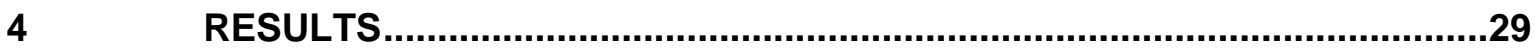

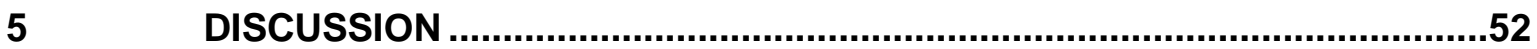

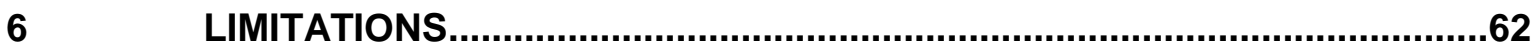

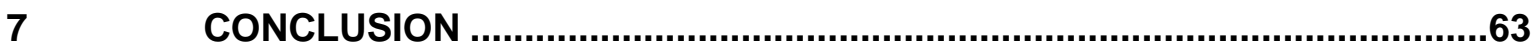

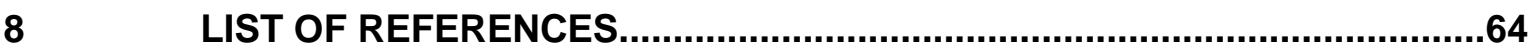


9.1 ANNEXURE A: Animal ethics committee approval form .............................74

9.2 ANNEXURE B: Data collection sheet ................................................ 75

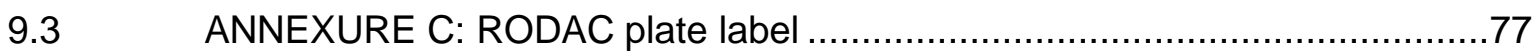

9.4 ANNEXURE D: Informed consent forms ............................................

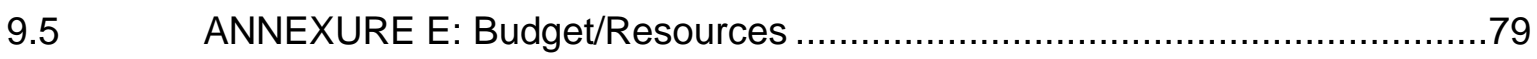

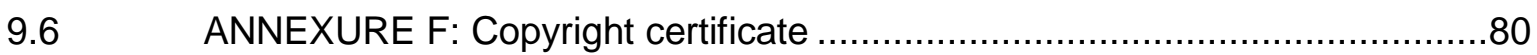

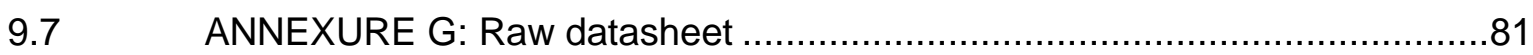




\section{LIST OF FIGURES}

Figure 1 Schematic representation of the production of electrolyzed water.......................... 11

Figure $2 \quad 2 \%$ Chlorhexidine gluconate and $70 \%$ ethanol solution. ..................................... 18

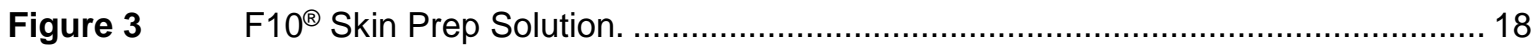

Figure $4 \quad$ Electrochemically activated water. ……...................................................... 19

Figure $5 \quad$ Clipping of hair as part of the preparation of the surgical site. ............................. 21

Figure 6 Presurgical wash with neutral detergent. (A-D) The wash started at the proposed incision site and then moved outwards in a circular fashion.

Figure 7 First skin sample taken from the caudal midline after the presurgical wash. 22

Figure 8 Second skin sample taken from the centre of the surgical field, over the umbilicus, three minutes following antiseptic application.

Figure 9 Third skin sample taken from cranial aspect of the surgical field two hours after the second sample.

Figure 10 Fourth skin sample taken from the right paramedian aspect of the surgical field at the end of surgery.

Figure 11 Case no. 13 showing an erythematous, crusted, pustular/papular rash. This dog was excluded from our trial due to bacterial skin disease. 29

Figure 12 Prevalence of all dogs with positive cultures at the four sampling times. 30

Figure 13 Total CFU count for all the dogs of each antiseptic at the four sampling times...... 31

Figure $14 \quad$ Level of bacterial contamination at the first sampling time...................................... 35

Figure 15 Level of bacterial contamination at the second sampling time ............................... 35

Figure $16 \quad$ Level of bacterial contamination at the third sampling time.................................. 36

Figure $17 \quad$ Level of bacterial contamination at the fourth sampling time. ............................... 36

Figure 18 Prevalence of the most common bacteria at the four sampling times.................... 39

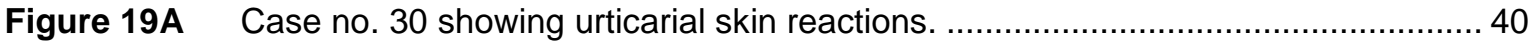

Figure 19B Close up of case no. 30 showing urticarial skin reactions..................................... 41

Figure 19C Case no. 32 showing urticarial skin reactions. .................................................... 41

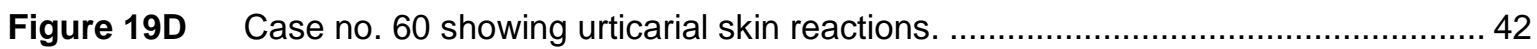


Figure 20 Case no. 55 showing excoriation and an erythematous skin reaction following an overzealous wash with a neutral detergent...

Figure 21A Case no. 25 showing an erythematous skin reaction................................... 43

Figure 21B Case no. 63 showing an erythematous skin reaction. ............................... 43

Figure 22A Case no. 80 showing an erythematous papular rash. ................................ 44

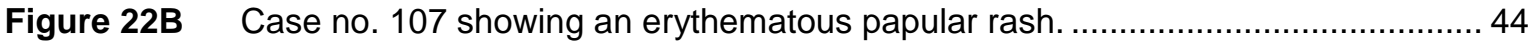

Figure 22C Case no. 127 showing an erythematous papular rash. ................................ 45

Figure 23 Prevalence of all dogs with positive cultures for pathogenic bacteria at the

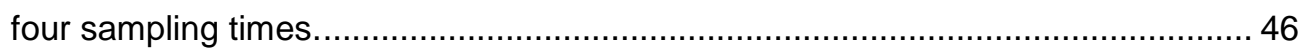

Figure 24 Total CFU count of the pathogenic bacteria for each antiseptic at the

Figure $25 \quad$ Level of pathogenic bacterial contamination at the first sampling time................. 49

Figure $26 \quad$ Level of pathogenic bacterial contamination at the second sampling time. .......... 49

Figure 27 Level of pathogenic bacterial contamination at the third sampling time...............50

Figure $28 \quad$ Level of pathogenic bacterial contamination at the fourth sampling time..............50 


\section{LIST OF TABLES}

Table 1 Free available chlorine, $\mathrm{pH}$ and oxidative reduction potential readings of electrochemically activated water

Table 2 Prevalence of all dogs with positive bacterial cultures at the four sampling times.

Table 3 Median colony forming unit counts for all dogs at the four sampling times.

Table 4 Median colony forming unit counts at the second, third and fourth sampling times for the three antiseptics

Table 5 Distribution of the level of bacterial contamination for the three antiseptics

Table 6 Odds ratio for clean or contaminated outcome of each antiseptic using chlorhexidine and alcohol as the reference

Table 7 Prevalence of the most common bacteria at the four sampling times

Table 8 Prevalence of all dogs with positive cultures for pathogenic bacteria at the four sampling times.

Table 9 Distribution of the level of pathogenic bacterial contamination of samples for the three antiseptics.

Table 10 Odds ratio for clean or contaminated outcome of the pathogenic bacteria of each antiseptic, with chlorhexidine and alcohol as the reference 


\section{LIST OF ABBREVIATIONS}

CFU

$\mathrm{CG}+\mathrm{A}$

$\mathrm{Cl}^{-}$

$\mathrm{Cl}_{2}$

EAW

ET

FAC

F10

$\mathrm{H}^{+}$

$\mathrm{H}_{2}$

$\mathrm{HCl}$

$\mathrm{HOCl}$

$\mathrm{I}_{2}$

IQR

MRSP

$\mathrm{mV}$

$\mathrm{Na}^{+}$

$\mathrm{NaCl}$

$\mathrm{NaOH}$

$\mathrm{O}_{2}$

$\mathrm{OCl}^{-}$

$\mathrm{OH}^{-}$

ORP

OVAH

$\mathrm{pH}$

PHMB

PPM

QAC

RODAC
Colony forming unit

Chlorhexidine gluconate and ethanol

Chlorine

Chlorine gas

Electrochemically activated water

Endotracheal

Free available chlorine

F10 ${ }^{\circledR}$ Skin Prep Solution

Hydrogen

Hydrogen gas

Hydrochloric acid

Hypochlorous acid

lodine

Interquartile range

Methicillin-resistant Staphylococcus pseudintermedius

Millivolts

Sodium

Sodium chloride

Sodium hydroxide

Oxygen gas

Hypochlorite ions

Hydroxide

Oxidation reduction potential

Onderstepoort veterinary academic hospital

Power of hydrogen

Polyhexamethylene biguanides

Parts per million

Quaternary ammonium compounds

Replicating organism detection and counting 


\section{INTRODUCTION}

Surgical site infections remain a serious complication in both human and veterinary surgery. ${ }^{1}$ The estimated post-operative wound infection rate in small animal surgery ranges from 2-5.5\%. ${ }^{2,3}$ Despite implementing modern principles of pre-operative preparation of the patient and the surgical team, the use of peri-operative antibiotics and the refinement of surgical techniques, post-operative infections remain a substantial cause of morbidity in veterinary patients. ${ }^{4}$ Achieving a low incidence of post-operative wound infections is one of the primary objectives of aseptic techniques ${ }^{5}$ and one of the basic principles of aseptic surgery is to prevent contamination of the surgical wound. Contamination may arise from a number of sources, such as the patient's skin, the surgical team, the theatre or hospital environment and surgical instruments or implants. ${ }^{6}$ The use of appropriate surgical attire including caps, masks, shoe covers and sterile gloves are all accepted protocols to reduce the risk of surgical wound contamination. ${ }^{5}$

Skin preparation of animals may be more challenging compared to human patients. The thick hair coat, infrequency of bathing, and more contaminated environment of animals may challenge the efficacy of surgical preparation techniques which work well in man. ${ }^{7}$ The preparation of the surgical site generally involves a series of steps which include the clipping of hair, the removal of dirt and oils and the removal or reduction of microbes. ${ }^{7}$ Each of these steps can be performed in a number of ways and have been studied extensively, but definitive conclusions as to the ideal method of patient preparation are yet to be established. ${ }^{5}$

Clipping of hair around the operative site is traditionally regarded as the first step of veterinary surgical preparation. The timing and the method of hair removal have both been studied in the human and veterinary fields. ${ }^{5}$ The use of a razor as opposed to clippers has been associated with a higher incidence of surgical infections. ${ }^{8}$ The clipping of hair in dogs and cats immediately before the surgical procedure resulted in a lower infection rate when compared to animals that were clipped at extended time intervals before surgery. ${ }^{2}$ Once the hair has been removed from the area, the surgical site is scrubbed according to one of the many recommended protocols in human and veterinary literature..$^{5-7,9-15}$ 
Most post-operative infections are caused by a continuing source of endogenous microorganisms on the patient's skin. ${ }^{16,17}$ Pre-operative skin preparations using a topical antiseptic on the surgical site is recognised as the most important measure in minimizing potential infection by reducing endogenous skin microflora. ${ }^{18,19}$

Asepsis is defined as the absence of pathogenic microbes or infection in living tissue. ${ }^{19}$ Surgical antisepsis is the application of antimicrobial chemicals to the skin to reduce the risk of infection. ${ }^{20}$ Surgical antisepsis most commonly involves the removal or reduction of normal flora by the topical application of antimicrobial substances to the skin before a surgical procedure. ${ }^{20}$ Sterilization is the process of destroying or eliminating all microorganisms by physical (heat and radiation) or chemical means. Only inanimate objects can be rendered sterile. Disinfectants are chemicals that destroy microorganisms, although they may not necessarily be effective against all viruses and spore-producing bacteria. Traditionally, disinfection refers to the use of germicidal agents applied to inanimate objects whereas antisepsis is the use of selected safe chemicals on living tissue. Some antiseptics are dilute forms of disinfectants that can be used on living tissue without causing damage. Like disinfectants, antiseptics may kill pathogenic microorganisms or simply inhibit their growth without necessarily destroying them. ${ }^{19,20}$

The characteristics of an ideal skin antiseptic include a broad spectrum of antimicrobial activity, especially against vegetative and spore-producing bacteria, rapid killing of pathogenic microbes, and a residual lethal effect against microorganisms. Cleansing capacity, lack of skin irritation or toxicity, an ability to retain antimicrobial efficacy in the presence of organic material, no teratogenic or carcinogenic effects or systemic side effects in the patient or user are other ideal attributes. ${ }^{9,16,21}$ Unfortunately, to date, a skin antiseptic possessing all of the above mentioned characteristics does not exist ${ }^{16}$ and the pursuit for the ideal antiseptic is still ongoing.

The subject of antiseptics and disinfectants has been extensively reviewed. 5,20,21,26 Some of the more commonly used groups of antiseptics groups include alcohols, aldehyde compounds (formaldehyde and glutaraldehyde), bisbiguanides (chlorhexidine), halogens (chlorine/chlorine compounds and iodine/iodine compounds) peroxygen compounds, phenolic compounds, quaternary ammonium compounds, heavy metals and dyes. 
The use of systemic peri-operative antimicrobial therapy has contributed to the reduction of post-operative infection but is not a substitute for aseptic techniques. The increase of antibiotic resistant micro-organisms has become a serious concern in both the human and veterinary fields. ${ }^{4,22,23}$ Resistance of bacteria to most of the commonly used biocides has serious economic, health and environmental implications in various applications. ${ }^{24,25}$

Chlorhexidine gluconate has traditionally been considered to be the skin antiseptic of choice because it possesses many of the above mentioned ideal characteristics. ${ }^{16,21}$ Research has been performed on well established antiseptics, but newer antiseptic surgical preparations, such as electrochemically activated water and F10 have been subjected to limited evaluation in a clinical (veterinary) setting, especially in comparison to well-established products.

This research project proposes to compare two modern antiseptic surgical preparations, F10 ${ }^{\circledR}$ Skin Prep Solution (F10) [Health and Hygiene (Pty) Ltd, Johannesburg, South Africa] and electrochemically activated water (EAW) [IQ Green Solutions (Pty) Ltd, Cape Town, South Africa] available to the veterinary market with a $2 \%$ chlorhexidine gluconate and $70 \%$ ethanol solution (CG+A) [Dismed Pharma (Pty) Ltd, Midrand, South Africa]. 


\section{JUSTIFICATION}

\subsection{Literature review}

The subject of disinfectants and antiseptics and has been extensively reviewed and information regarding commonly used products in the veterinary industry is readily available.5,19-21,26 The purpose of this study is to compare the efficacy of three surgical antiseptic preparations, namely: i) $2 \%$ chlorhexidine gluconate and $70 \%$ ethanol, ii) $\mathrm{F} 10^{\circledR}$ Skin Prep Solution and iii) electrochemically activated water.

The combination of chlorhexidine and alcohol is a commonly used surgical preparation in the veterinary and human fields and is still regarded as the antiseptic of choice. Its antimicrobial activity is well established in vitro and in vivo and numerous studies have shown its efficacy in human and veterinary surgery. ${ }^{21,27-29}$

Quite some research has been performed on well-established antiseptics, but newer antiseptic surgical preparations, such as ECW and F10 have been subjected to limited evaluation in a veterinary clinical setting, especially in comparison to the well-established products.

\subsubsection{Chlorhexidine}

Chlorhexidine is a cationic bisbiguanide that was first synthesised in 1950s by Imperial Chemical Industries Limited (Manchester, UK) while researching the synthesis of antimalarial agents. ${ }^{30-32}$ It consists of two chlorguanide chains linked by a hexamethylene chain. ${ }^{31}$ At product dependent concentrations chlorhexidine is widely used as a disinfectant in a range of healthcare products, including topical skin disinfectants, wound and burn care products, oral care products, hand washing solutions, urology catheter lubricants, central venous catheters and needleless intravenous catheter connectors. It is available as a solution (chlorhexidine diacetate) and as a scrubbing preparation (chlorhexidine gluconate). ${ }^{5,20}$ Chlorhexidine scrub is commonly used to prepare the surgeon and the patient before surgery. ${ }^{20}$ 
The mechanisms of antibacterial action of chlorhexidine has shown to differ at certain concentrations. At high concentrations it has a bactericidal effect caused by coagulation of the bacteria's cellular contents. ${ }^{30}$ At low concentrations it exerts a bacteriostatic effect by influencing cell membrane permeability and causing leakage of the cell contents. A surgical scrub formulation of between $2-4 \%$ is generally recommended. Wound treatment formulations are typically $0.05 \%$ or less and disinfectant formulations are between 0.5 $2 \% .^{21}$

Chlorhexidine exhibits a broad spectrum of antibacterial activity and has rapid bactericidal effects. $^{20}$ The primary site of action is the cytoplasmic membrane. Rupture of the cytoplasmic membrane of the microbe occurs without lysis of the cell wall. ${ }^{20}$ Gram positive bacteria are more sensitive to the effects of chlorhexidine than Gram negative bacteria. ${ }^{6,20}$ Chlorhexidine is effective against yeasts but has no activity against mycobacteria. It is also not considered to be sporicidal at normal temperatures ${ }^{33}$ and has variable efficacy against viruses and fungi. ${ }^{30}$ Chlorhexidine has also been shown to be effective against multi-drugresistant strains of bacteria such as Pseudomonas aeruginosa and methicillin-resistant Staphylococcus aureus. ${ }^{34,35}$ The potential for the development of bacterial resistance to chlorhexidine is said to be low but cases of resistance have been reported. ${ }^{20,25}$

Chlorhexidine remains effective in the presence of organic material although its activity is reduced. Regardless, it has proved to remain effective in the presence of blood, pus and other organic material. ${ }^{36}$ The antimicrobial activity of chlorhexidine is also $\mathrm{pH}$ dependant, with the optimum $\mathrm{pH}$ range between 5.5 and $7.5,9,35$ Within a wider $\mathrm{pH}$ range of between 5 and 8, antimicrobial activity may vary depending on the organism. For example, antimicrobial activity against Staphylococcus aureus and Escherichia coli improves with a higher $\mathrm{pH}$ whereas the reverse is true for Pseudomonas aeruginosa. Chlorhexidine is also incompatible with organic anions such as soaps at a higher $\mathrm{pH}^{9}{ }^{9}$ It is therefore advised that standing soap lather should be removed by rinsing prior to applying chlorhexidine solution to the skin. It appears to be compatible with non-ionic substances such as detergents but its activity and effectivity may be reduced, ${ }^{9}$ especially the diacetate form of the product. ${ }^{37}$

Longer contact times of chlorhexidine have been shown to decrease the initial bacterial counts. A recent study by Stinner and others described the time-dependant effects of chlorhexidine surgical preparations. Based on the results of this study, the authors recommend using $4 \%$ chlorhexidine alone for surgical site preparation and allowing a minimum of 2 minutes of contact time prior to making the skin incision. ${ }^{30,38}$ 
Another author suggested that the contact time for some chlorhexidine and alcohol preparations could be as little as 30 seconds. $^{7}$ One of the advantages attributed to chlorhexidine as a surgical preparation is its persistent or residual activity. ${ }^{39,40}$ Chlorhexidine binds covalently to proteins in stratum corneum of the skin and mucosa and results in a persistent antimicrobial effect with limited systemic absorption. ${ }^{31}$ This active residue continues to kill resident bacteria as they emerge from sebaceous glands, sweat glands and hair follicles. Increased contact time improves the residual activity. ${ }^{18}$ Some authors have debated the residual claim of chlorhexidine arguing that it is difficult to separate the prolonged effects of thorough initial antiseptic preparation from its true residual antimicrobial effect. ${ }^{5}$

Shmon reported the residual action of chlorhexidine to range from 6 to 48 hours following application. ${ }^{9}$ Alcohol does not inactivate chlorhexidine or affect its protein-binding properties in vitro but it may reduce its residual action. ${ }^{20,40}$ Some studies indicate that chlorhexidine solutions combined with alcohol have improved efficacy compared to saline or aqueous solutions. ${ }^{11,10,41}$

There are few reports of adverse effects associated with the use of chlorhexidine. ${ }^{20}$ Chlorhexidine does not generally cause skin irritation however contact dermatitis, hypersensitivity and photosensitivity have been sporadically reported after prolonged use. ${ }^{9}$ Skin absorption of chlorhexidine is minimal or non-existent, and there is no evidence of systemic toxicity, even in neonates. ${ }^{30,35}$ Chlorhexidine is however ototoxic and neurotoxic meaning that contact with the middle or inner ear, the brain or the meninges should be avoided. ${ }^{20,30}$ The neurotoxicity of chlorhexidine was investigated by Henschen in 1984, who proved that a dose dependant degeneration of adrenergic nerve fibres occurred following its application. At concentrations higher than $0.05 \%$ chlorhexidine can cause ocular damage. Similarly, certain formulations of chlorhexidine such as hand solutions or products containing detergents have been shown to damage the eye. ${ }^{30}$ Sanchez reported that chlorhexidine, at the minimum bactericidal concentration of $0.05 \%$, is lethal to canine embryonic fibroblasts. ${ }^{36}$ Although chlorhexidine has a low overall toxicity it should be used with caution around wounds and exposed tissues. ${ }^{42,43}$ There has also been no evidence of carcinogenicity associated with the use of chlorhexidine. ${ }^{30}$

Dilute chlorhexidine solutions should be stored at room temperature and a shelf life of at least one year can be expected. Prolonged exposure to high temperatures or light should be avoided because this can adversely affect stability. ${ }^{35}$ 


\subsubsection{Alcohols}

Alcohol is most likely the oldest recognised antiseptic agent. ${ }^{44}$ Wine was used liberally throughout history, both internally and externally, to heal all sorts of wounds and ailments. ${ }^{26}$ Distilled spirits became known in Europe in the thirteenth century and the first report of brandy being used for military dressings was in 1363. There are several references to the use of alcohol for wound management during the eighteenth century and in 1763 it became available for surgeons to use in a hospital in Paris for dressing wounds. The first scientific investigations of the antimicrobial properties of alcohol were performed by Buchholtz in 1875 and Nealton was the first to apply alcohol as a pre-operative antiseptic in nineteenth century. ${ }^{26}$

In many parts of Europe the use of alcohols has remained the standard for hand and skin antisepsis since the early part of the century. ${ }^{44}$ In many other parts of the world the use of alcohol as a primary skin antiseptic has been replaced by antiseptic preparations containing various active ingredients including iodophors, chlorhexidine gluconate, phenolic derivatives and quaternary ammonium compounds (QAC). ${ }^{44,45}$ Isopropanol, ethanol and npropanol are common alcohols used for antisepsis. ${ }^{31}$

Alcohols coagulate and denature proteins in the cytoplasmic membrane resulting in cell lysis and impaired cellular metabolism. ${ }^{31}$ They have a broad spectrum of bactericidal activity and are effective against fungi and mycobacterium. ${ }^{20}$ The isopropyl form is more bactericidal but ethyl alcohol is more effective against viruses. Alcohol has little effect against bacterial spores. ${ }^{9}$ The efficacy of alcohol is decreased substantially in the presence of organic material such as blood or pus. ${ }^{5}$ Alcohols have a rapid bactericidal effect with short contact times. ${ }^{20}$ Although alcohols show extremely good immediate reductions in bacterial counts, the maximum bactericidal activity requires contact with the skin for at least two minutes before it is allowed to evaporate. ${ }^{9}$ Alcohols are relatively non-toxic when applied to intact skin but cytotoxicity will result from contact with open wounds. Cutaneous absorption is minimal in adults but can lead to systemic toxicity in new-borns. Prolonged exposure tends to dry out and irritate the skin. Isopropyl alcohol is more irritating than ethyl alcohol. ${ }^{9}$ Alcohol preparations have the fastest onset of action, followed by chlorhexidine. Alcohols differ from many antiseptics by their lack of residual effect. ${ }^{44}$ Although alcohols are now nearly universally recognised as effective antimicrobial agents, the literature of alcohol use for antisepsis, disinfection and sterilisation remains controversial. ${ }^{44}$ Issues such as spectrum of action, concentration levels, time of action and formulations have been consistently argued in the literature. ${ }^{44}$ 
Antiseptic formulations that contain both chlorhexidine and alcohol combine the rapid effects of alcohol with the persisting effects of chlorhexidine. ${ }^{31}$ A clinical study comparing the use of $2 \%$ chlorhexidine with isopropyl alcohol, $2 \%$ chlorhexidine alone and $70 \%$ isopropyl alcohol alone for surgical skin preparation proved that the combined chlorhexidine-alcohol preparation achieved the highest bacterial count reduction. ${ }^{28}$

\subsection{3 $\quad \mathrm{F}^{\circledR} \mathrm{O}^{\circledR}$ Skin Prep Solution}

F10 ${ }^{\circledR}$ Skin Prep Solution (Health and Hygiene Ltd, Johannesberg, South Africa) contains the following active ingredients:

- $0.05 \%$ quaternary ammonium compounds (alky benzyl dimethyl ammonium chloride and didecyl dimethyl ammonium chloride)

- $\quad 0.05 \%$ biguanide compound (polyhexamethylene biguanide hydrochloride)

- $10-20 \%$ alcohol (ethanol)

\section{Quaternary Ammonium Compounds}

The first observations of the antimicrobial properties of QAC were made in 1916 by Jacobs and colleagues. ${ }^{26}$ Quaternary ammonium compounds are surface-active cations. They impair bacterial permeability by binding irreversibly to phospholipids and proteins in the bacterial cell membrane. ${ }^{46}$ They are slow acting and more effective against Gram positive than Gram negative bacteria and can fail when exposed to resistant microbes. ${ }^{20}$ Quaternary ammonium compounds are more effective in preventing bacterial growth than in killing them. They have been shown to be inactivated by organic material and have reduced activity in the presence of soap, hard water and gauze. ${ }^{20,47,48}$ Skin bacteria have been shown to survive beneath the layer of applied QAC. ${ }^{20}$ Undiluted preparations may cause chemical burns and ulceration of the skin and mucous membranes in dogs and cats. ${ }^{20}$ Quaternary ammonium compounds are not reliable surgical disinfectants and have been replaced by other disinfectants and antiseptics in the veterinary industry. ${ }^{20}$ Due to their narrow spectrum of action the current use of QAC in veterinary practices is limited to environmental disinfection of floors, walls and equipment surfaces.

\section{Biguanides}

Biguanides were first synthesized in the early part of the $20^{\text {th }}$ century and have since then been included in a wide variety of drugs with a broad spectrum of pharmacological activities (anti-malarial, hypoglycaemic drugs, antiseptic and anti-protozoal). ${ }^{49,49}$ Potent antibacterial activity was noted for mixtures of polyhexamethylene biguanides (PHMB). Further synthesis of this molecule lead to the closely related bisbiguanides (Chlorhexidine). ${ }^{49}$ 
The biguanides have been used as general purpose environmental biocides and antiseptics. Polyhexamethylene biguanide was reported by Gilbert as being one of the most promising modern day substances from a clinical perspective with regards to its efficacy, safety and clinical applications. ${ }^{49}$

As a strong base PHMB interacts with acidic, negatively charged phospholipids in the bacterial membrane. This leads to increased permeability and loss of integrity of the membrane which subsequently leads to the death of the organism. Polyhexamethylene biguanide is also transferred to the cytoplasm where it disrupts the bacterial metabolism. ${ }^{49,50}$

Polyhexamethylene biguanides has a broad spectrum of antimicrobial activity against Gram positive and Gram negative bacteria, Chlamydia, Mycoplasma and fungi including Candida and Aspergillus species. ${ }^{51-54}$ Efficacy against Staphylococcus aureus, Enterococcus faecalis, Lactococcus lactis, E. coli and Pseudomonas aeruginosa has also been reported. ${ }^{50}$

Polyhexamethylene biguanides are compatible with acids, QAC, and neutral detergents. It has however been shown to be incompatible with anionic detergents, soaps and alkyl sulphates. ${ }^{50}$ Polyhexamethylene biguanides has been shown to have a better antimicrobial efficacy than chlorhexidine under clean and dirty environments. ${ }^{50}$ Its antimicrobial activity does not appear to be impaired by the presence of blood or albumin and the optimal $\mathrm{pH}$ range is between 5 and $6 .{ }^{52,55}$ No literature is available on the residual action of PHMB. A recent review article by Fjeld reported that the number of clinical studies on PHMB are small and not necessarily well controlled. ${ }^{56}$ Few adverse effects from the substance were reported. There are no published clinical studies of its use in veterinary asepsis.

Topical applications of PHMB appear to be well tolerated when applied to the skin, eye, nose, ciliated epithelium and wounds. ${ }^{50}$ It also appears as if there is no systemic uptake of PHMB from intact skin or wounds. There has been no indication of carcinogenic properties in vitro or in vivo. ${ }^{50}$ There is limited literature available on the synergistic effect of biguanides and QAC. 


\subsubsection{Electrochemically activated water}

Electrolysis is defined as the passage of a direct electric current through an ionic substance that is dissolved in a suitable solvent, resulting in chemical reactions at the electrodes and the separation of anions and cations. Electrochemically activated water (EAW) is produced by the electrolysis of water containing dissolved sodium chloride $(\mathrm{NaCl})$.

Over the course of the last 30 years Russian scientists have developed and refined the process of EAW. ${ }^{57,58}$ More than 300 Russian patents have been established using this technology and more than 20000 units producing electrochemically activated water are currently operating in Russian hospitals. This technology has also been widely used in various industries such as agriculture, cooling towers, swimming pools, dermatology, dressing and cleaning of wounds and disinfection of instruments. ${ }^{59}$ Electrochemically activated water is produced from tap water and saline solution by a special unit that contains a cylindrical electrolytic cell containing an anode and a cathode separated by a permeable membrane. ${ }^{60}$

The key innovation of the electrochemical activation process is the placement of an ion permeable membrane between the positive and negative electrodes. The design and choice of the materials used for the electrodes also plays a huge role in the electrochemical activation process. ${ }^{61}$

The production of EAW is illustrated in Figure 1. The voltage between the electrodes is typically set at 9-10 Volts. ${ }^{61}$ During the process of electrolysis, $\mathrm{NaCl}$ dissolved in deionised water dissociates into negatively charged chlorine $\left(\mathrm{Cl}^{-}\right)$and positively charged sodium $\left(\mathrm{Na}^{+}\right)$. Simultaneously hydroxide $\left(\mathrm{OH}^{-}\right)$and hydrogen $\left(\mathrm{H}^{+}\right)$ions are produced. Negatively charged ions such as $\mathrm{Cl}^{-}$and $\mathrm{OH}^{-}$migrate to the anode to release electrons and become oxygen gas $\left(\mathrm{O}_{2}\right)$, chlorine gas $\left(\mathrm{Cl}_{2}\right)$, hypochlorite ions $\left(\mathrm{OCl}^{-}\right)$, hypochlorous acid $(\mathrm{HOCl})$, and hydrochloric acid. The positively charged ions such as $\mathrm{H}^{+}$and $\mathrm{Na}^{+}$move to the cathode to take up electrons and become hydrogen gas $\left(\mathrm{H}_{2}\right)$ and sodium hydroxide $(\mathrm{NaOH}){ }^{62}$ 


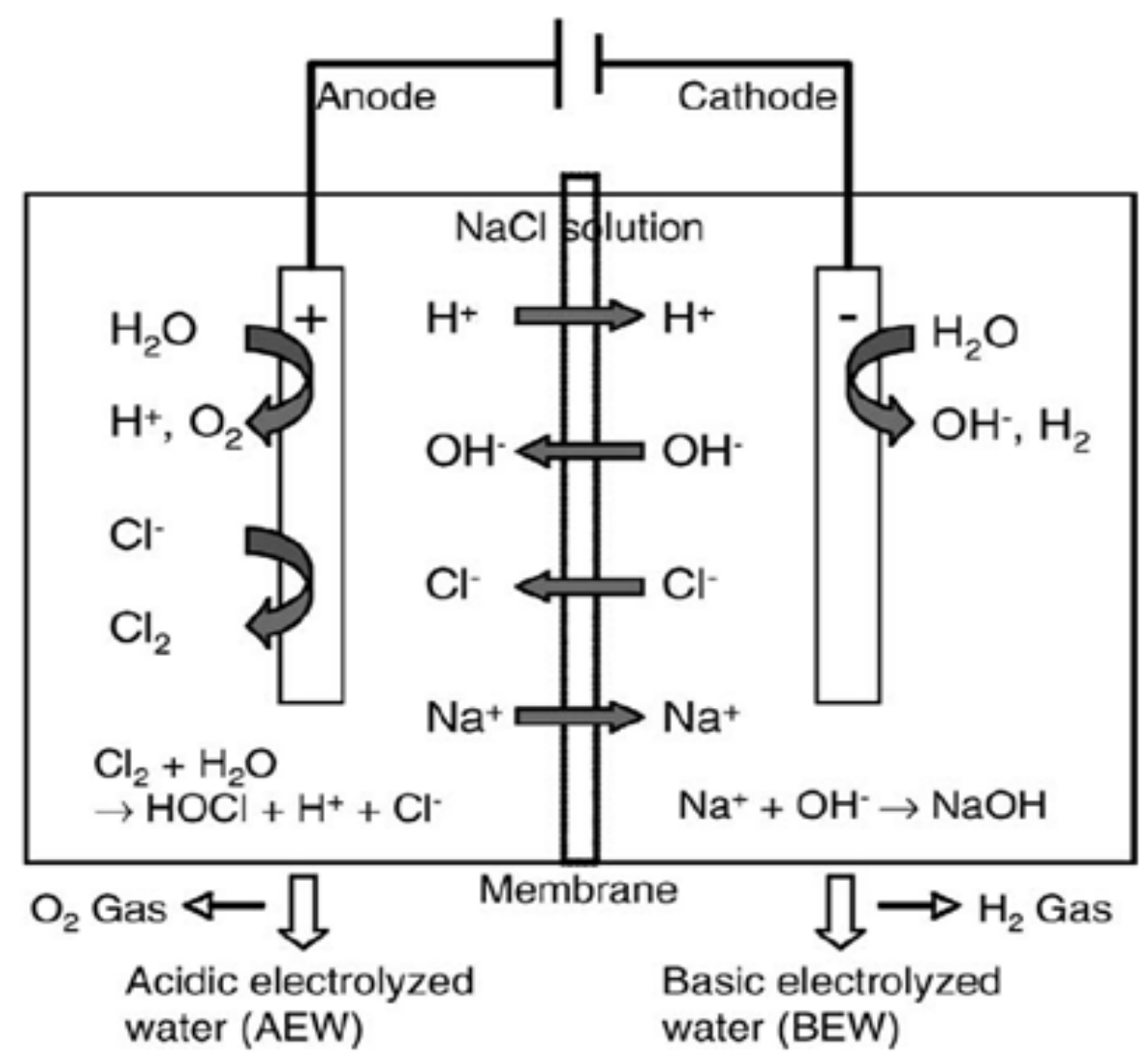

Figure 1 Schematic representation of the production of electrolyzed water.

(Illustration with permission from Hricova D, Stephan R, Zweifel C: Electrolyzed water and its application in the food industry. J Food Prot 2008; 71:1934-1947).

The ability of a solution to oxidize or reduce is known as the oxidation reduction potential (ORP). The solution that forms at the anode is acidic $(\mathrm{pH} 2-3)$, has a high ORP of $>1100 \mathrm{mV}$ and has an active chlorine content of 10 to $90 \mathrm{ppm}$. It is commonly referred to as anolyte, acidic electrolyzed water, acid oxidising water or electrolyzed oxidising water. ${ }^{62}$

The solution that forms at the cathode is basic $(\mathrm{pH} \mathrm{10-13)} \mathrm{and} \mathrm{has} \mathrm{a} \mathrm{low} \mathrm{ORP} \mathrm{of}-800$ to $900 \mathrm{mV}$. This solution is known as catholyte, basic electrolyzed water, alkaline electrolyzed water, or electrolyzed reducing water ${ }^{62}$ and is known to have a strong cleaning or detergent effect. $^{63}$

Neutral electrolyzed water is generated in much the same way as acidic electrolyzed water except that the solution gets partially mixed with $\mathrm{OH}^{-}$which is then transferred through the membrane into the cathode chamber. ${ }^{64}$ This solution typically has a $\mathrm{pH}$ of between $6.5-8.5$ and an ORP of more than $700 \mathrm{mV} 61,62,64$. This was the solution used in our study and for purposes of this dissertation is generally referred to as electrochemically activated water. 
Electrochemically activated water has as strong antimicrobial activity against a wide spectrum of microorganisms. ${ }^{62}$ The exact mechanism of antimicrobial action of electrochemical activation is yet to be fully described. ${ }^{63}$ It is not clear whether $\mathrm{pH}$, chlorine compounds, ORP, or a combination of these factors are responsible for the antimicrobial activity of EAW. ${ }^{62}$ The presence of chlorine compounds and a high ORP appear to be the main contributors to the antimicrobial activity of EAW. ${ }^{61}$ The low $\mathrm{pH}$ of anolyte is also believed to reduce bacterial growth and make the bacterial cells more susceptible to active chlorine by sensitising their outer membrane to the entry of $\mathrm{HOCl} .{ }^{65}$ Active chlorine compounds are known to destroy the membranes of microorganisms, but other modes of chlorine action such as the decarboxylation of amino acids, reactions with nucleic acids and the destruction of key enzymes have also been proposed. ${ }^{62}$ Studies suggest that $\mathrm{HOCl}$ is the most active of the chlorine compounds ${ }^{62,66}$ and has been shown to be affective against a wide range of bacterial, viral and fungal pathogens. ${ }^{67} \mathrm{HOCl}$ penetrates cell membranes and produces hydroxyl radicals which exert their antimicrobial activity through the oxidation of important metabolic systems. ${ }^{62}$

Some authors have suggested that the high ORP is the determining factor for the antimicrobial activity of EAW. ${ }^{24,61,63} \mathrm{Al}-\mathrm{Haq}$ et al reported that inactivation of $E$. coli was directly related to the ORP and not as a result of residual chlorine compounds. ${ }^{61}$ The higher the ORP of a solution, the greater its oxidizing strength. The oxidation of EAW is thought to damage cell membranes and cause disruption to metabolic cell processes thereby inactivating the bacterial cells. ${ }^{68}$ Hricova et al have suggested that the high ORP and low $\mathrm{pH}$ of anolyte seem to work synergistically with $\mathrm{HOCl}$ to inactivate microorganisms. ${ }^{62}$

A limiting factor for the use of EAW is its loss of activity over time due to chlorine loss and ensuing $\mathrm{HOCl}$ decomposition. ${ }^{62}$ When stored under open conditions, acidic electrolyzed water rapidly loses its residual chlorine due to chlorine evaporation. ${ }^{61}$ Under closed conditions, chlorine loss is due to self-decomposition which is much slower than the evaporation loss under open conditions. ${ }^{62,69}$ The decomposition of chlorine is enhanced by exposure to light and agitation. ${ }^{69}$ The ratio of $\mathrm{Cl}_{2}$ and chlorine compounds is $\mathrm{pH}$ dependant. More volatile chlorine is present in solutions that have a low $\mathrm{pH}^{69}$ A solution with a more neutral $\mathrm{pH}$ therefore has a substantially longer shelf life than the acidic solution. ${ }^{62}$

Temperature, agitation, and contact with organic material also influence the antimicrobial activity of EAW. ${ }^{62}$ At higher temperatures, cell membranes of Gram negative bacteria become more permeable, and EAW enters the cells more rapidly. ${ }^{70}$ Low storage temperatures appear to stabilize residual chlorine and ORP. ${ }^{71}$ 
When the use of EAW was combined with agitation, greater microbial reductions were observed. Agitation is thought to facilitate the penetration of EAW into the cell membrane and allow a better distribution of chlorine compounds. ${ }^{72}$

Electrochemically activated water is environmentally friendly because it is generated by the electrolysis of water and a dilute $\mathrm{NaCl}$ solution, and after use, it reverts back to normal water. ${ }^{61}$ Because of EAW's non-selective antimicrobial properties it does not promote the development of bacterial resistance. ${ }^{61,62}$

Depending on the $\mathrm{pH}$ of the solution, EAW may be corrosive or irritating to the skin because of its high ORP and large free chlorine concentrations. By increasing the $\mathrm{pH}$ of the solution (neutral electrochemically activated water) the amount of free chlorine in the solution is reduced and these side effects are not seen. Numerous studies in the food and medical industry have been performed comparing the antimicrobial efficacy of acidic electrolyzed water to neutral electrolyzed water. Both solutions have been shown to have excellent broad spectrum antimicrobial efficacy. ${ }^{61,62,64,73}$

Electrochemically activated water has shown to have potential applications in a number of fields and industries and can potentially be considered as an environmentally friendly substitute for chemical agents. The use of EAW as a surgical preparation and its residual effect has not been described or marketed in a clinical setting.

The use of $\mathrm{HOCl}$ in wound care is currently being researched and has revealed favourable effects on cytotoxicity and fibroblast migration. ${ }^{67}$ No toxic side effects were reported when $\mathrm{HOCl}$ was used in an animal experimental model as an ocular preparation at varying concentrations. ${ }^{74}$ A dermal sensitisation study using $\mathrm{HOCl}$ in guinea pigs also revealed no evidence of skin reactions. ${ }^{74}$

An electrochemically activated water solution with a $\mathrm{pH}$ of $6.5-7.5$, a ORP $>750 \mathrm{mV}$ and a free available chlorine concentration of more than $180 \mathrm{mg} / \mathrm{l}$ was used in our study.

Some other commonly used antiseptics include iodine, phenols, heavy metals and dyes. 


\subsubsection{Phenols}

Phenols are one of the oldest examples of antiseptic compounds. They have a wide spectrum of activity against bacteria, viruses and fungi but they also have minimal sporicidal activity. They are classified as intermediate to low level germicides. Phenols no longer play a significant role as antibacterial agents due to their toxicity and irritant effects. Chloroxylenol, a synthetic halogen, has substituted the phenol derivatives and has been used extensively as a preservative, disinfectant and topical antiseptic. ${ }^{20}$ Surgical $^{2}$ preparations containing chloroxylenol have been evaluated in dogs. ${ }^{6}$

\subsection{6 lodine and iodine compounds}

lodine is a non-metallic essential element that was discovered by the French scientist Courtois in 1812. ${ }^{75}$ It was first used as a wound treatment in 1839. lodine is an excellent, rapid and effective bactericidal agent with a broad range of action. ${ }^{20}$ lodine is found in various forms in aqueous solutions but only two forms play a role in its antimicrobial properties: Molecular iodine $\left(I_{2}\right)$ and hypoiodic acid. ${ }^{20}$ The mechanism of action is incompletely understood but involves blocking protein synthesis and altering the microbial cell membrane. ${ }^{75}$ Bacterial resistance to iodine appears to be uncommon. ${ }^{20}$ The activity of iodine is decreased in the presence of organic debris and blood. ${ }^{5}$

There are two main groups of iodine preparations that are used clinically. The first preparation releases free iodine whereas the second preparation contains complex-bound iodine. The use of the preparations that release free iodine are limited within veterinary hospitals because of their odour, staining and toxic properties. ${ }^{20,75}$

To reduce the undesirable effects of iodine it has been combined with high-molecular weight carriers such as polyvinylpyrrolidone. These complexes are termed iodophors and allow for the slow, continuous release of free iodine. ${ }^{9}$ The best known iodophor is povidone iodine which is frequently used as an antiseptic in veterinary practice. ${ }^{20}$ lodophors must be in contact with the skin for at least 2 minutes to release enough iodine to become bactericidal. ${ }^{9}$

Cutaneous absorption of iodine, particularly in traumatized skin, can result in increased levels of serum iodine and iodine toxicity. ${ }^{5,20}$ lodine should therefore be used with caution around open wounds. At concentrations of $0.5 \%$ or greater povidone iodine has been shown to be lethal to canine embryonic fibroblasts. ${ }^{36}$ Concentrations of $1 \%$ or greater are necessary for bactericidal activity. ${ }^{5}$ 


\subsubsection{Heavy metals}

Mercury and silver are some of the earliest reported chemical disinfectants used in the medical field, dating back to early civilizations in China, India and Egypt. ${ }^{26}$ The first reported use of mercury in European literature was 1140 by Matthaeus Platearius. ${ }^{26}$ John Higginbottom was the first surgeon to use silver nitrate in wounds and fracture management. ${ }^{26}$ Clinical uses of silver, copper compounds, mercury compounds have been reported. ${ }^{76}$ The high toxicity of systemically administered heavy metals resulted in their discontinuation in the United States for antimicrobial therapy. Compounds containing heavy metals however still play an important role in topical antimicrobial therapy eg. silver nitrate. The most commonly used topical antimicrobial agent to treat burn wounds in patients is silver sulfadiazine. Heavy metals influence microorganisms by affecting their growth, morphology and various biochemical activities. There is limited literature available comparing the relative efficacy of heavy metals to the more commonly used disinfectants. ${ }^{76}$

\subsubsection{Dyes}

Dyes are defined as a chemical compounds capable of imparting colour to a substance to which it is applied. ${ }^{77}$ Various dyes have been used in veterinary medicine as stains for tissues, test reagents, therapeutic agents and coloring agents in pharmaceutical preparations. ${ }^{77}$ The antibacterial activity of dyes was first reported in 1913. The most commonly used dyes in traditional veterinary asepsis are the aniline (triphenylmethane) dyes and the acridine dyes. ${ }^{78}$

Examples of the aniline dyes include gentian violet, brilliant green, malachite green and magenta. These dyes are bacteriostatic against Gram positive bacteria but less active against Gram negative microbes. They have no effect against spores but show some activity against yeasts and fungi. They are inactivated by organic matter and cause staining of tissues and fabrics. Many of these dyes are carcinogenic and have generally been substituted for safer products. ${ }^{19,26,78}$ The acridine dyes, of which acriflavine, euflavine and proflavine are examples, share similar characteristics to the aniline group. They are also bacteriostatic against Gram positive bacteria and less active against the Gram negatives. They also have no effect against spores with limited effect on yeasts and fungi. Their activity is not influenced by tissue fluid. The acridine dyes are slow acting and also cause staining. These dyes were mainly used for the treatment of wounds. ${ }^{19,78}$

These products have largely been replaced by more modern antiseptics with a wider spectrum of action, less side effects and improved safety margins. 


\subsection{Problem statement}

The difference in antimicrobial efficacy between the combination of chlorhexidine and alcohol, $\mathrm{F} 10^{\circledR}$ Skin Prep Solution and electrochemically activated water as a surgical skin preparation in a clinical setting in dogs has not been determined yet.

\subsection{Hypothesis}

There is no difference in antimicrobial efficacy between the combination of chlorhexidine and alcohol, $\mathrm{F} 10^{\circledR}$ Skin Prep Solution and chemically activated water when used as surgical site skin preparations in dogs.

\subsection{Aims and objectives}

To determine the difference in antimicrobial efficacy between the combination of chlorhexidine and alcohol, $\mathrm{F} 10^{\circledR}$ Skin Prep Solution and electrochemically activated water when used as a surgical preparation in canine patients. 


\section{MATERIALS AND METHODS}

\subsection{Model system}

A live animal model including 117 intact female dogs admitted for student ovariohysterectomy to the Onderstepoort Veterinary Academic Hospital (OVAH). This study was approved by the Animal Ethics Committee of the University of Pretoria (Project number V064-15). The dogs met the following inclusion criteria:

- $\quad$ Clinically healthy as described in section 3.3 below

- $\quad$ More than $4.5 \mathrm{~kg}$ in weight

- $\quad$ Free of clinical skin condition

- $\quad$ Fully vaccinated

- Normal haematology and serum chemistry

The dogs were assigned to one of three skin antiseptic groups using simple random sampling by drawing numbers out of a hat. 39 dogs were assigned to the first $(C G+A)$ and second (F10) antiseptic groups and 38 dogs to the third group (EAW). The dog's age, weight and breed were recorded. The antiseptic solutions were numbered as follows:

No 1: $2 \%$ Chlorhexidine gluconate $70 \%$ ethanol (Figure 2)

No 2: $\quad F 10^{\circledR}$ Skin Prep Solution (Figure 3)

No 3: Electrochemically activated water (Figure 4) 


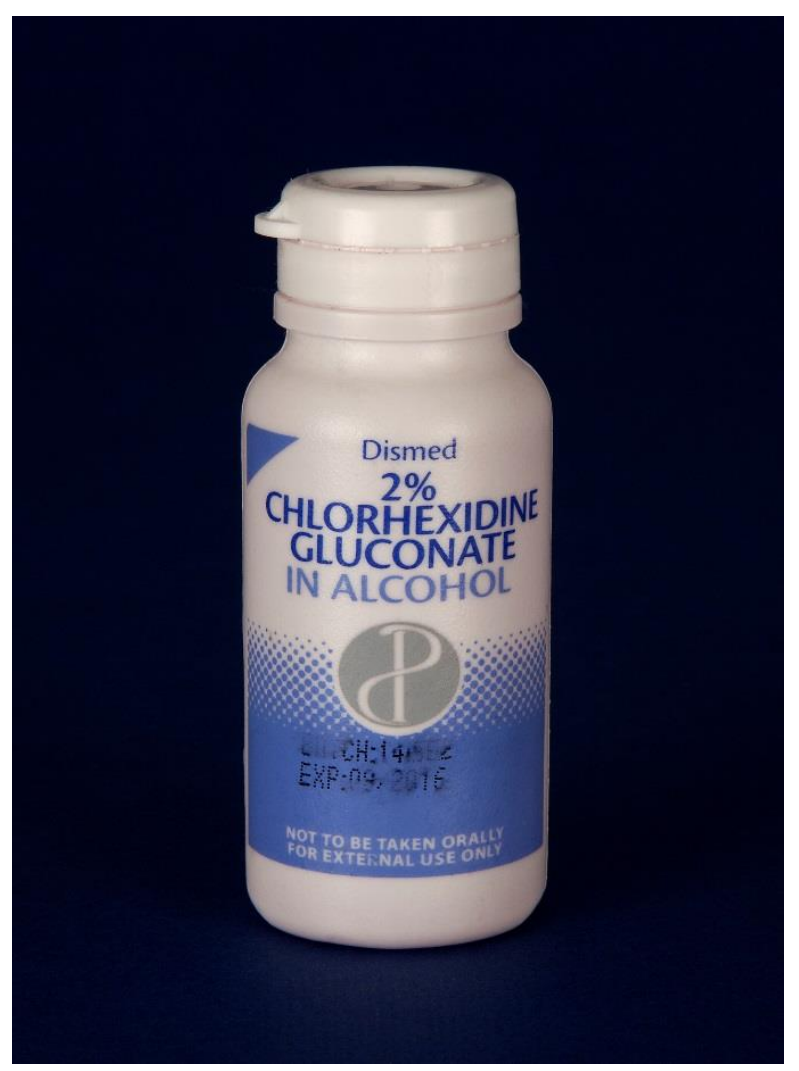

Figure 2 2\% Chlorhexidine gluconate and 70\% ethanol solution.

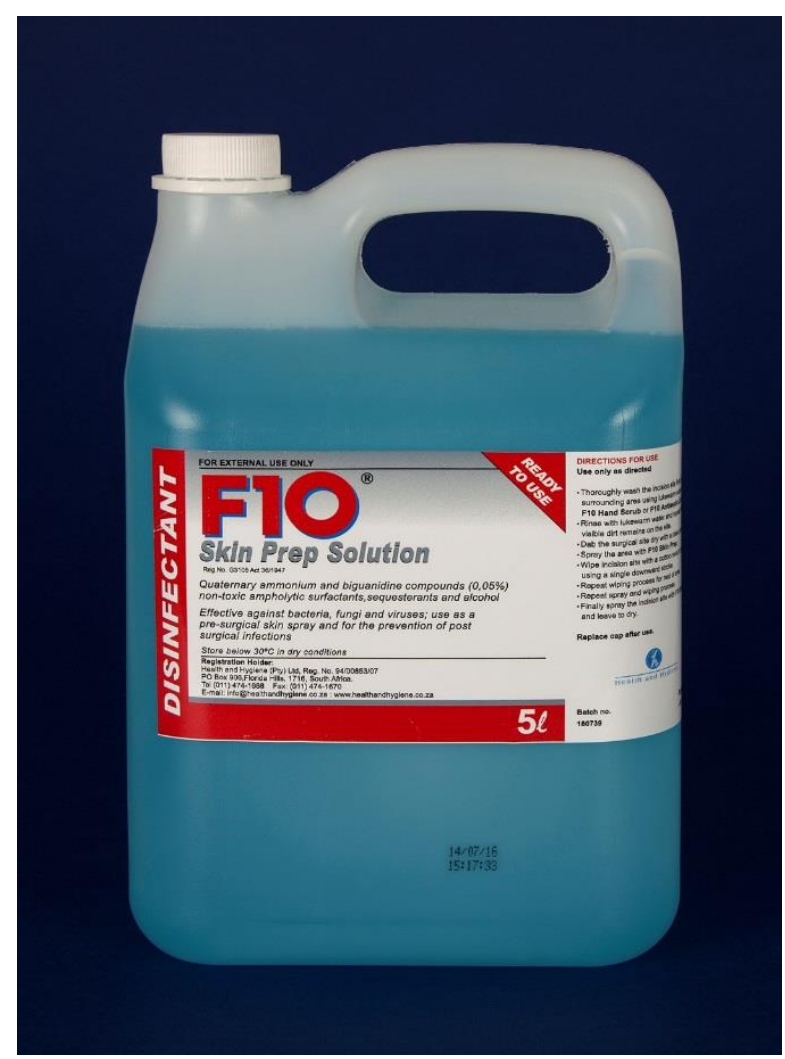

Figure $3 \quad F 10^{\circledR}$ Skin Prep Solution. 


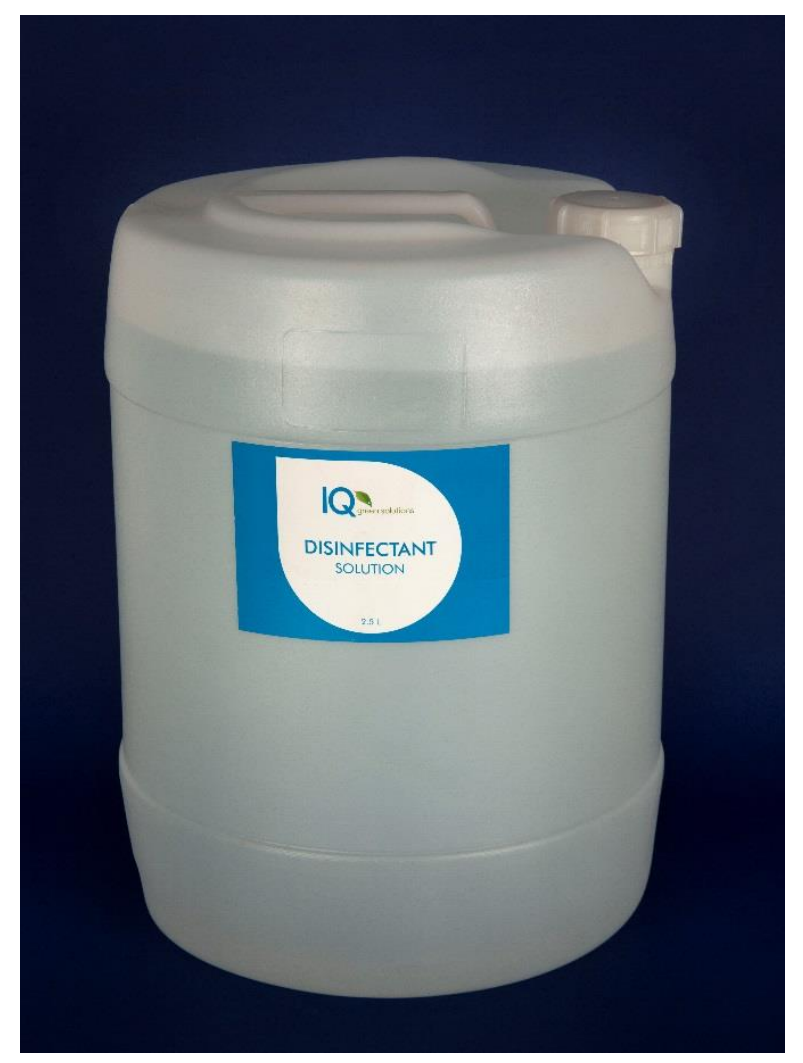

Figure 4 Electrochemically activated water.

\subsection{Study design}

Prospective randomised clinical study

\subsection{Study procedure}

Clinical examinations, which included recording the temperature, pulse and respiration of the dogs, were performed by final year veterinary students the day before the patients were admitted for surgery. The following tests were performed as per the ovariohysterectomy protocol at the OVAH:

- Blood smear

- Haematocrit

- $\quad$ Creatinine

- Glucose 


\section{Anaesthesia}

The dogs were fasted for 12 hours prior to the surgery and transferred to the induction area of the theatre complex the following morning. Premedication of morphine at $0.2 \mathrm{mg} / \mathrm{kg}$ (Morphine sulphate Fresenius PF, Fresenius Kabi, South Africa) and acepromazine (Neurotranq ${ }^{\circledR}$, Virbac, South Africa) at $0.02 \mathrm{mg} / \mathrm{kg}$ intramuscularly was administered 30 minutes prior to induction. Propofol induction at $6 \mathrm{mg} / \mathrm{kg}$ (Propofol Fresenius 1\%, Fresenius Kabi, South Africa) was given intravenously, to effect. Carprofen at $4.4 \mathrm{mg} / \mathrm{kg}$ (Rimadyl, Zoetis, Sandton) was administered subcutaneously at the time of induction. Orotracheal intubation was performed using an appropriate sized cuffed endotracheal (ET) tube. Anaesthesia was maintained with isoflurane (Isoflurane; Safeline Pharmaceuticals, South Africa) in $100 \%$ oxygen delivered via a precision vaporiser (Ohmeda Isotec 5; BOC Health Care, United Kingdom) connected to a circle circuit. A balanced crystalloid solution (Lactated Ringer's solution; Intramed, South Africa) was infused intravenously at 10 $\mathrm{ml} / \mathrm{kg} /$ hour throughout the surgery. No antibiotics were administered in the peri-operative period.

\section{Skin preparation}

The clipper blades were sterilised in formaldehyde gas ${ }^{79}$ the day before the dogs were due to be operated. Each dog was clipped with a sterilized blade. The dogs were placed in dorsal recumbency and the entire ventral abdomen was clipped from the xiphoid to the pubis and from flank fold to flank fold using electric clippers in the surgical preparation area. The hair was removed manually and vacuumed after the clipping procedure (Figure 5). Any skin reactions to the clipping procedure were recorded. 


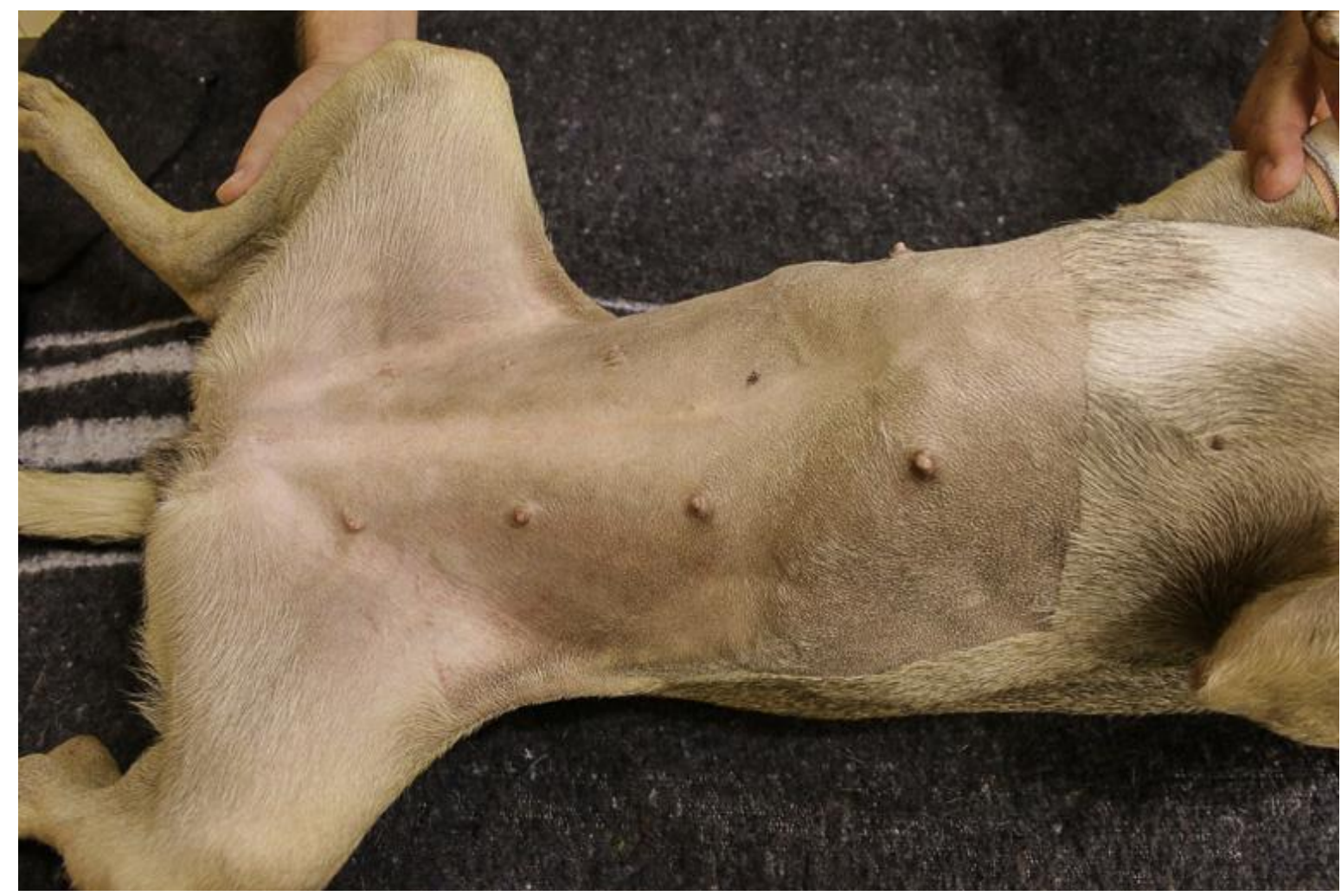

Figure 5 Clipping of hair as part of the preparation of the surgical site.

Final year veterinary students wearing scrub suits, surgical caps, latex gloves and masks performed the skin asepsis. The ventral abdomen was washed with abdominal sponges soaked in a neutral detergent solution with no proven antibacterial properties supplied by Health and Hygiene (Pty) Ltd and sterile water to remove surface dirt. The wash started at the proposed incision site and then moved outwards in a circular fashion (Figure 6). The area was then rinsed using sterile water before the second wash was started. This procedure was repeated for a minimum of three times or until the skin was clear of visible hair, dirt and debris. The surgical site was dried with a sterile paper towel and the time taken for the wash was recorded. The first skin sample was taken at this point using replicating organism detection and counting (RODAC) plates from the caudal midline (Figure 7). 


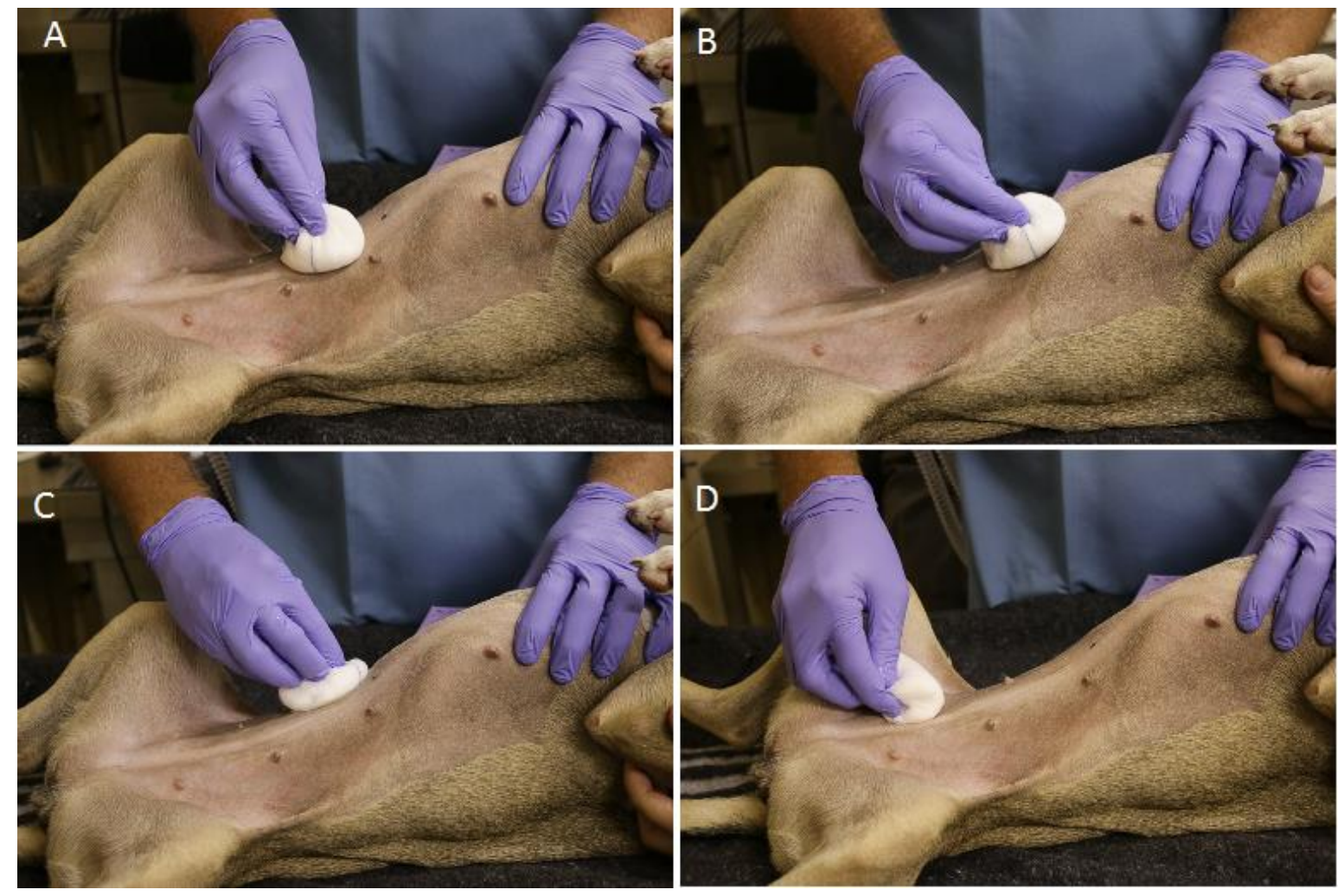

Figure 6 Presurgical wash with neutral detergent. (A-D) The wash started at the proposed incision site and then moved outwards in a circular fashion.

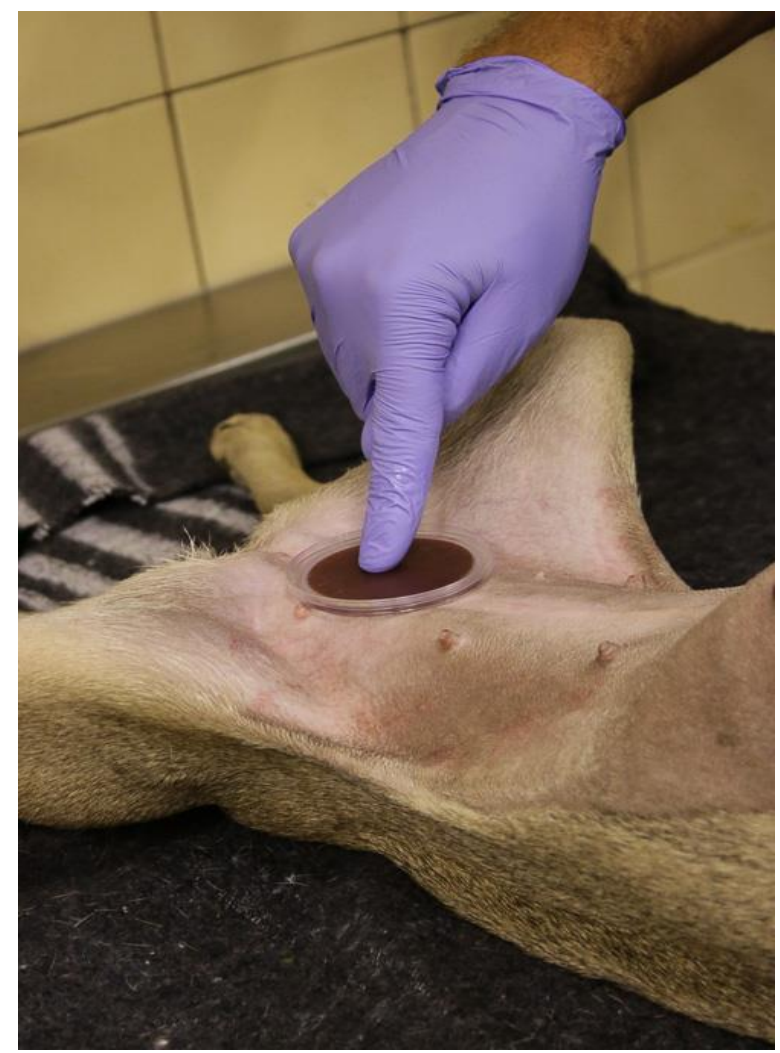

Figure 7 First skin sample taken from the caudal midline after the presurgical wash. 
The patient was then transferred to the operating room. In the operating room, one of the three antiseptic solutions: Chlorhexidine gluconate and ethanol, $\mathrm{F} 10^{\circledR}$ Skin Prep solution or electrochemically activated water, was sprayed onto the entire clipped area until the skin was saturated. After 3 minutes, sterile dry gauze swabs handled with sterile cheatle forceps were used to soak up the pooled antiseptic. The second skin sample was taken at this point from the centre of the surgical field, over the umbilicus (Figure 8).

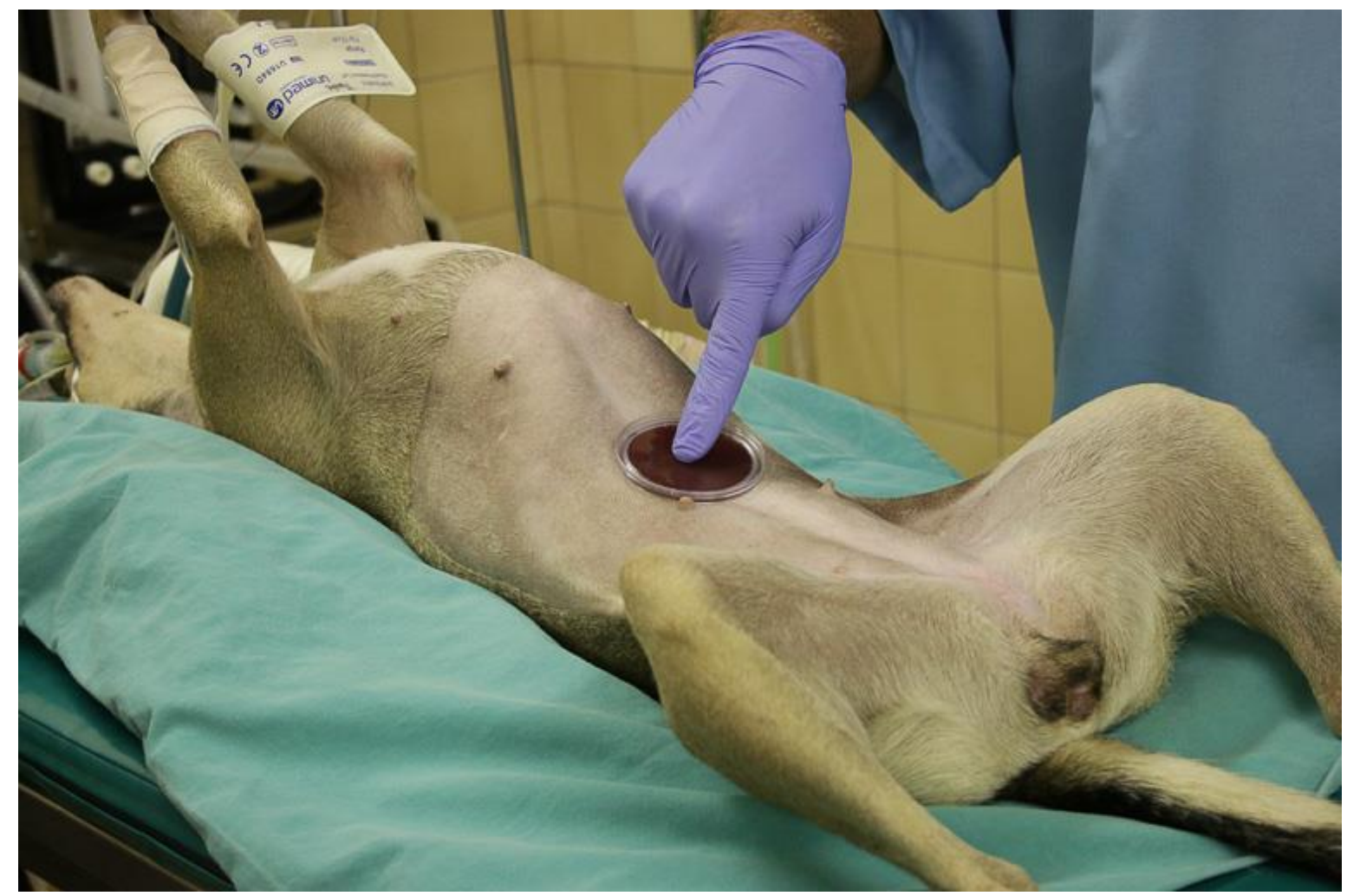

Figure 8 Second skin sample taken from the centre of the surgical field, over the umbilicus, three minutes following antiseptic application.

The patient was then draped using the standard four corner cloth draping technique. Final year veterinary students performed routine, standardized, ventral median ovariohysterectomy after appropriate hand scrubbing, gowning and gloving. The duration of the ovariohysterectomy was recorded.

The third skin sample was taken two hours after the second sample, from the cranial aspect of the surgical field (Figure 9). A fourth sample was taken at the end of surgery, from the right paramedian aspect of the surgical field, adjacent to the centre of the incision (Figure 10). 


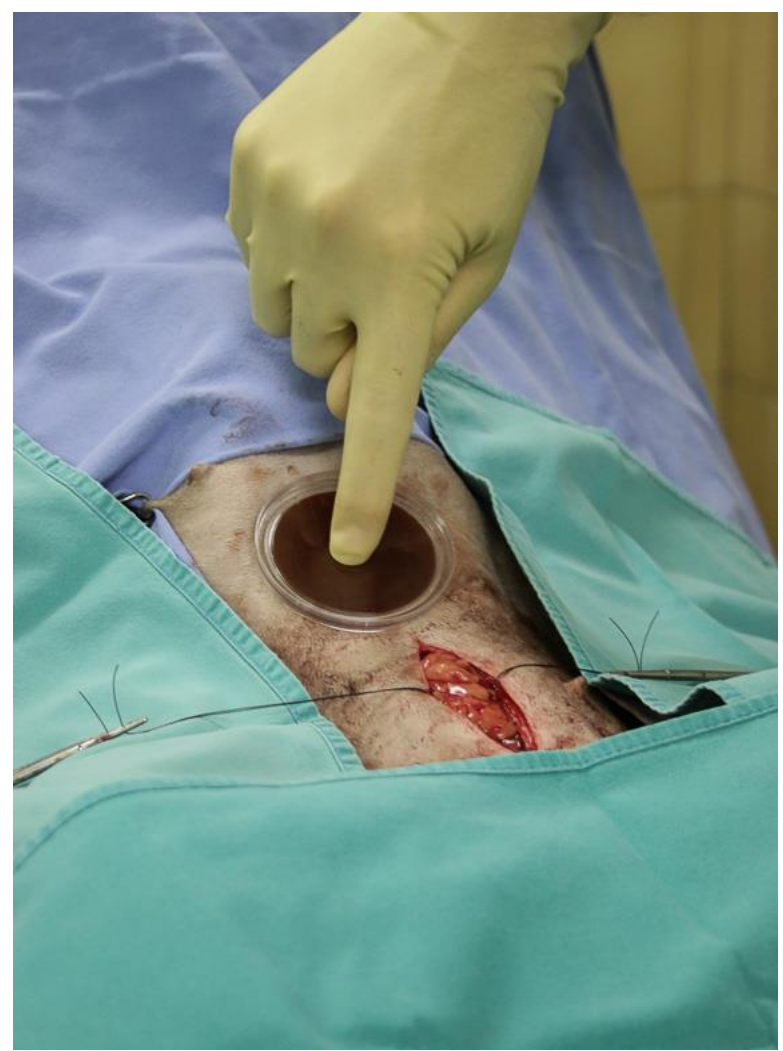

Figure 9 Third skin sample taken from cranial aspect of the surgical field two hours after the second sample.

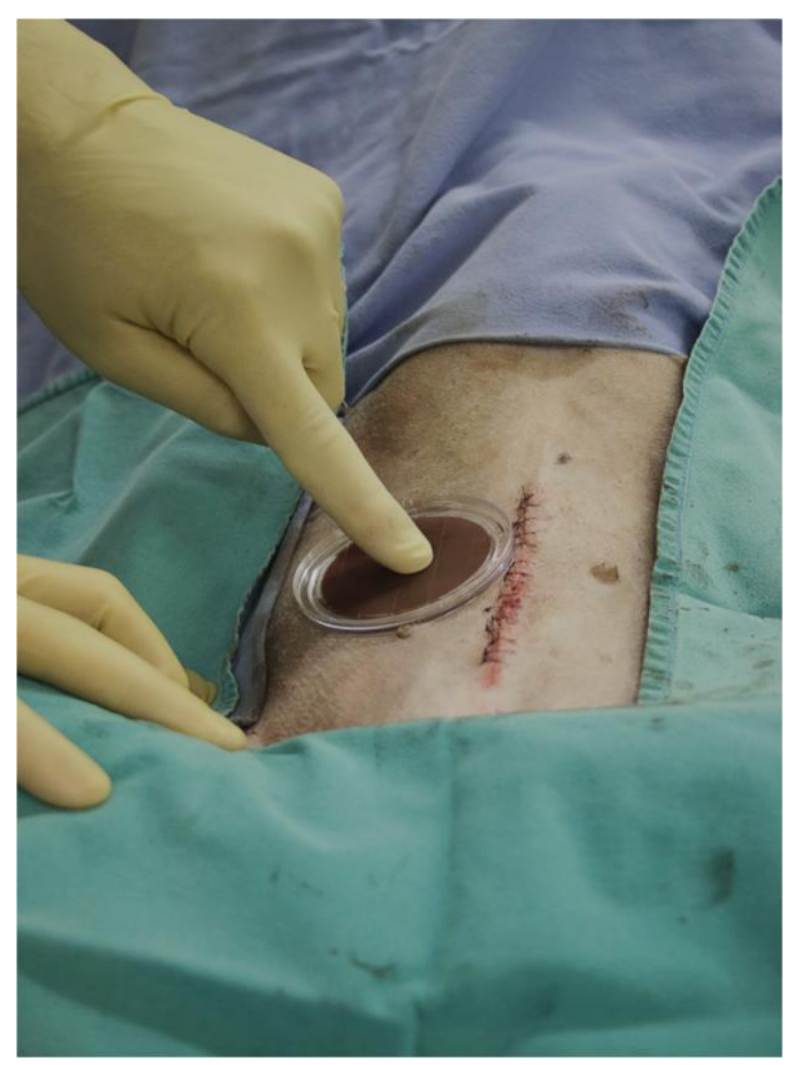

Figure 10 Fourth skin sample taken from the right paramedian aspect of the surgical field at the end of surgery 
Care was taken to ensure that there was no overlapping of the skin samples. Overlapping of the sampling sites would result in the inhibition of the antiseptics on the skin, by polysorbate 80 and lecithin residues and also the mechanical stripping of bacteria, which might have artificially influenced subsequent CFU counts.

\section{Skin sampling}

Skin sampling was performed by the same person wearing a scrub suit surgical cap, latex gloves and a mask on the given day. Sterile gloves were used to take the third sample so as not to contaminate the surgical field.

RODAC plates were pressed onto the skin at the four different sampling times. The lid of the RODAC plate was lifted off and the sterile inner surface of the plate was pressed down gently onto the specific site and held in place for five seconds before removing the plate from the surgical field. Any break in asepsis or intra-operative incidents that could have influenced the CFU counts were documented and the sample excluded from the study.

\section{Agar Plate Preparation and Quality Control}

Quantification of skin bacterial numbers was performed using sterile replicating organism detection and counting (RODAC) plates. ${ }^{16,18,40}$ RODAC plates were prepared in the bacteriology laboratory of the teaching hospital and contained bacteriological Agar No 1 (Oxoid Ltd., Basingstoke, Hampshire, England), 5\% equine blood (Equine Research Centre, University of Pretoria, Onderstepoort, Gauteng, South Africa) and BD Trypticase ${ }^{\mathrm{TM}}$ soy agar with lecitin and polysorbate 80 (Becton, Dickinson and Company, Johannesburg, Gauteng, South Africa) to neutralize residual antiseptic. Inclusion of blood allowed for the detection of Streptococcus canis, common $\beta$-haemolytic skin commensals and potential pathogens. The agar was added at $3 \%$ to inhibit the swarming by Proteus spp. and thus overgrowth of other bacteria. Each batch of agar was checked for typical bacterial growth using Staphylococcus aureus (ATCC 25923) and E. coli (ATCC 25922). Five randomly selected plates from each batch were also checked for sterility by incubating at $37^{\circ} \mathrm{C}$ in $5 \%$ $\mathrm{CO}_{2}$ for 72 hours.

\section{Incubation and CFU Counting}

Standard plate incubation and counting of CFU's were performed by staff that were blinded to the antiseptic solution being used. Following receipt of the RODAC plate samples, they were placed directly into the incubator containing $5 \%$ carbon dioxide $\left(\mathrm{CO}_{2}\right)$. 
The plates were incubated for 24 hours after which the bacterial CFU's were counted and the bacteria were subcultured. The subcultures were plated out on Columbia blood agar with $5 \%$ horse blood and MacConkey agar. The Columbia blood agar was placed in an incubator containing $5 \% \mathrm{CO}_{2}$ at $37^{\circ} \mathrm{C}$ for 24 hours. The MacConkey agar was cultured at $37^{\circ} \mathrm{C}$ for 24 hours. The plates were then removed and the bacteria isolated on the pure subcultures were identified to at least the genus level. The isolation and identification of bacteria were performed using standardized, prescribed and validated methods accredited by the South African National Accreditation system. ${ }^{97}$ The bacterial identification and their prevalence were noted and described. Where no bacterial growth was detected after the initial incubation period of 24 hours, the RODAC plates were re-incubated for up to 72 hours to confirm a negative result.

The results of each culture were classified according to the level of contamination, measured in CFU's. Negative cultures were classified as "No contamination" (0 CFU's). Positive cultures were classified as "low contamination" (1-12 CFU's) or "high contamination" (>12 CFU's). ${ }^{92}$

\section{Skin Reactions and Post-operative infections}

Cutaneous reactions were recorded following the initial wash with the neutral detergent, following the application of the antiseptic and at the end of surgery. These dogs were classified as having skin reactions if they showed evidence of urticaria, erythema or a rash.

The surgical wounds were examined within 24 hours of the surgery and again at suture removal (10-14 days). If the sutures were removed elsewhere, this information was obtained by a telephonic interview with the owner. Criteria used to identify surgical site infections were a purulent exudate and/or signs of inflammation.

\section{Peri-operative antibiotics}

Peri-operative antibiotics were not used in conjunction with this study. The incision sites were not covered with any form of primary dressing, in order to better assess the wounds after 24 hours. 


\section{Storage and shelf life}

The antiseptics were stored in the theatre complex in a secure dark cupboard at room temperature. The electrochemically activated water solution was discarded 60 days after opening the bottle and replaced with a fresh solution. The free available chlorine (FAC), pH and oxidative reduction potential (ORP) were measured for the old and the new solutions after a 60 day period for quality control purposes (Table 1). According to manufacture guidelines a FAC of more than $180 \mathrm{mg} / \mathrm{l}$, a pH of between 6.5 and 8.5 and an ORP of more than $700 \mathrm{mV}$ was recommended.

Table 1 Free available chlorine, $\mathrm{pH}$ and oxidative reduction potential readings of electrochemically activated water

\begin{tabular}{lcccc}
\hline & \multicolumn{2}{c}{ Batch 1 } & \multicolumn{2}{c}{ Batch 2 } \\
\cline { 2 - 5 } & Day 1 & Day 60 & Day 1 & Day 60 \\
\hline FAC $(\mathrm{mg} / \mathrm{l})$ & 290 & 183 & 340 & 210 \\
$\mathrm{pH}$ & 7.5 & 6.6 & 7.4 & 6.9 \\
ORP $(\mathrm{mV})$ & 826 & 780 & 840 & 790 \\
& & & & \\
\hline FAC = Free available chlorine; & & &
\end{tabular}

\subsection{Statistical analysis}

One-way ANOVA was initially used to compare means of CFU's between antiseptics at different time intervals. Levene's test however, demonstrated unequal variances between the antiseptics. Data analyses then resorted to the use of non-parametric methods for the analysis.

Kolomogorov-Smirnov was used to test for normality. Age, body weight, duration of wash, surgical time and CFU counts at the different sampling times, were reported as median and interquartile range (IQR). Kruskal-Wallis test was used to compare medians of body weight, total surgery time, duration of wash and CFU counts across the antiseptics at each of the sampling times. Wilcoxon's matched pairs signed ranks test was employed to compare two stages within a treatment. Mann-Whitney $U$ test, using pair-wise comparisons between the antiseptics was used to compare CFU counts at the four sampling times. 
To facilitate interpretation, data were grouped to represent levels of contamination. ${ }^{92}$ The three antiseptics were compared with respect to the level of contamination distribution using Fisher's exact test. The odds ratio for CFU outcome (clean or contaminated) of each antiseptic, with $C G+A$ as the reference was calculated. Fisher's exact test was also used to compare cutaneous reactions and post-operative infections between the antiseptics. The fourth sample was adjusted for surgery time using logistic regression.

A logistic regression model was also used to determine the correlation between postoperative wound infections and CFU's at the end of surgery and post-operative wound infection and surgery time. A simple linear regression model was used to determine the correlation between surgery time and CFU's.

Results for pathogenic bacteria only (Staphylococcus pseudintermedius, Staphylococcus aureus, Corynebacterium spp., Enterococcus spp. and the Gram negative bacteria) ${ }^{1}$ were extracted from the data set and analysed similarly.

The statistical analyses were performed with SPSS v.17 (IMB, Armonk, NY) and StataCorp 2015 (Stata: Release 14. Statistical Software. College Station, TX: StataCorp LP) statistical software. Significance was set at $P<.05$. 


\section{RESULTS}

One dog was excluded from the study due to clinical and diagnostic findings consistent with a pre-existing bacterial skin disease (Figure 11). The lab results confirmed overgrowth of Staphylococcus pseudintermedius at all the sampling times.

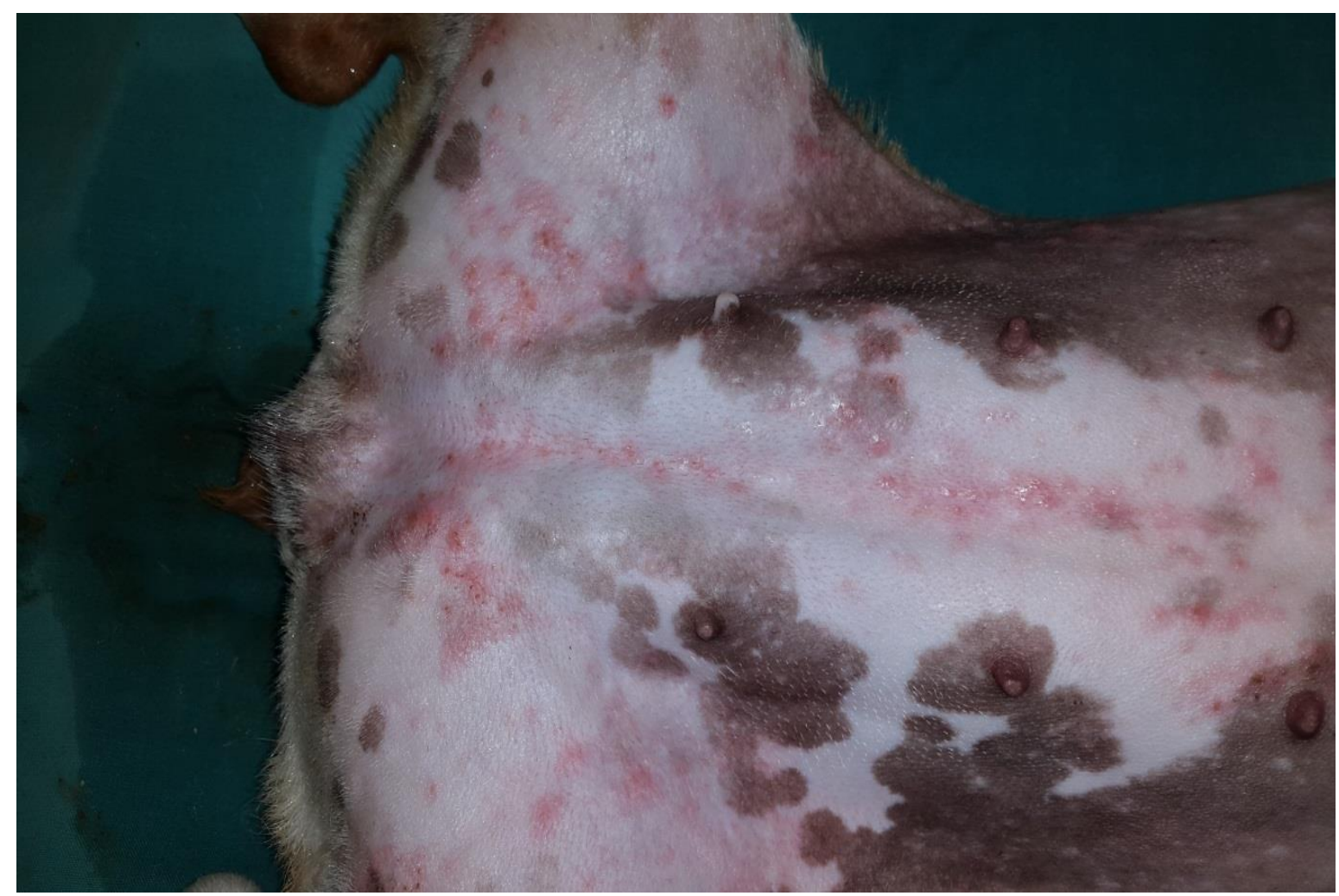

Figure 11 Case no. 13 showing an erythematous, crusted, pustular/papular rash. This dog was excluded from our trial due to bacterial skin disease.

Four dogs were excluded from the study due to contamination of the agar. One sample at the fourth sampling time was excluded due to a break in aseptic technique at the end of surgery.

The median age for all dogs was 11 months (IQR 18) and weight $7.8 \mathrm{~kg}$ (IQR 8.6). The median duration of the neutral detergent wash was 8 minutes (IQR 4) and the surgical time 146 minutes (IQR 55).

There was no statistically significant difference in body weight $(P=.983)$, total surgery time $(P=.875)$, duration of wash $(P=.222)$ or age $(P=.942)$ between the three antiseptic groups. 


\section{Positive bacterial cultures}

The prevalence of dogs that had positive bacterial cultures at the four sampling times are reported in Table 2 and Figure 12.

Table 2 Prevalence of all dogs with positive bacterial cultures at the four sampling times.

Sampling time Number of dogs with bacterial growth

\begin{tabular}{ll}
\hline Sample 1 (Post wash) $n=117$ & $106(90 \%)$ \\
Sample 2 (Post antiseptic) $n=117$ & $36(31 \%)$ \\
Sample 3 (Two hours) $n=117$ & $52(44 \%)$ \\
Sample 4 (End of surgery) $n=116$ & $66(57 \%)$ \\
\hline
\end{tabular}

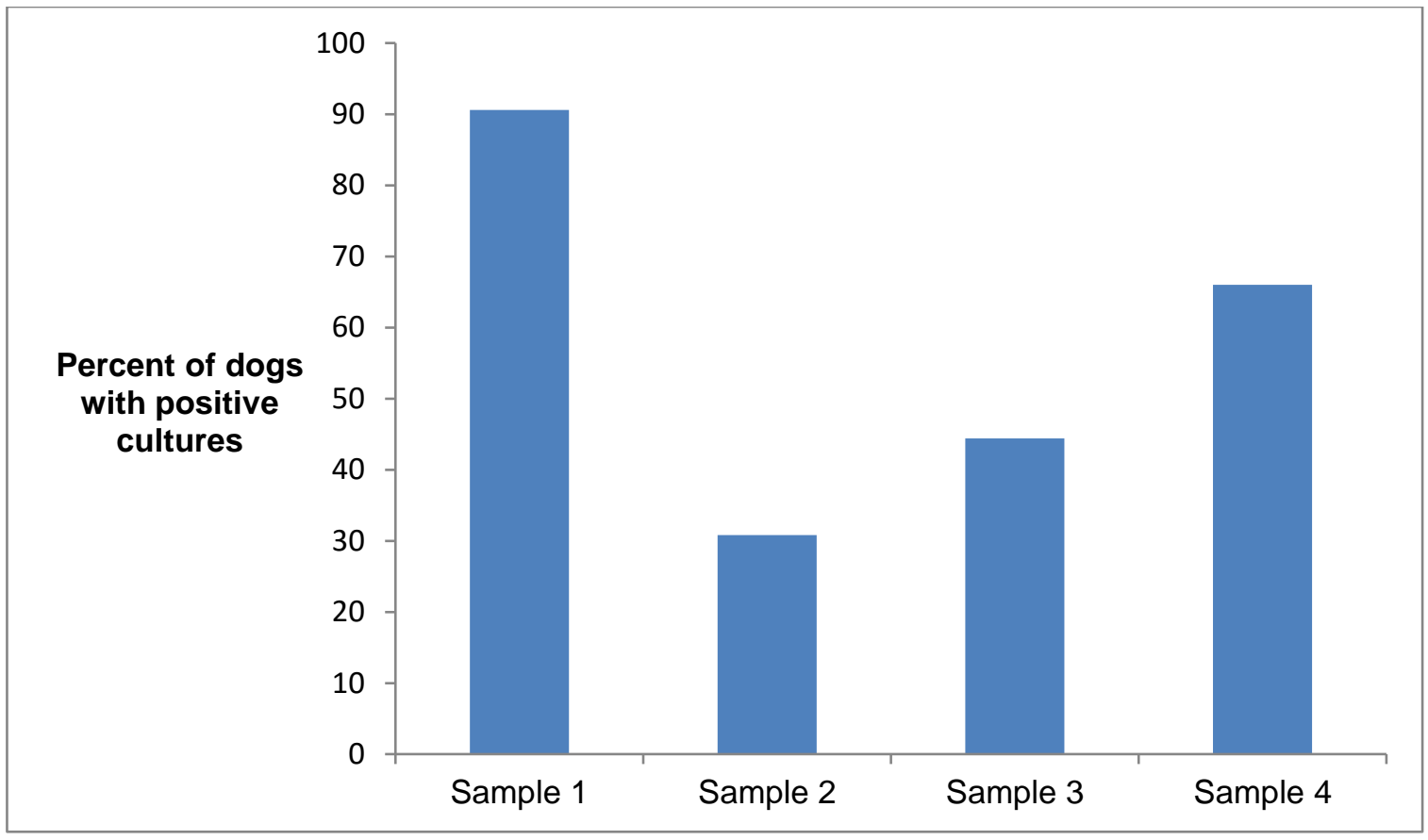

Figure 12 Prevalence of all dogs with positive cultures at the four sampling times. 


\section{Total colony forming unit counts}

The total CFU count for all the dogs of each antiseptic group at the four sampling times are illustrated below (Figure 13).

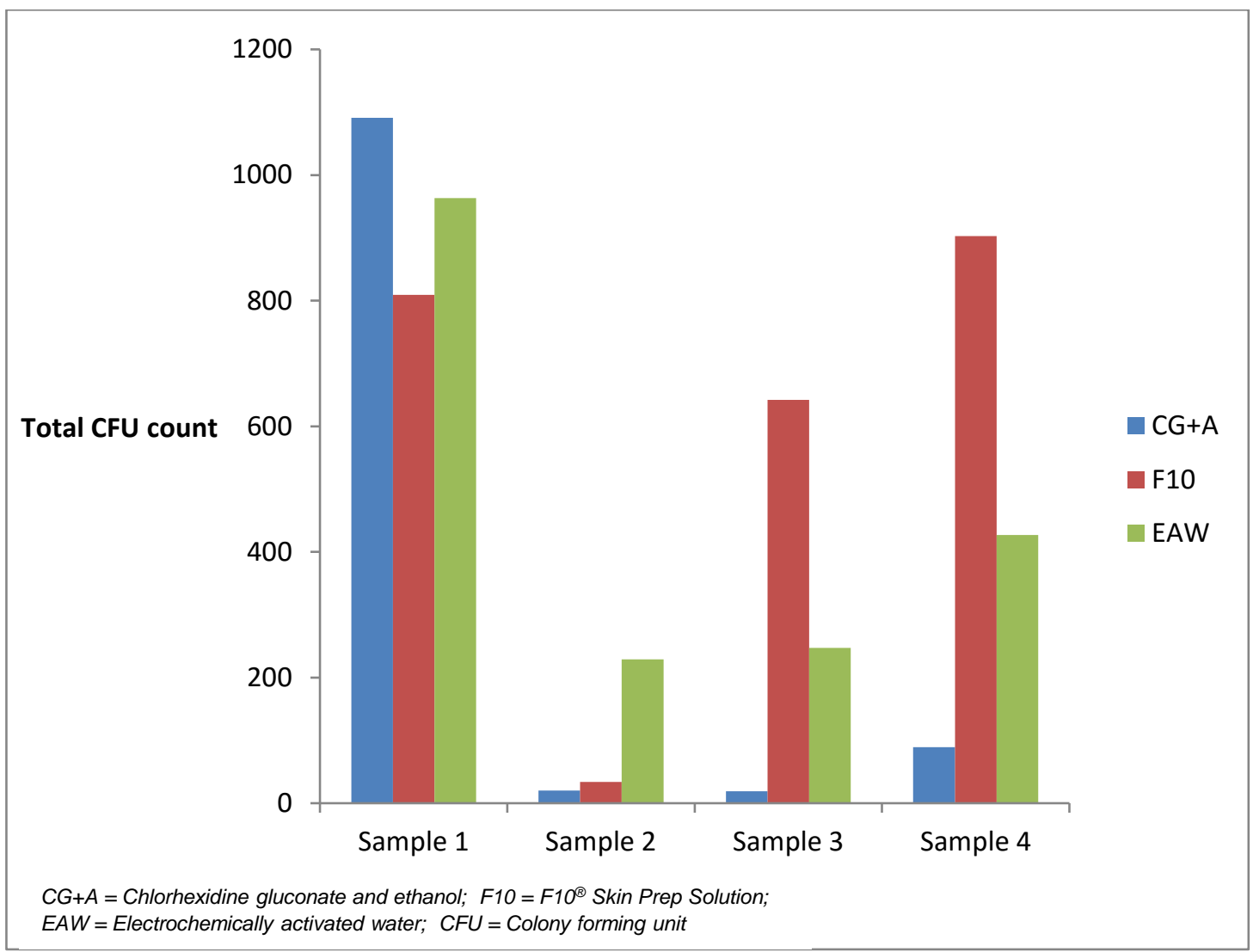

Figure 13 Total CFU count for all the dogs of each antiseptic at the four sampling times. 


\section{Median colony forming unit counts}

The median CFU counts at the four sampling times for all the dogs are summarized in

Table 3.

Table 3 Median colony forming unit counts for all dogs at the four sampling times

\begin{tabular}{lccc}
\hline \multicolumn{1}{c}{ Sampling time } & \multicolumn{3}{c}{ CFU count } \\
\cline { 2 - 4 } & Median & IQR & Range \\
\hline Sample 1 & 6.0 & $2.0-20.5$ & $0.0-250.0$ \\
Sample 2 & 0.0 & $0.0-1.0$ & $0.0-177.0$ \\
Sample 3 & 0.0 & $0.0-2.0$ & $0.0-250.0$ \\
Sample 4 & 1.0 & $0.0-2.0$ & $0.0-250.0$ \\
\hline
\end{tabular}

$\overline{C F U}=$ Colony forming unit; $I Q R=$ Interquartile range

No statistical difference was demonstrated in the distribution of CFU's at the first sampling time $(P=.779)$ across the three antiseptics groups. However, a statistical difference was demonstrated at the second $(P=.001)$, third $(P=.002)$ and fourth $(P=.005)$ sampling times. There was a significant reduction in CFU counts between the first and the second sample across all the antiseptics $(P=.001)$. 
When comparing the three antiseptics pair-wise, there were significantly less CFU's in the $\mathrm{CG}+\mathrm{A}$ group when compared to $\mathrm{F} 10(P=.003, P=.001, P=.005)$ and EAW $(P=.001, P=.008$, $P=.004$ ) at the second, third and fourth sampling times respectively (Table 4). However, there were no significant differences in the CFU counts when F10 was compared to EAW at these times $(P=.667, P=.527, P=.785)$.

Table 4 Median colony forming unit counts at the second, third and fourth sampling times for the three antiseptics (pair-wise comparisons)

\begin{tabular}{|c|c|c|c|c|}
\hline \multicolumn{2}{|c|}{ Sampling times } & \multicolumn{3}{|c|}{ Antiseptic } \\
\hline & & $\mathrm{CG}+\mathrm{A}$ & F10 & EAW \\
\hline \multirow[t]{2}{*}{ Sample 2} & Median/IQR & $0(0.0-0.0)$ & $0(0.0-1.0)$ & $0(0.0-1.0)$ \\
\hline & P Value & & $P=.003$ & $P=.001$ \\
\hline \multirow[t]{2}{*}{ Sample 3} & Median/IQR & $0(0.0-0.0)$ & $1(0.0-3.5)$ & $0.5(0.0-2.0)$ \\
\hline & $P$ value & & $P=.001$ & $P=.008$ \\
\hline \multirow[t]{2}{*}{ Sample 4} & Median/ IQR & $0(0.0-1.0)$ & $1(0.0-3.0)$ & $1(0.0-4.3)$ \\
\hline & $P$ value & & $P=.005$ & $P=.004$ \\
\hline
\end{tabular}




\section{Level of contamination}

There was no significant difference in the level of contamination between the antiseptic groups at the first sampling time $(P=.454)$. However, the level of contamination for $\mathrm{CG}+\mathrm{A}$ was significantly lower compared to $\mathrm{F} 10$ and EAW at the second, third and fourth sampling times $(P=.001, P=.01, P=.02)$ (Table 5 and Figures 14-17).

Table 5 Distribution of the level of bacterial contamination for the three antiseptics

\begin{tabular}{|c|c|c|c|c|c|c|}
\hline Time & $\begin{array}{l}\text { CFU } \\
\text { count }\end{array}$ & $\begin{array}{c}\text { Level of } \\
\text { contamination }\end{array}$ & $\begin{array}{l}C G+A \\
(n=39)\end{array}$ & $F 10(n=39)$ & $\begin{array}{l}\text { EAW } \\
(n=38)\end{array}$ & $\begin{array}{c}\text { Fisher's exact } \\
\text { test }\end{array}$ \\
\hline \multirow[t]{3}{*}{ Sample 1} & 0 & No & $3(8 \%)$ & $6(15 \%)$ & $2(5 \%)$ & $P=.454$ \\
\hline & $1-12$ & Low & $23(59 \%)$ & $21(54 \%)$ & $27(71 \%)$ & \\
\hline & $>12$ & High & $13(33 \%)$ & $12(30 \%)$ & 9 (24\%) & \\
\hline \multirow[t]{3}{*}{ Sample 2} & 0 & No & 36 (92\%) & $21(54 \%)$ & $24(63 \%)$ & $P=.001$ \\
\hline & $1-12$ & Low & $2(5 \%)$ & $18(46 \%)$ & 11 (29\%) & \\
\hline & $>12$ & High & $1(3 \%)$ & $0(0 \%)$ & $3(8 \%)$ & \\
\hline \multirow[t]{3}{*}{ Sample 3} & 0 & No & 30 (77\%) & 15 (39\%) & $19(50 \%)$ & $P=.01$ \\
\hline & $1-12$ & Low & $9(23 \%)$ & 19 (49\%) & $16(42 \%)$ & \\
\hline & $>12$ & High & $0(0 \%)$ & $5(13 \%)$ & $3(8 \%)$ & \\
\hline \multirow[t]{3}{*}{ Sample 4} & 0 & No & $25(64 \%)$ & 13 (33\%) & $11(29 \%)$ & $P=.02$ \\
\hline & $1-12$ & Low & 12 (40\%) & 20 (51\%) & $20(53 \%)$ & \\
\hline & $>12$ & High & $2(5 \%)$ & $6(15 \%)$ & 7 (18\%) & \\
\hline
\end{tabular}

$\overline{C F U}=$ Colony forming unit; $C G+A=$ Chlorhexidine gluconate and ethanol; $F 10=F 10^{\circledR}$ Skin Prep Solution; $E A W=$ Electrochemically activated water $P=P$ value 


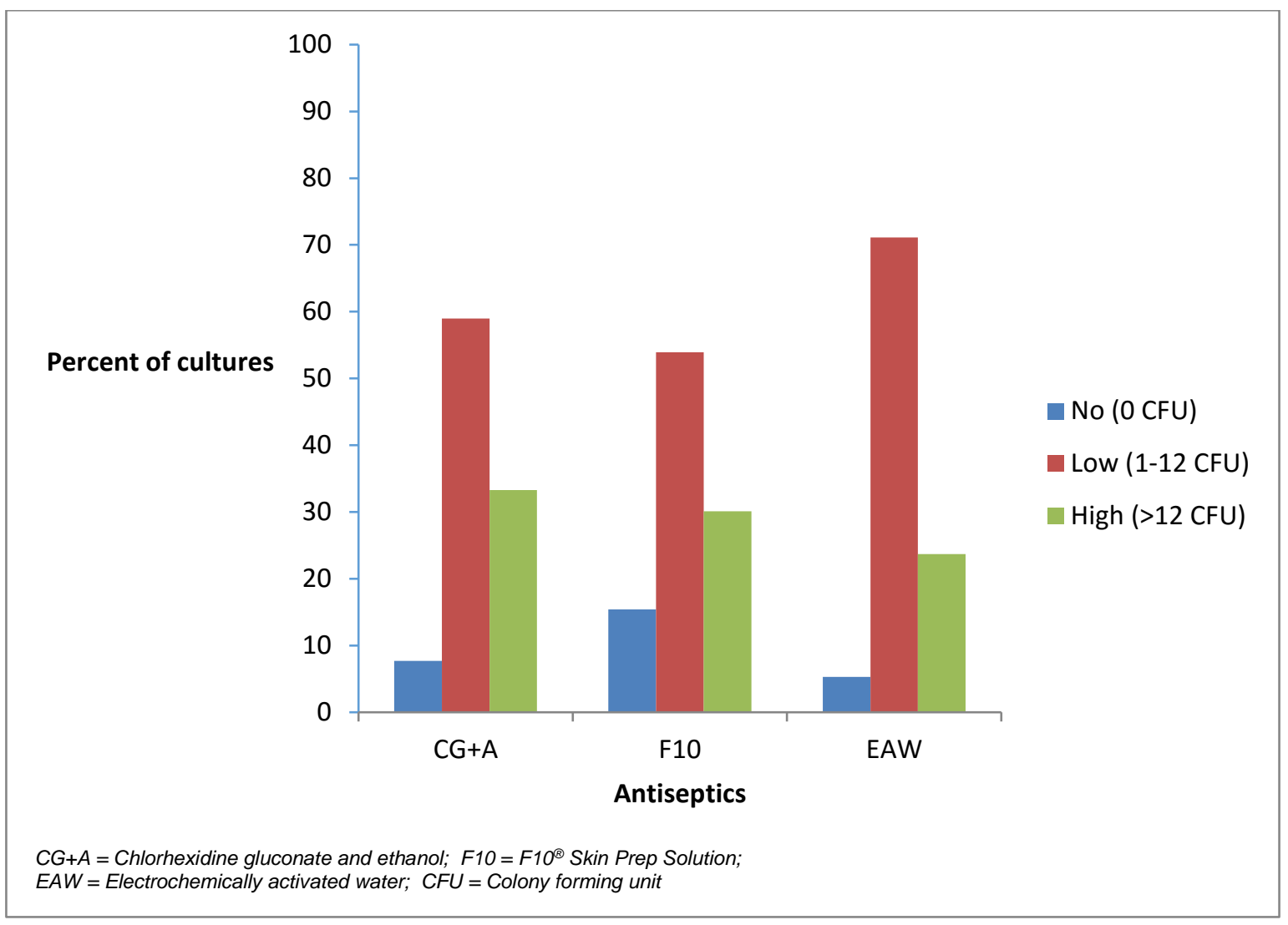

Figure 14 Level of bacterial contamination at the first sampling time.

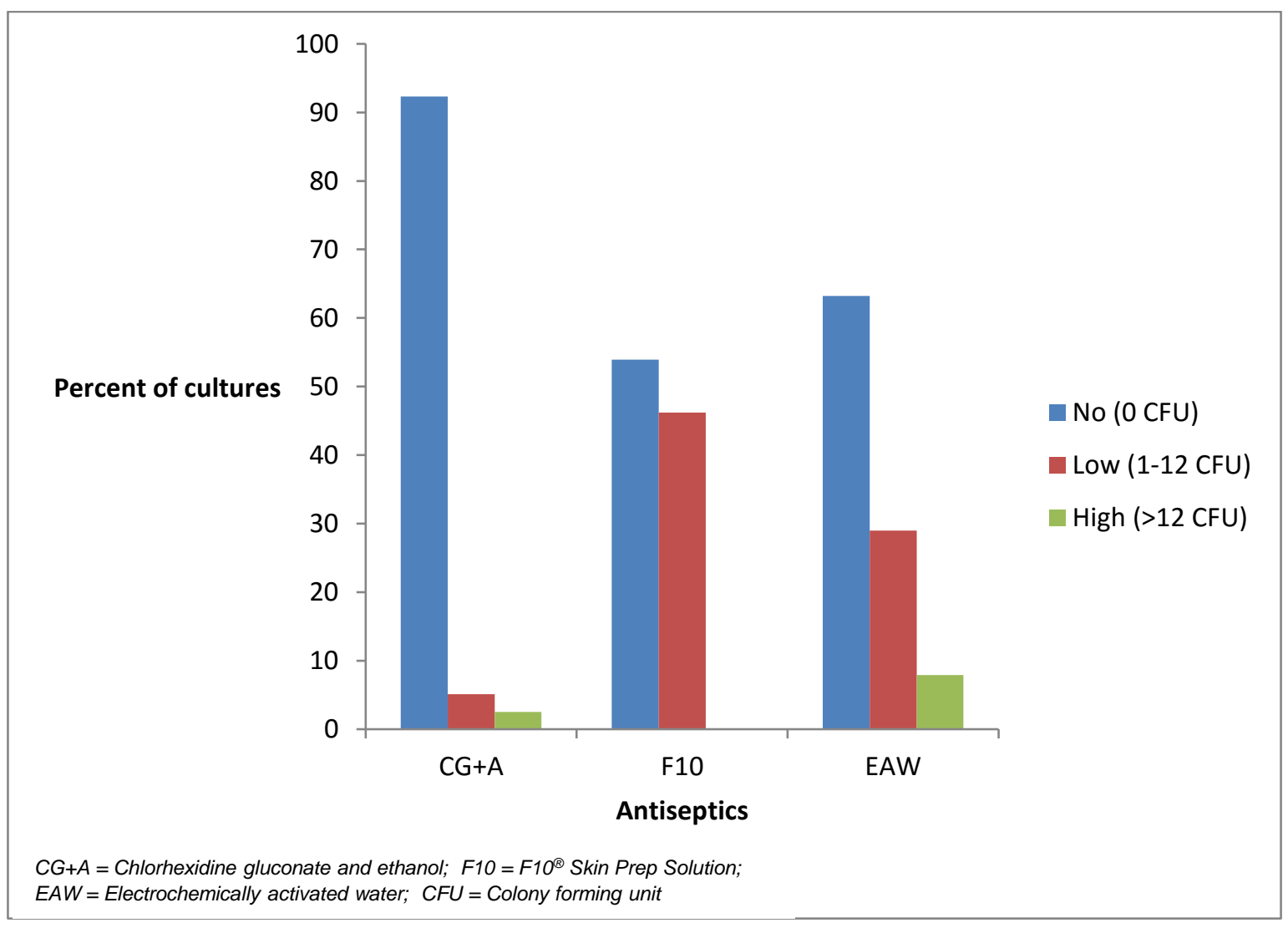

Figure 15 Level of bacterial contamination at the second sampling time. 


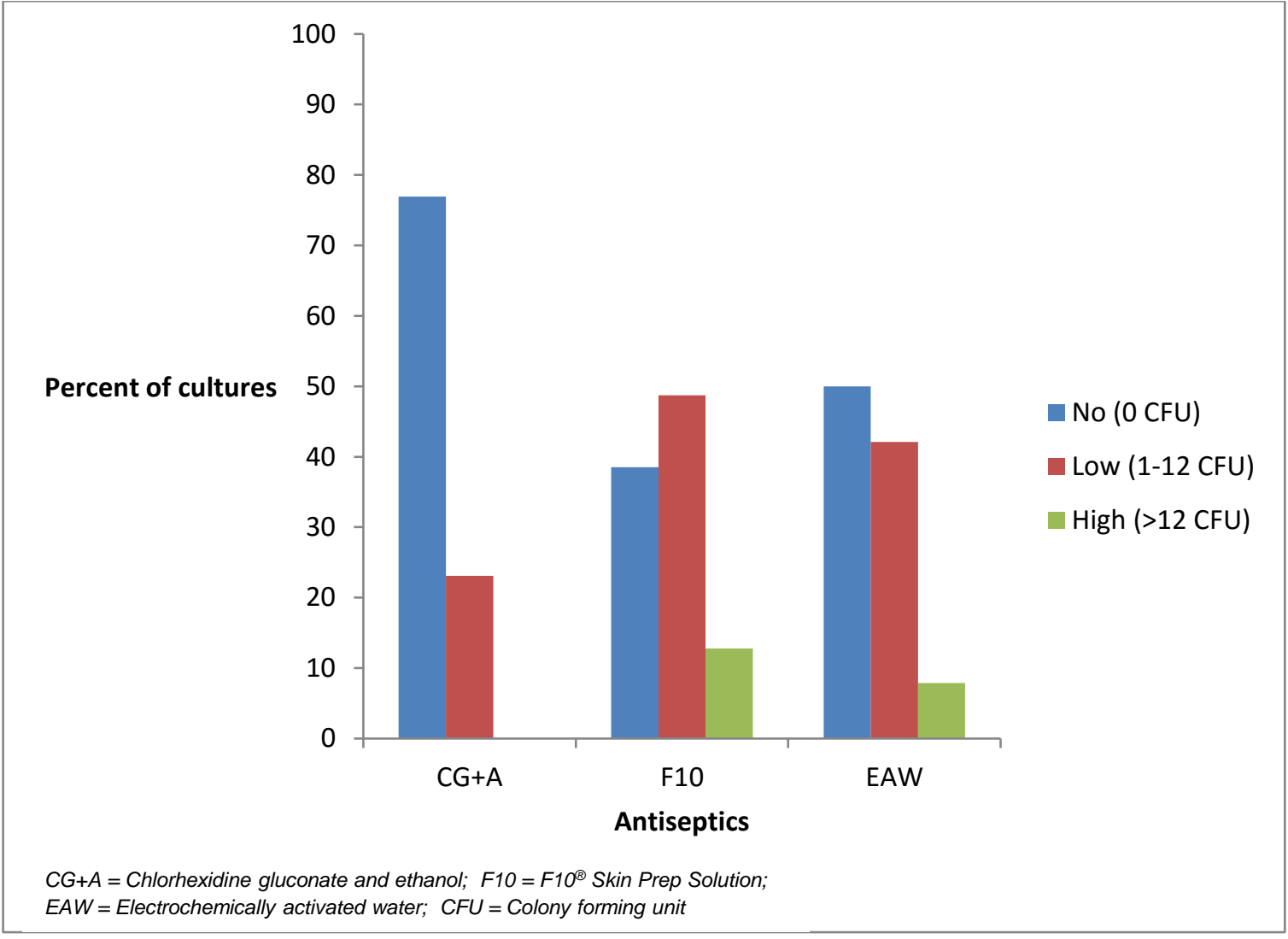

Figure 16 Level of bacterial contamination at the third sampling time.

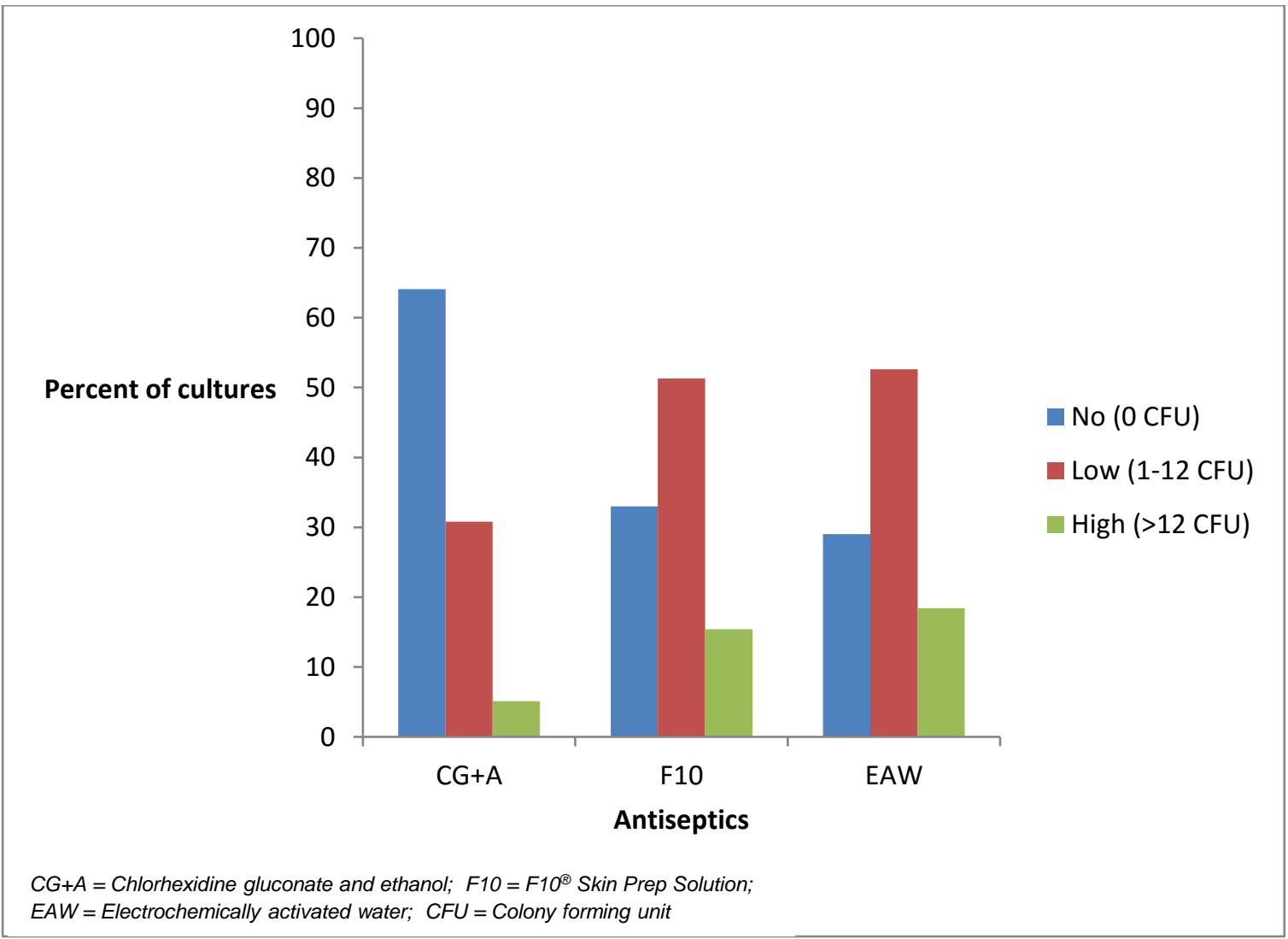

Figure 17 Level of bacterial contamination at the fourth sampling time. 


\section{Clean versus contaminated outcome}

Relative to $\mathrm{CG}+\mathrm{A}$, EAW had a 7 fold increased risk for bacterial contamination $(P=.001)$ and $\mathrm{F} 10$ a 10 fold increased risk for bacterial contamination $(P=.001)$ at the second sampling time for a clean $(\mathrm{CFU}=0)$ or contaminated $(\mathrm{CFU} \geq 1)$ outcome. Similar results were obtained at the third and fourth sampling times when EAW had a 3 and 4 fold increased risk for bacterial contamination respectively $(P=.015)$ and $\mathrm{F} 10$ had a 5 and 4 fold increased risk $(P=.001)$ (Table 6).

Table 6 Odds ratio for clean or contaminated outcome of each antiseptic using chlorhexidine and alcohol as the reference

\begin{tabular}{|c|c|c|c|c|}
\hline Time & Antiseptic & Odds ratio & $\begin{array}{c}\text { 95\% Confidence } \\
\text { interval }\end{array}$ & P-value \\
\hline \multirow[t]{3}{*}{ Sample 1} & $\mathrm{CG}+\mathrm{A}$ & 1 & & \\
\hline & F10 & 0.45 & $(0.1 ; 2)$ & $P=.291$ \\
\hline & EAW & 1.5 & $(0.2 ; 9.7)$ & $P=.667$ \\
\hline \multirow[t]{3}{*}{ Sample 2} & $\mathrm{CG}+\mathrm{A}$ & 1 & & \\
\hline & F10 & 10.3 & $(2.3 ; 45.7)$ & $P=.001$ \\
\hline & EAW & 7.0 & $(1.6 ; 29.9)$ & $P=.002$ \\
\hline \multirow[t]{3}{*}{ Sample 3} & $\mathrm{CG}+\mathrm{A}$ & 1 & & \\
\hline & F10 & 5.33 & $(1.8 ; 15.7)$ & $P=.001$ \\
\hline & EAW & 3.33 & $(1.19 ; 9.3)$ & $P=.015$ \\
\hline \multirow[t]{3}{*}{ Sample $4^{\star}$} & $\mathrm{CG}+\mathrm{A}$ & 1 & & \\
\hline & F10 & 3.57 & $(1.33 ; 9.6)$ & $P=.007$ \\
\hline & EAW & 4.38 & $(1.56 ; 12.3)$ & $P=.002$ \\
\hline
\end{tabular}

*Odds ratio adjusted for surgery time

$\overline{C G}+A=$ Chlorhexidine gluconate and ethanol; $F 10=F 10^{\circledR}$ Skin Prep Solution; $E A W=$ Electrochemically activated water 


\section{Bacterial identification}

Table 7 and Figure 18 summarizes the prevalence of the most common bacteria that were isolated from all dogs at the four different sampling times during the trial.

Table 7 Prevalence of the most common bacteria at the four sampling times

\section{Sampling Time}

\begin{tabular}{lcccc}
\hline Bacterium Identification & Sample 1 & Sample 2 & Sample 3 & Sample 4 \\
& $\mathbf{n = 1 8 8}$ & $\mathbf{n = 4 0}$ & $\mathbf{n = 6 3}$ & $\mathbf{n = 6 6}$ \\
\hline Bacillus spp. & $69(37 \%)$ & $17(43 \%)$ & $18(29 \%)$ & $22(33 \%)$ \\
Staphylococcus. pseudintermedius & $55(29 \%)$ & $10(25 \%)$ & $19(30 \%)$ & $21(32 \%)$ \\
Coagulase negative Staphylococcus sp. & $32(17 \%)$ & $8(20 \%)$ & $14(22 \%)$ & $7(11 \%)$ \\
Micrococcus spp. & $10(5 \%)$ & $1(3 \%)$ & $3(5 \%)$ & $3(5 \%)$ \\
Corynebacterium spp. & $5(3 \%)$ & $0(0 \%)$ & $3(5 \%)$ & $7(11 \%)$ \\
Gram negative bacteria & $9(5 \%)$ & $2(5 \%)$ & $2(3 \%)$ & $2(3 \%)$ \\
TOTAL & $\mathbf{1 8 3 ( 9 7 \% )}$ & $\mathbf{3 9}(\mathbf{9 7} \%)$ & $\mathbf{6 0}(\mathbf{9 5} \%)$ & $\mathbf{6 3}(\mathbf{9 5} \%)$ \\
\hline$n=$ number of bacterial isolates & & &
\end{tabular}

The remaining $3-5 \%$ percent was made up by other insignificant bacterial species. 


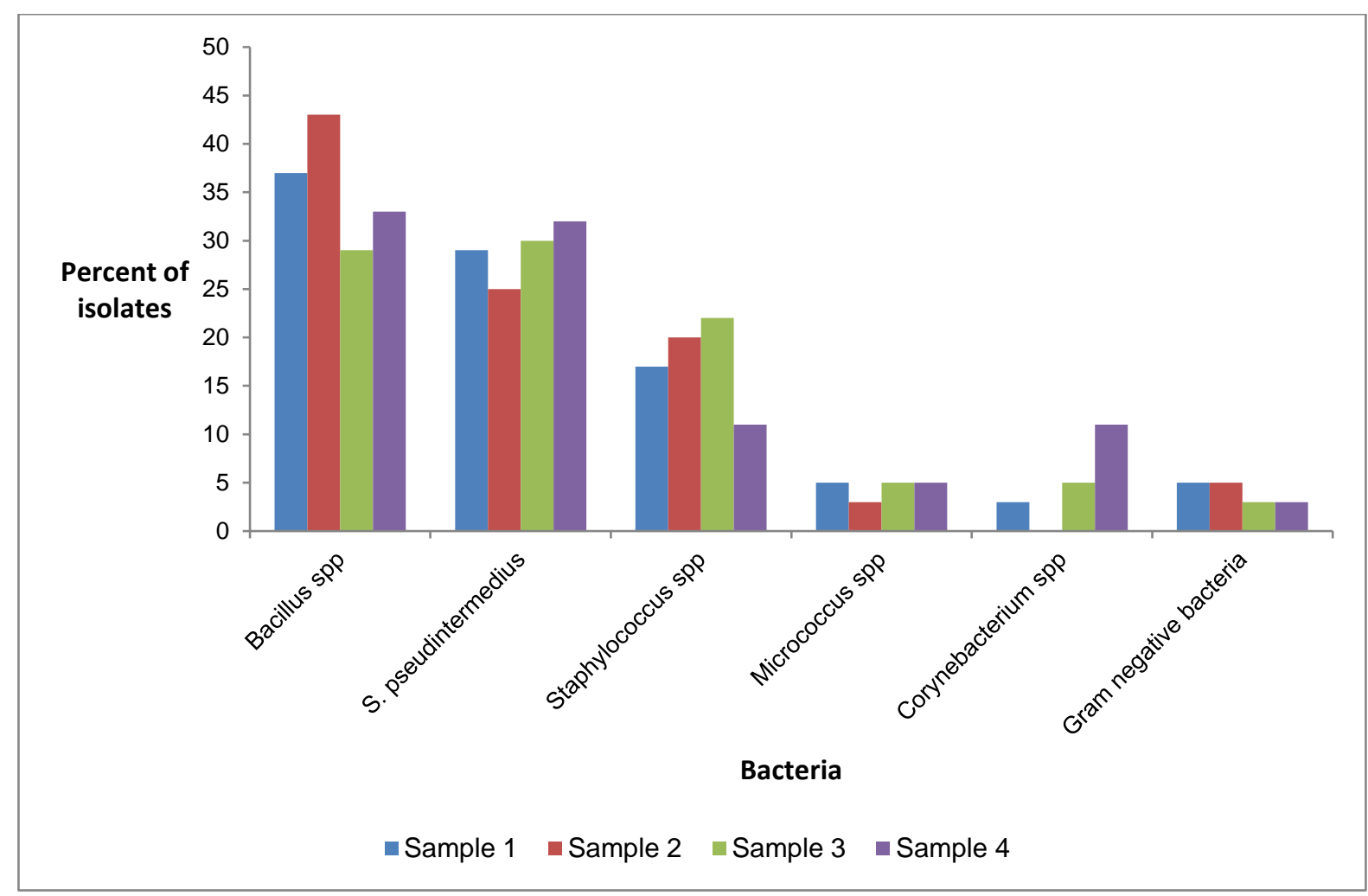

Figure 18 Prevalence of the most common bacteria at the four sampling times.

One of the cultured Staphylococcus pseudintermedius was identified as methicillin-resistant Staphylococcus pseudintermedius (MRSP). This specific case had a CFU count of 18 at the first sampling time. No CFUs were cultured at the second sampling time, and 7 and 9 MRSP CFUs were cultured at the third and fourth respectively. The antiseptic that was used in this case was EAW.

The two most commonly isolated bacteria in the Gram negative group were Pseudomonas spp. and E coli. Staphylococcus aureus was isolated from one dog.

There was no significant difference in the distribution of skin reactions after the initial wash with the neutral detergent $(P=.441)$, following the application of the antiseptic $(P=.441)$ or at the end of surgery $(P=.118)$ across the antiseptic groups. 


\section{Skin reactions}

Forty two out of 117 dogs developed skin reactions following the initial wash with the neutral detergent. Examples of uricarial skin reactions, erythema and a papular rash are illustrated below (Figures 19-22). No dogs showed any worsening in the degree of skin reactions following the application of the antiseptic or post-operatively. Forty three percent of the dogs that reacted initially, showed an improvement in the severity of the skin reaction by the end of surgery. No dogs that reacted normally to the neutral detergent wash, showed any evidence of skin irritation either immediately after the application of the antiseptic or after the surgery.

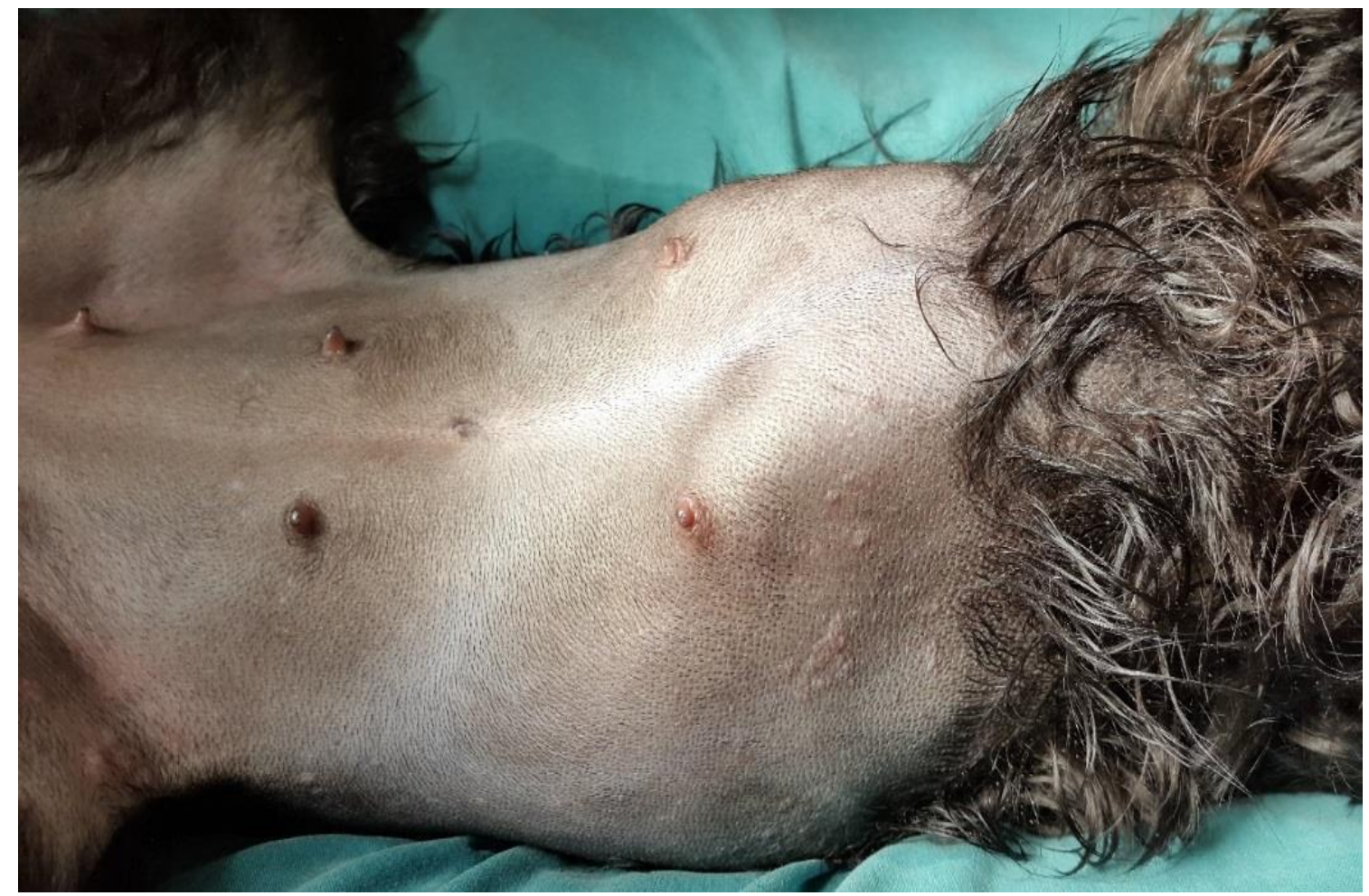

Figure 19A Case no. 30 showing urticarial skin reactions. 


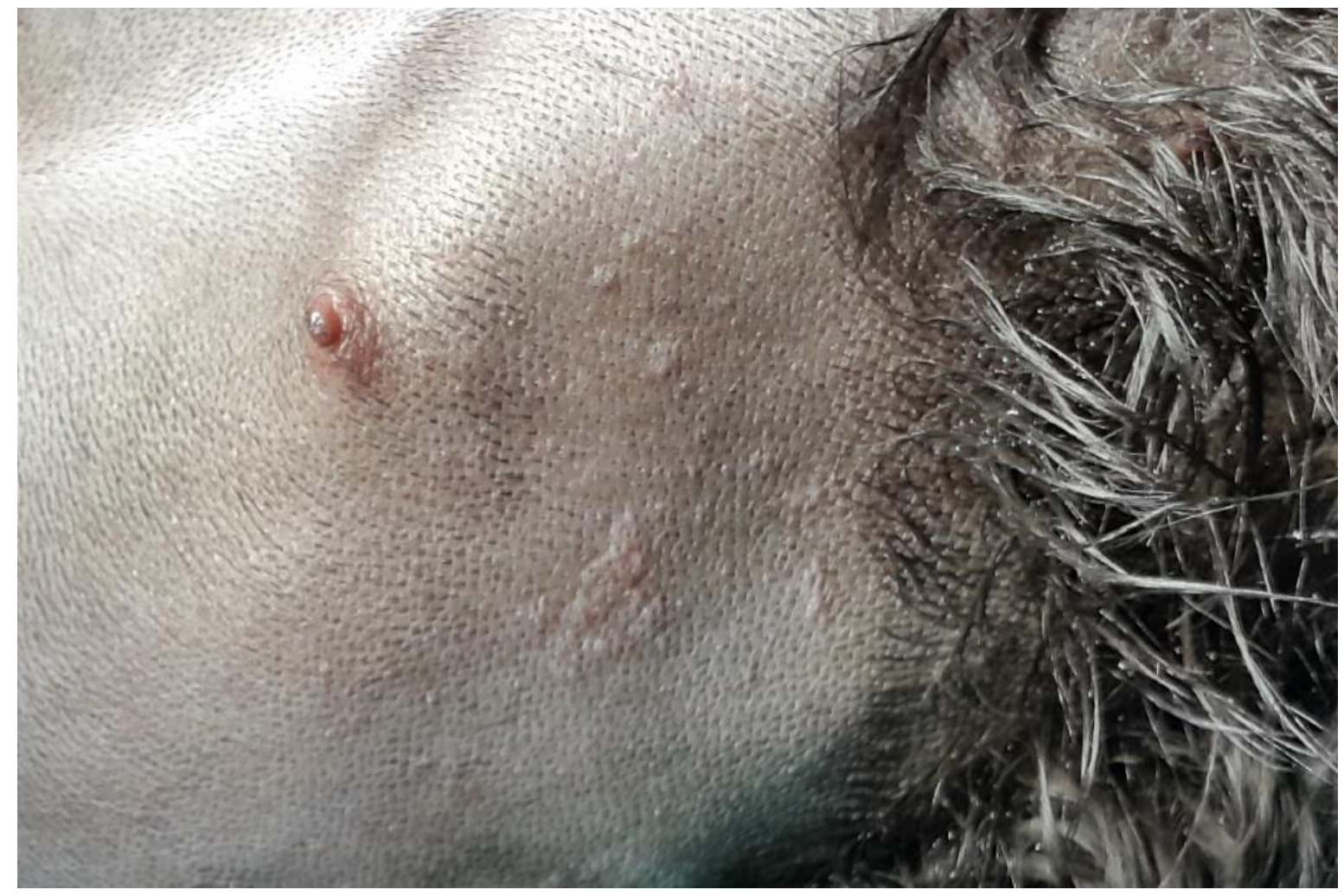

Figure 19B Close up of case no. 30 showing urticarial skin reactions.

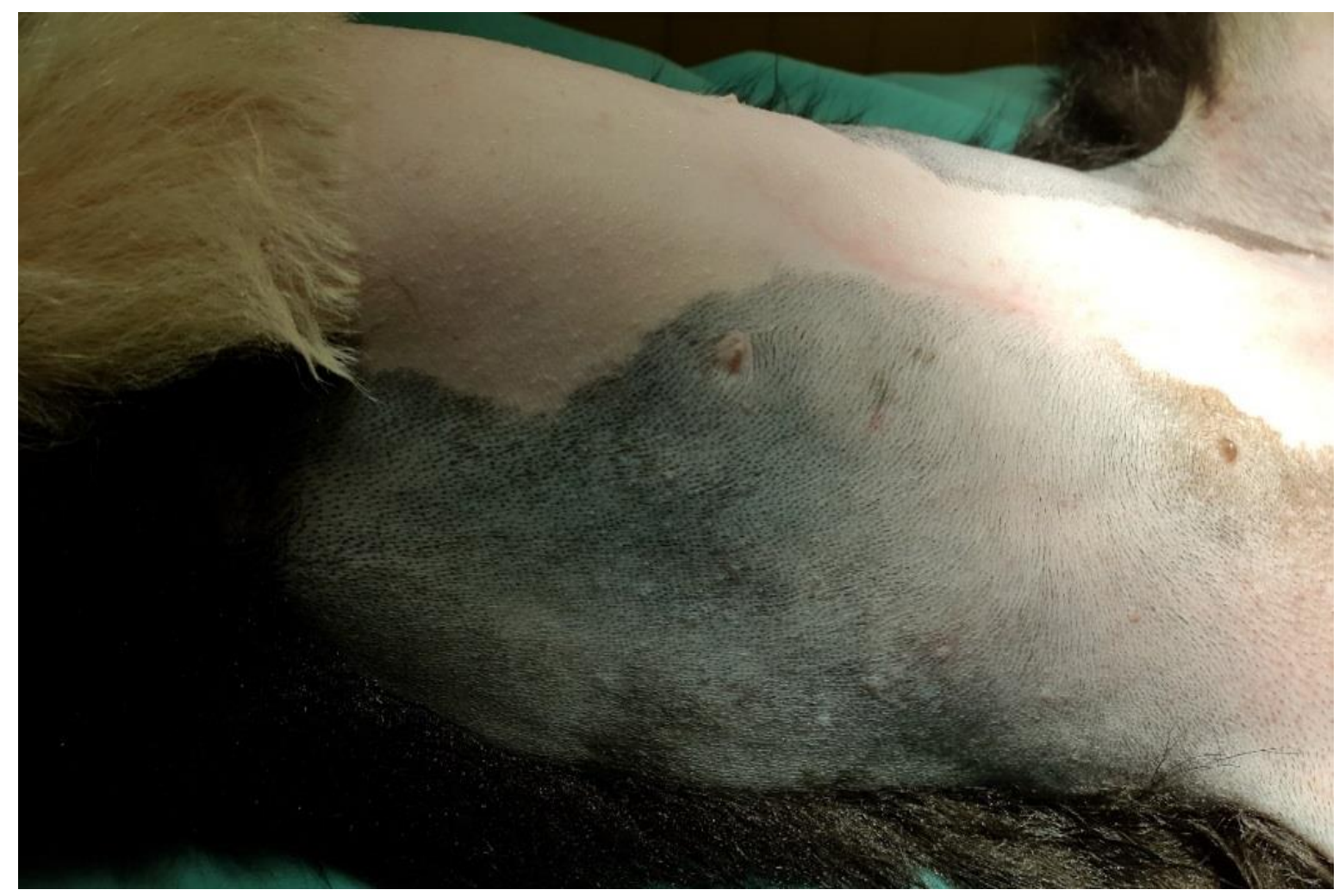

Figure 19C Case no. 32 showing urticarial skin reactions. 


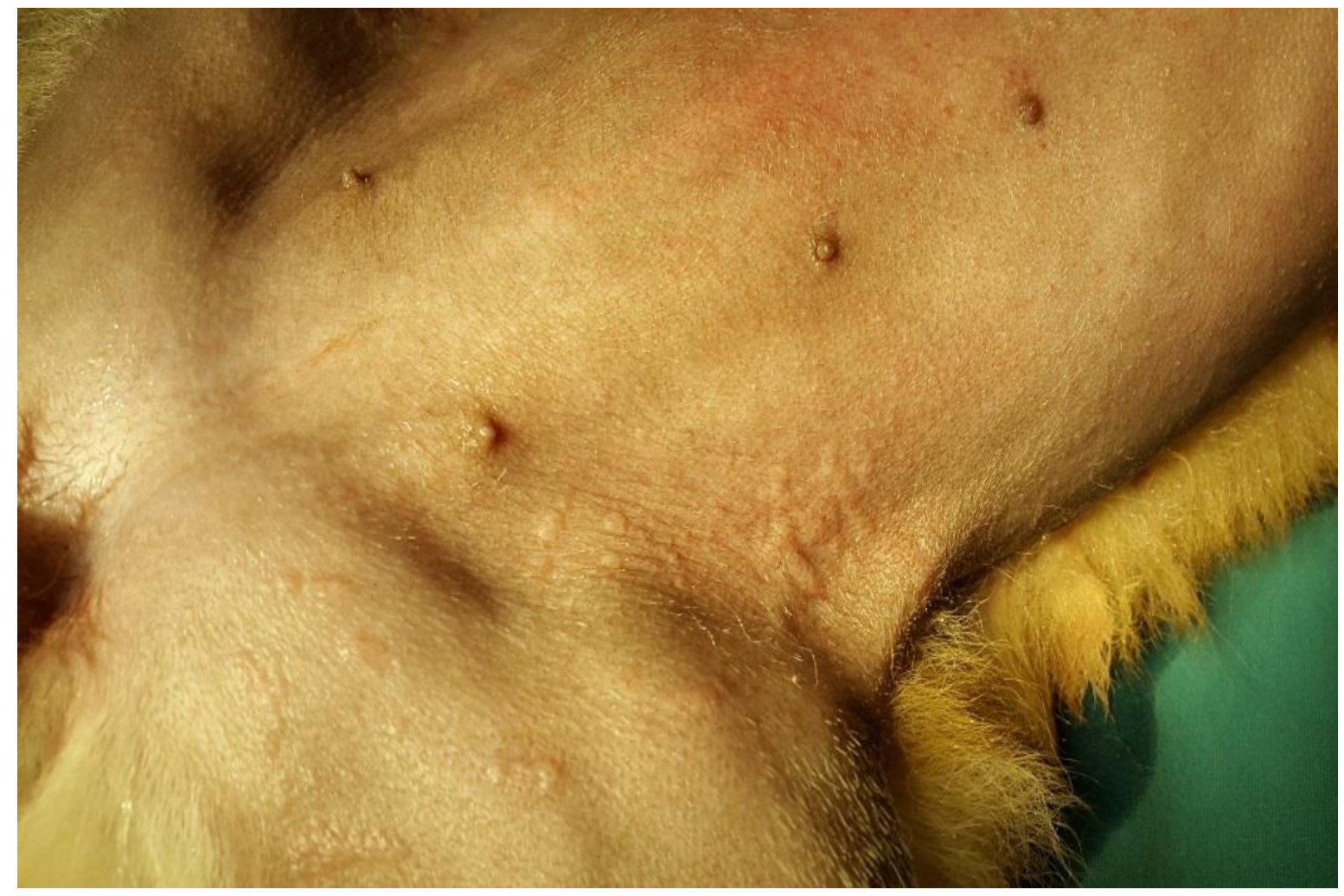

Figure 19D Case no. 60 showing urticarial skin reactions.

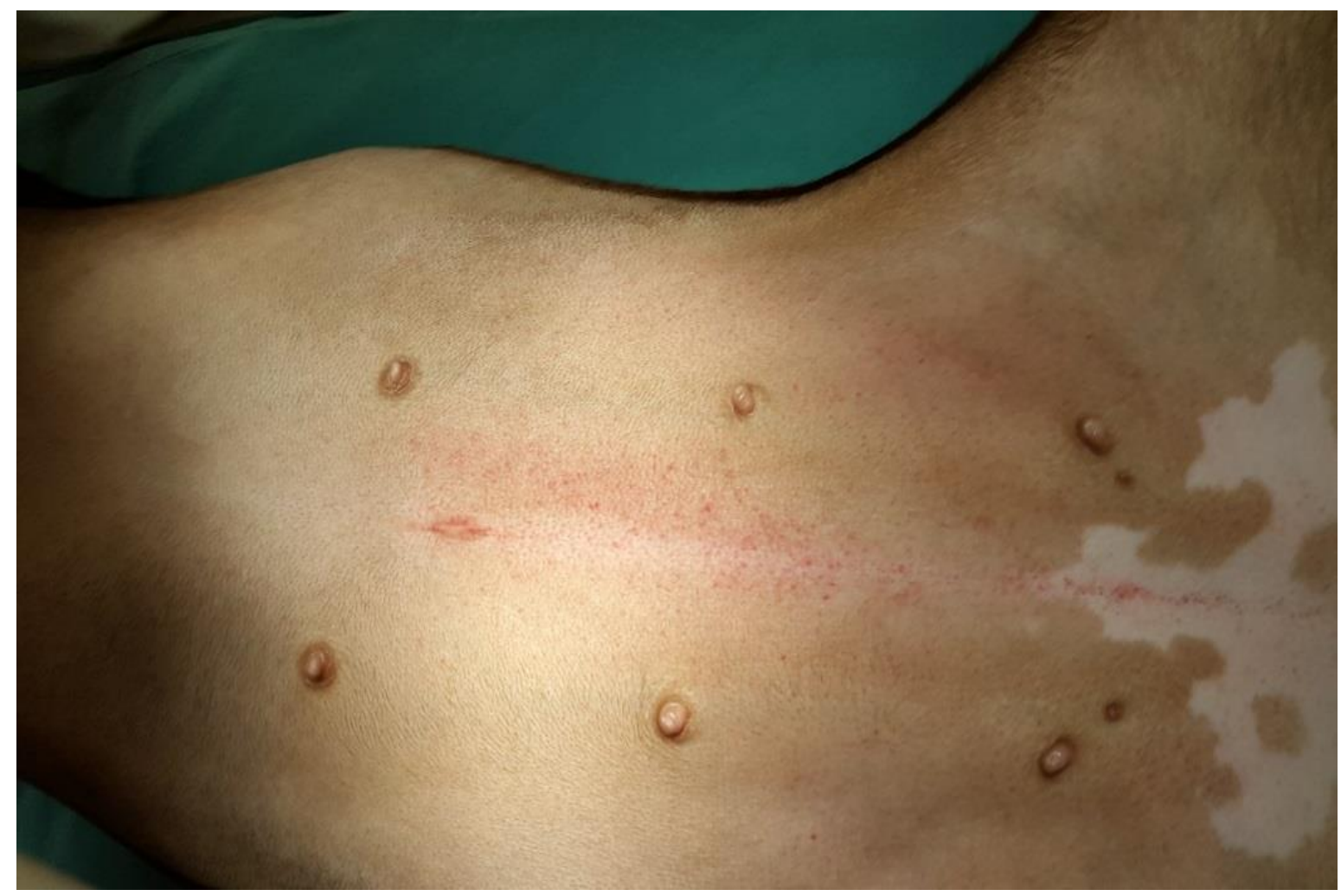

Figure 20

Case no. 55 showing excoriation and an erythematous skin reaction following an overzealous wash with a neutral detergent. 


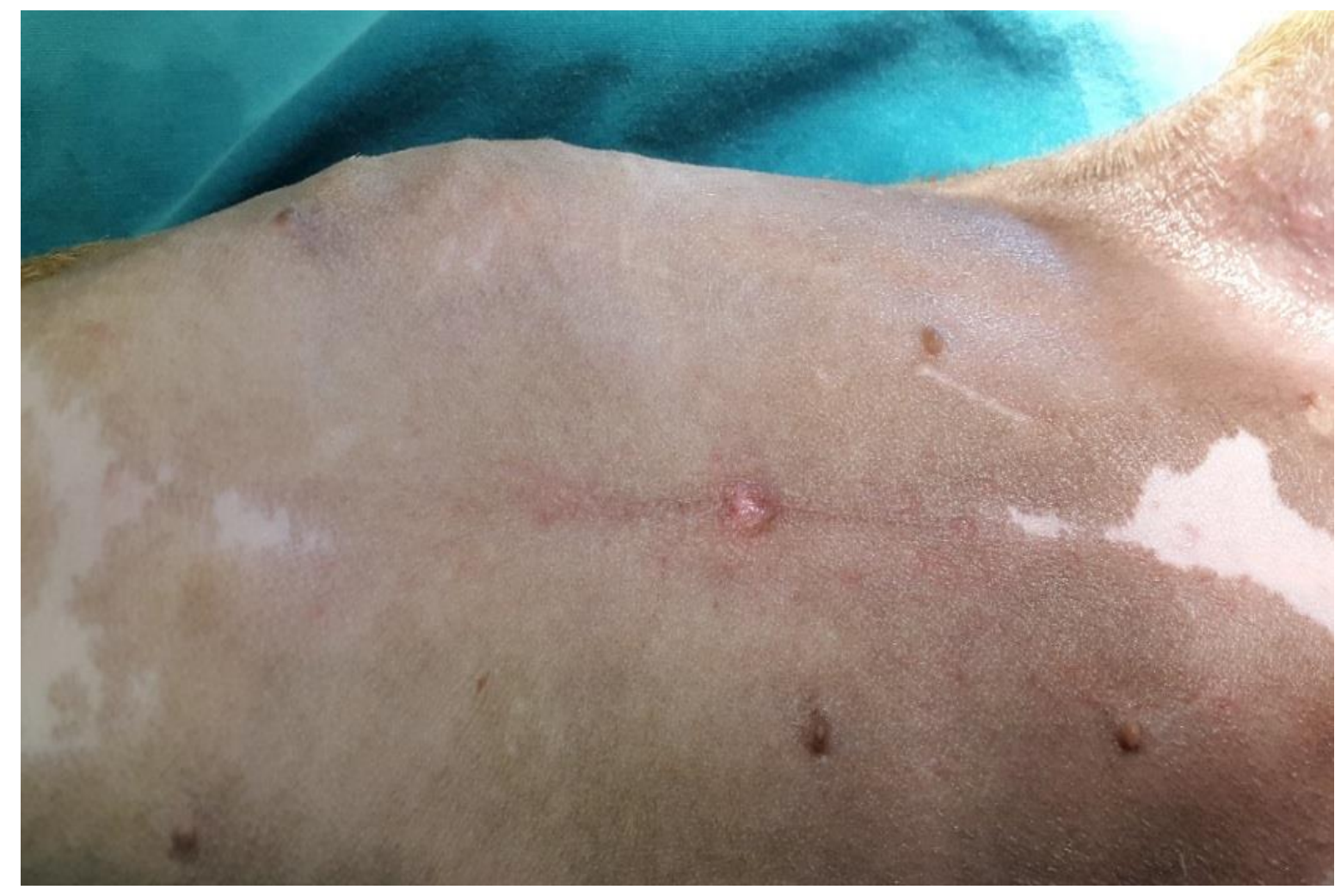

Figure 21A Case no. 25 showing an erythematous skin reaction.

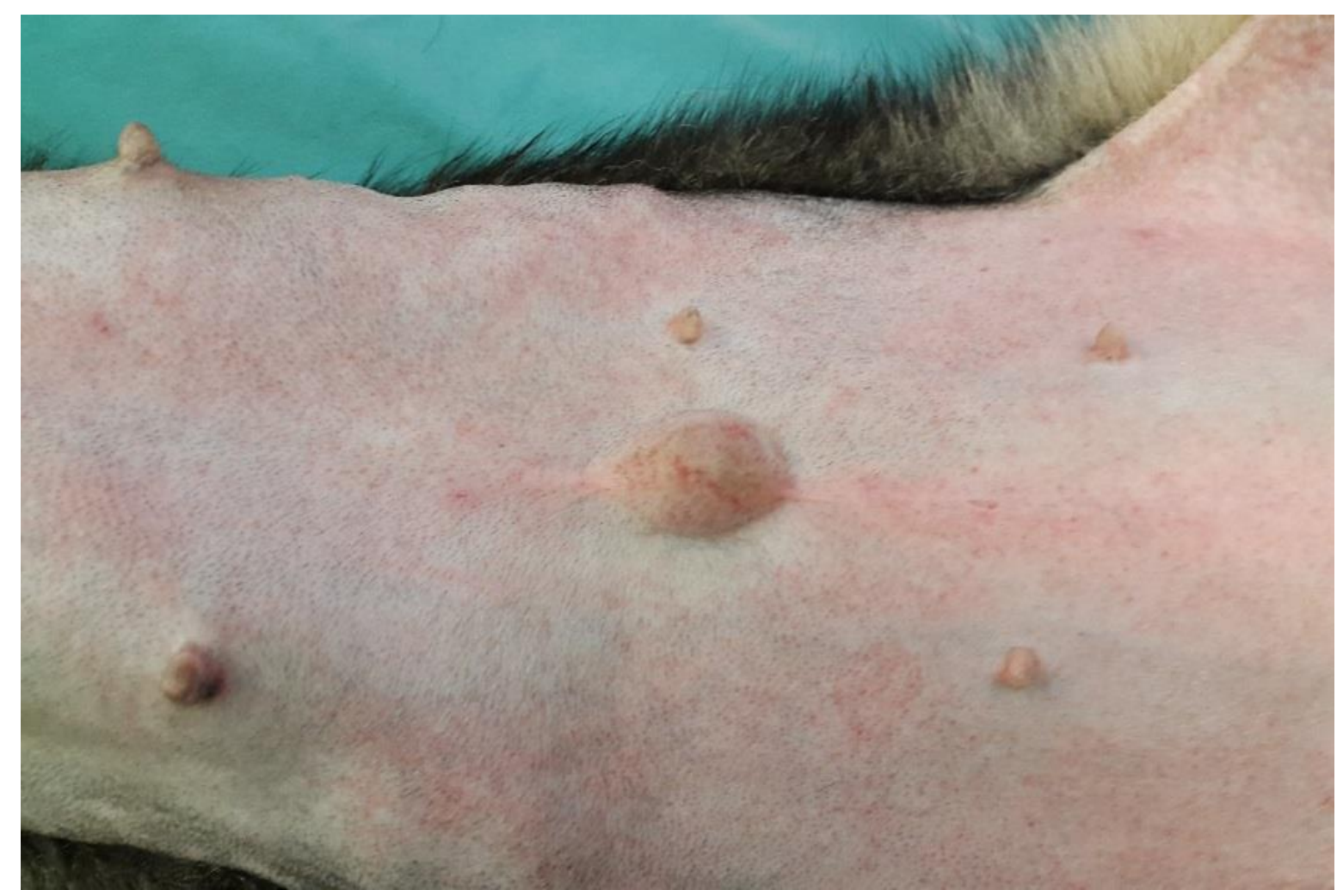

Figure 21B Case no. 63 showing an erythematous skin reaction. 


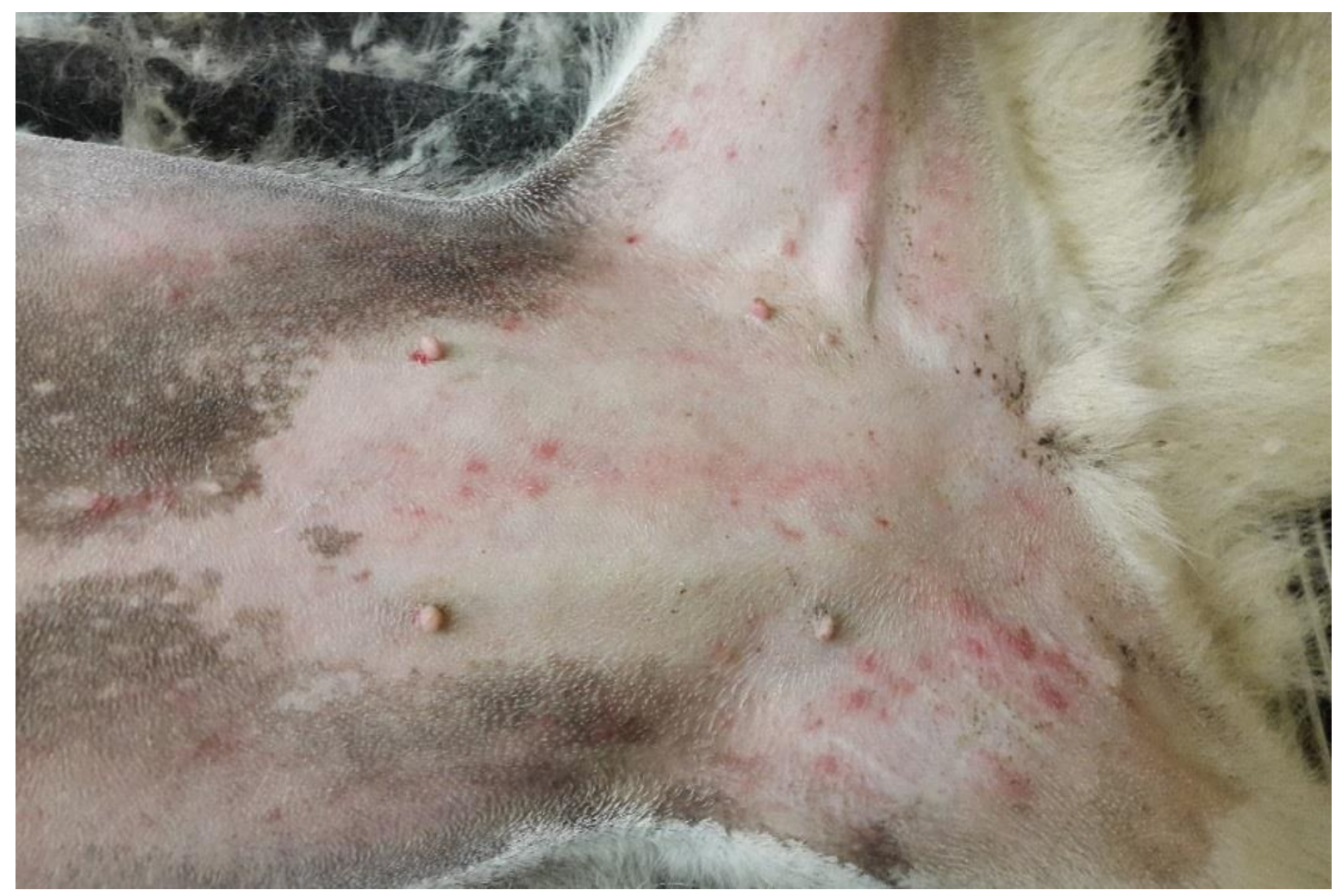

Figure 22A Case no. 80 showing an erythematous papular rash.

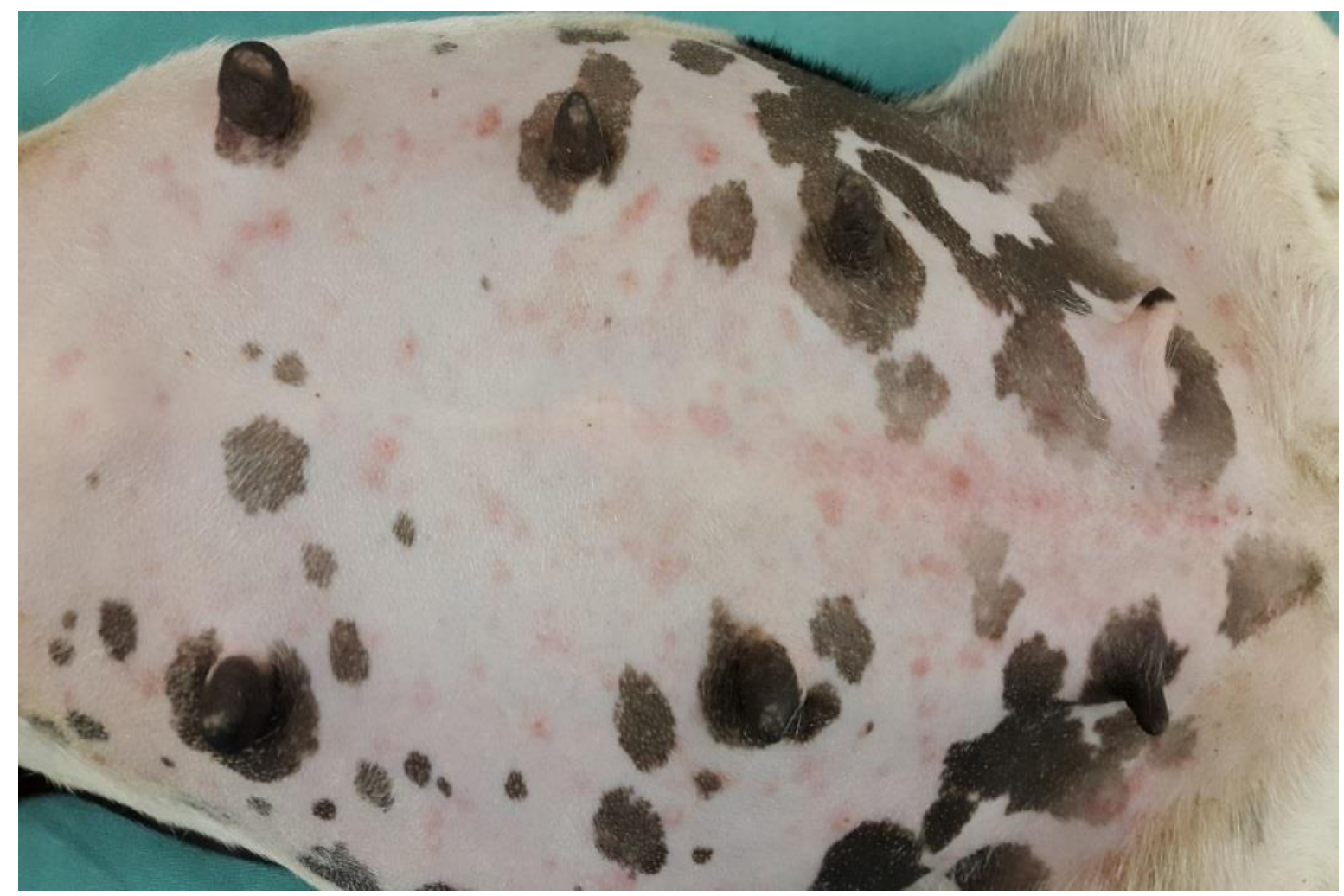

Figure 22B Case no. 107 showing an erythematous papular rash. 


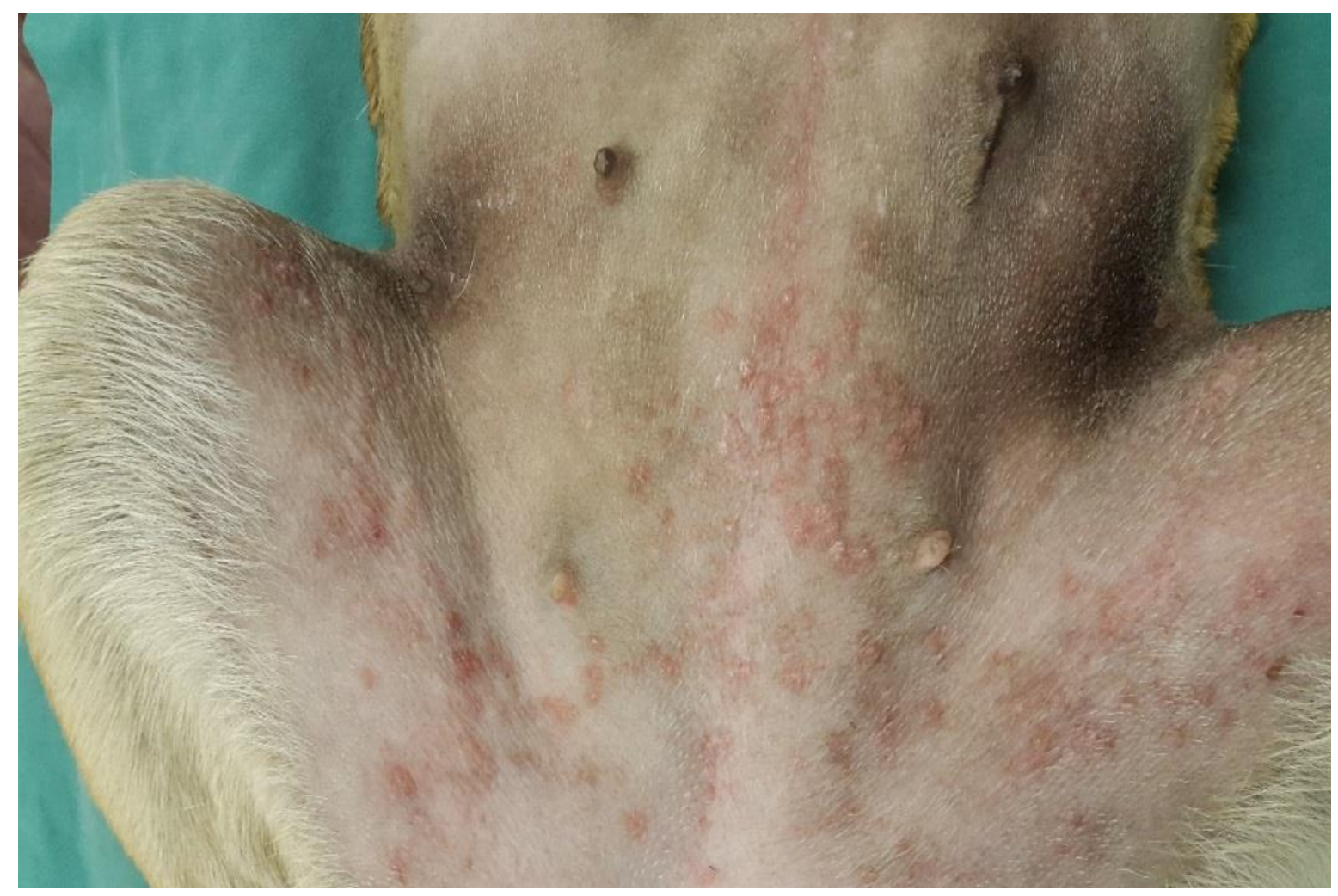

Figure 22C Case no. 127 showing an erythematous papular rash.

There was also no significant difference in the distribution of post-operative infections across the antiseptics $(P=.161)$.

\section{Post operative infections}

Six out of 117 (5\%) developed post-operative wound infections of which three dogs fell into the $\mathrm{CG}+\mathrm{A}$ group and three dogs in the F10 group. Four out of the six dogs showed signs of mild superficial skin infection at the time of suture removal. One dog returned to the hospital after 5 days with a purulent discharge. This patient was treated orally with amoxicillin/clavulanic acid at $20 \mathrm{mg} / \mathrm{kg}$ twice daily and the infection had cleared by the time of suture removal. One dog had a purulent discharge at the cranial aspect of the wound which was treated with a topical antibacterial ointment and recovered uneventfully.

There was no correlation between post-operative wound infections and CFU's at the end of surgery $(P=.774)$ nor post-operative wound infections and surgery time $\left(P=.802 ; r^{2}=.002\right)$. There was also no significant correlation between surgery time and post-operative CFU counts at the end of surgery $\left(P=.280 ; r^{2}=.010\right)$. 


\section{Pathogenic bacteria}

The prevalence of dogs that had positive cultures for pathogenic bacteria at the four sampling times are reported in Table 8 and Figure 23 and include Staphylococcus pseudintermedius, Staphylococcus aureus, Corynebacterium spp., Enterococcus spp. and the Gram negative bacteria. ${ }^{1}$

Table 8 Prevalence of all dogs with positive cultures for pathogenic bacteria at the four sampling times

\section{Sampling time \\ Number of dogs with pathogenic bacterial growth}

\begin{tabular}{ll}
\hline Sample $1(n=117)$ & $64(54 \%)$ \\
Sample $2(n=117)$ & $12(10 \%)$ \\
Sample 3 $(n=117)$ & $26(22 \%)$ \\
Sample $4(n=116)$ & $31(27 \%)$
\end{tabular}

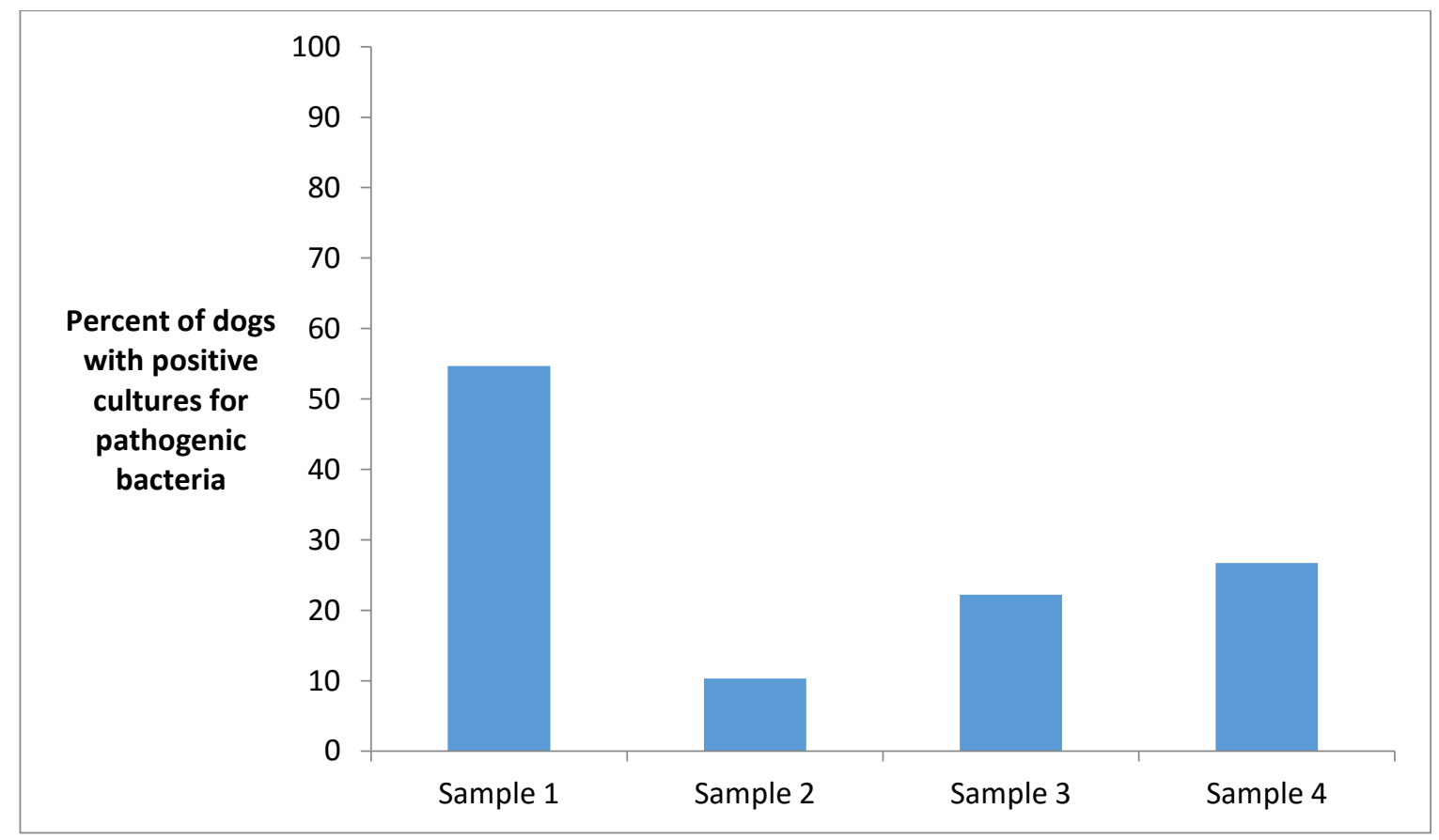

Figure 23 Prevalence of all dogs with positive cultures for pathogenic bacteria at the four sampling times. 
The total CFU counts of the pathogenic bacteria for each antiseptic group at the four sampling times are illustrated below (Figure 24).

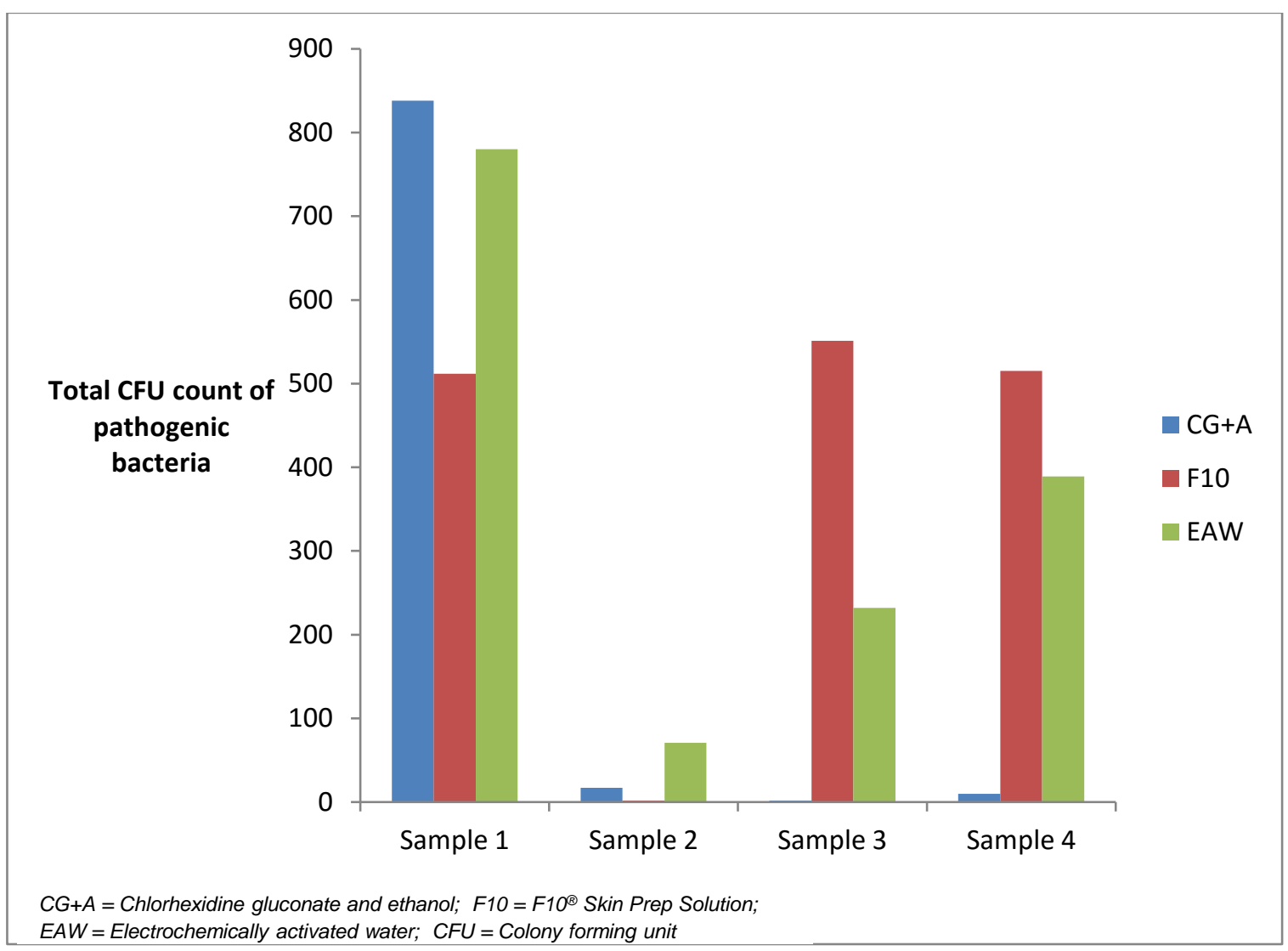

Figure 24 Total CFU count of the pathogenic bacteria for each antiseptic at the sampling times.

The initial non-parametric analysis revealed similar results as to the full data set. However, when comparing the three antiseptics pair-wise, there were significantly fewer CFU's at the second and fourth sampling times in the $\mathrm{CG}+\mathrm{A}(P=.004 ; P=.001)$ and $\mathrm{F} 10(P=.003 ; P=.032)$ groups when compared to EAW. There were no significant differences in CFU's between $\mathrm{CG}+\mathrm{A}$ and $\mathrm{F} 10(P=.971 ; P=.055)$ at these times. At the third sampling time however, there were significantly fewer CFU's for $\mathrm{CG}_{+} \mathrm{A}$ when compared to $\mathrm{F} 10(P=.022)$ and EAW $(P=.001)$. There were also no significant differences between F10 and EAW $(P=.126)$ at this time.

Similarly, there was no significant difference in the level of contamination between the antiseptics at the first sampling time $(P=.477)$. However, there was a lower level of contamination for $\mathrm{CG}+\mathrm{A}$, and $\mathrm{F} 10$ compared to $\mathrm{EAW}$ at the second and fourth sampling times $(P=.002 ; P=.001)$. There was a lower level of contamination for the $\mathrm{C} G+\mathrm{A}$ compared to $\mathrm{F} 10$ and EAW at the third sampling time ( $P=.007)$ (Table 9 and Figures 25-28). 
Table 9 Distribution of the level of pathogenic bacterial contamination of samples for the three antiseptics.

\begin{tabular}{|c|c|c|c|c|c|}
\hline Time & $\begin{array}{l}\text { CFU } \\
\text { counts }\end{array}$ & $\begin{array}{l}C G+A \\
(n=39)\end{array}$ & $\begin{array}{l}\text { F10 Solution } \\
(n=39)\end{array}$ & $\begin{array}{l}\text { EAW } \\
(n=38)\end{array}$ & Fisher's exact test \\
\hline \multirow[t]{3}{*}{ Sample 1} & 0 & $17(44 \%)$ & $22(56 \%)$ & $13(34 \%)$ & $P=.251$ \\
\hline & $1-12$ & $12(31 \%)$ & $11(28 \%)$ & $18(47 \%)$ & \\
\hline & $>12$ & $10(26 \%)$ & $6(15 \%)$ & $7(18 \%)$ & \\
\hline \multirow[t]{3}{*}{ Sample 2} & 0 & $38(97 \%)$ & $38(97 \%)$ & $28(74 \%)$ & $P=.001$ \\
\hline & $1-12$ & $0(0 \%)$ & $1(3 \%)$ & $8(21 \%)$ & \\
\hline & $>13$ & $1(3 \%)$ & $0(0 \%)$ & $2(5 \%)$ & \\
\hline \multirow[t]{3}{*}{ Sample 3} & 0 & 37 (95\%) & $30(77 \%)$ & $23(61 \%)$ & $P=.003$ \\
\hline & $1-12$ & $2(5 \%)$ & $6(15 \%)$ & $12(32 \%)$ & \\
\hline & $>12$ & $0(0 \%)$ & $3(8 \%)$ & $3(8 \%)$ & \\
\hline \multirow[t]{3}{*}{ Sample 4} & 0 & 36 (92\%) & $29(76 \%)$ & $19(50 \%)$ & $P=.001$ \\
\hline & $1-12$ & $3(8 \%)$ & $7(18 \%)$ & $14(38 \%)$ & \\
\hline & $>12$ & $0(0 \%)$ & $2(5 \%)$ & $5(13 \%)$ & \\
\hline
\end{tabular}

$E A W=$ Electrochemically activated water $P=P$ value 


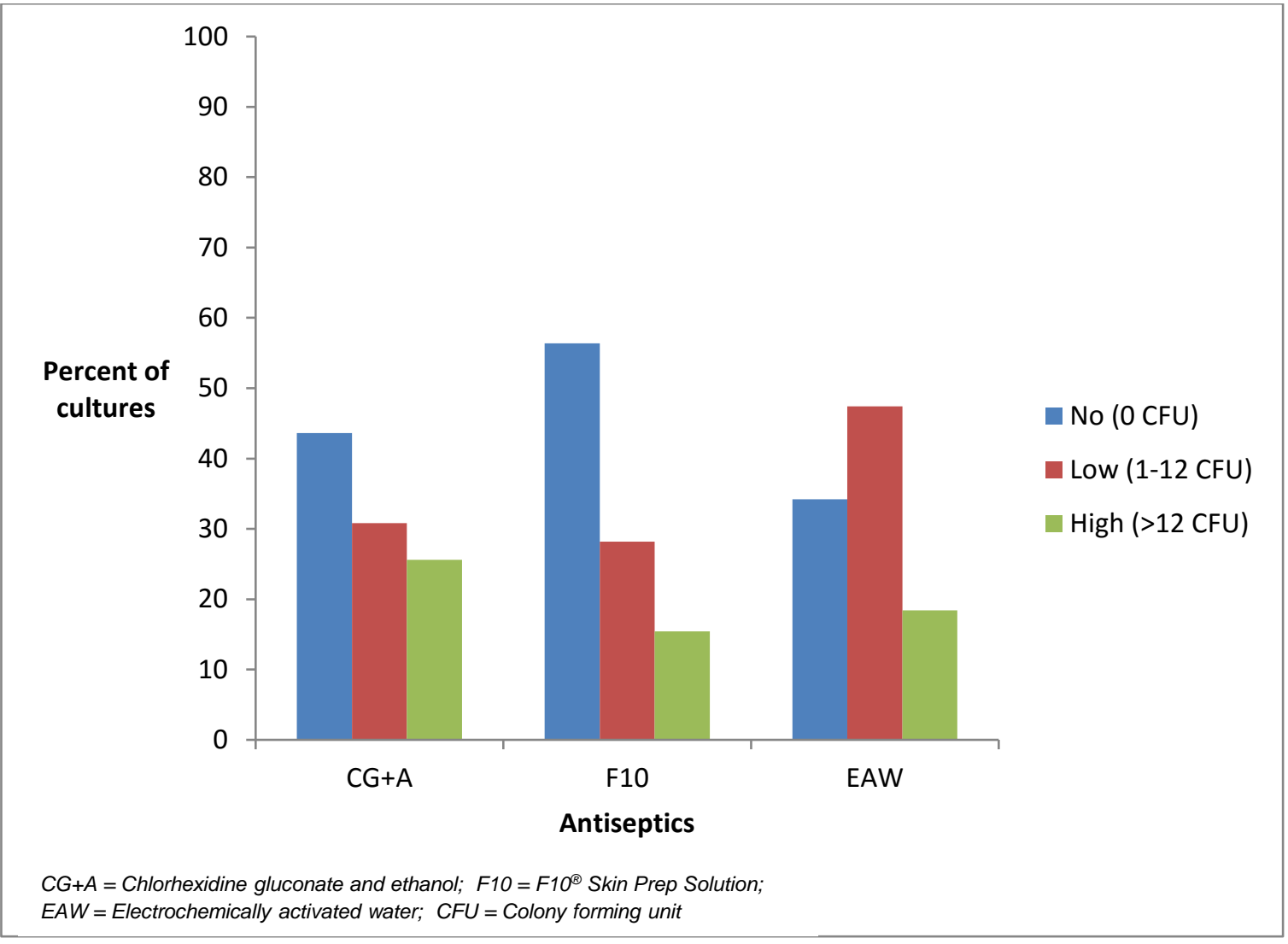

Figure 25 Level of pathogenic bacterial contamination at the first sampling time.

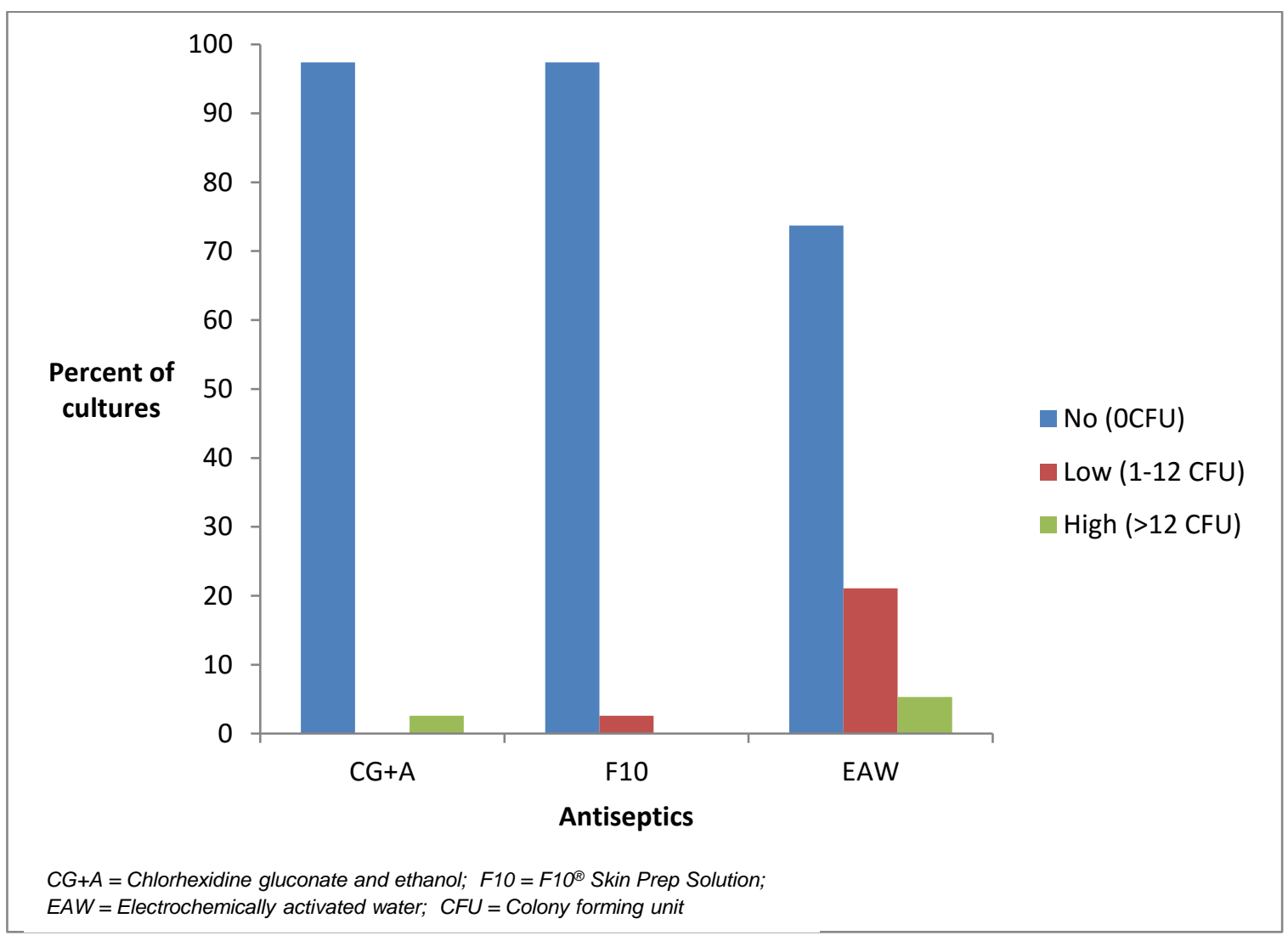

Figure 26 Level of pathogenic bacterial contamination at the second sampling time. 


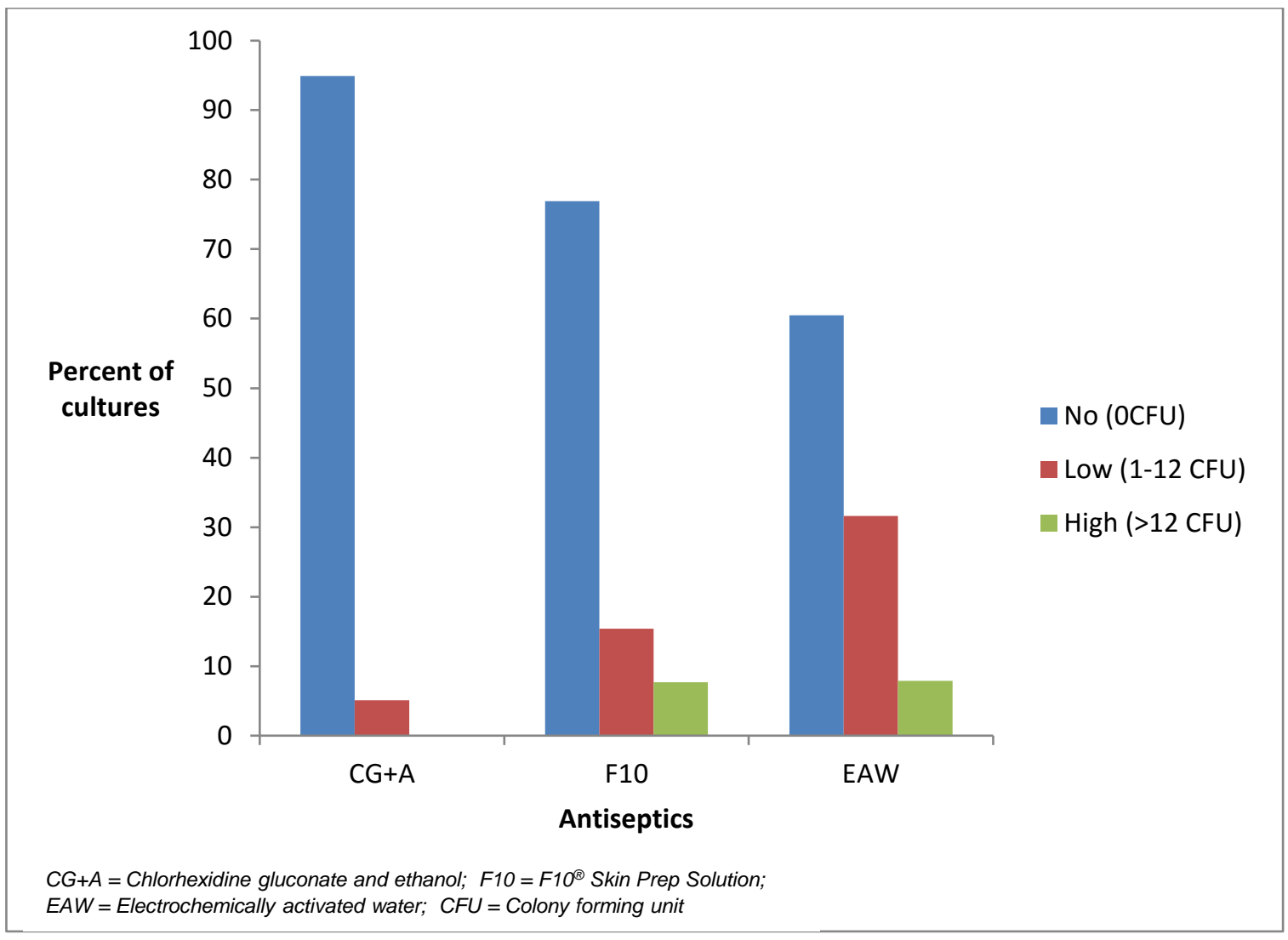

Figure 27 Level of pathogenic bacterial contamination at the third sampling time.

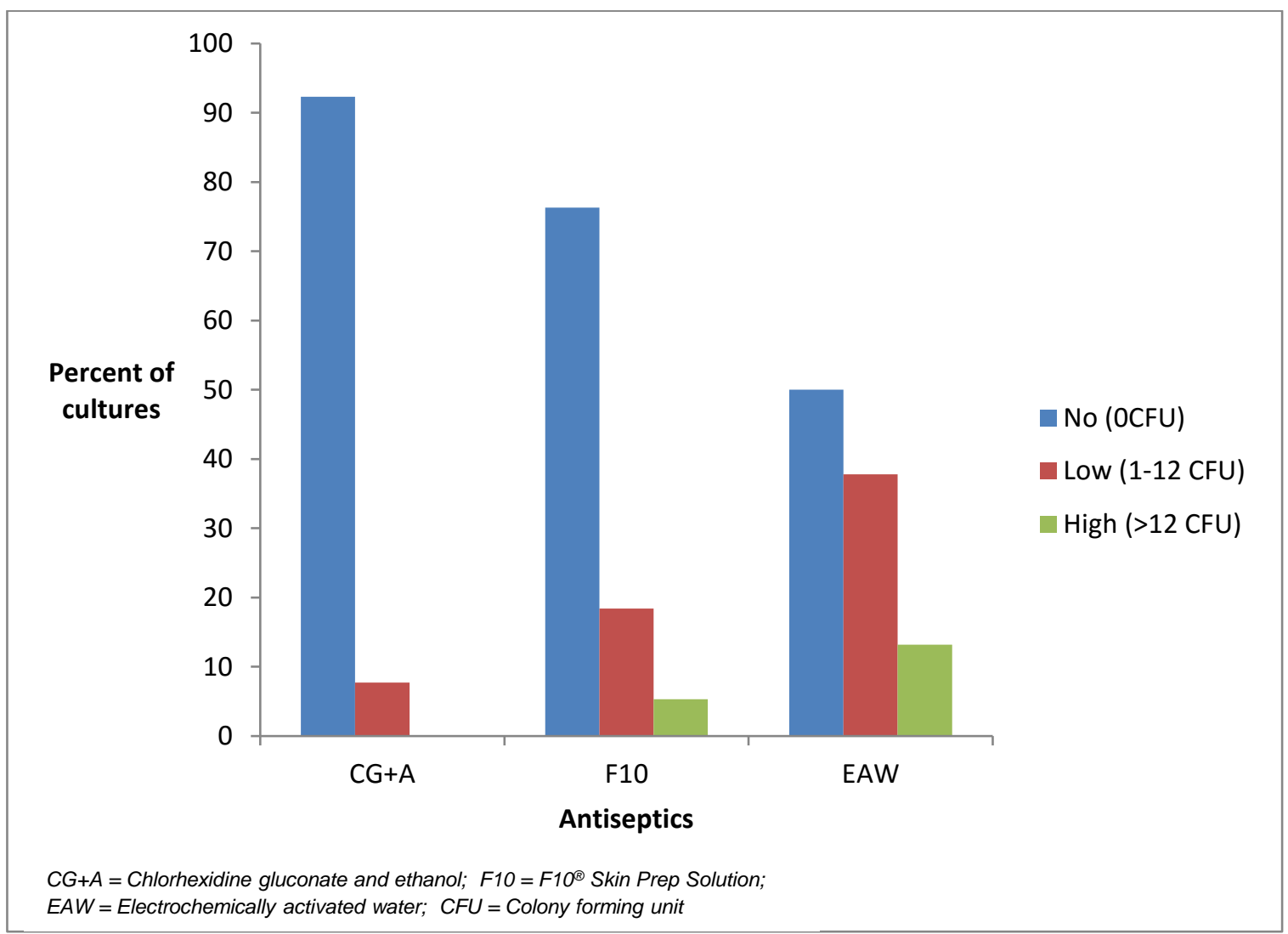

Figure 28 Level of pathogenic bacterial contamination at the fourth sampling time. 
Relative to chlorhexidine and alcohol, EAW had a 13 fold increased risk for bacterial contamination $(P=.003)$ while F10 showed no increased risk for bacterial contamination $(P=1)$ at the second sampling time for a clean or contaminated outcome. Similar results were obtained at the fourth sampling time where EAW had a 12 fold increased risk for bacterial contamination $(P=.001)$. Although the relative risk for bacterial growth of $\mathrm{F} 10$ was calculated at 4 times that of $C G+A$ at this sampling time, this was not found to be statistically significant $(P=.055)$. At the third sampling time, relative to $C G+A$, EAW had a 12 fold increased risk for bacterial contamination $(P=.001)$ while F10 showed a 6 fold increased risk. $(P=.24)$ (Table 10).

Table 10 Odds ratio for clean or contaminated outcome of the pathogenic bacteria of each antiseptic, with chlorhexidine and alcohol as the reference

\begin{tabular}{llccc}
\hline Time & Antiseptic & Odds ratio & $\begin{array}{c}\text { 95\% Confidence } \\
\text { interval }\end{array}$ & P-value \\
\hline Sample 1 & CG+A & 1 & $(0.2 ; 1.4)$ & $P=.261$ \\
& F10 & 0.6 & $(0.6 ; 3.8)$ & $P=.402$ \\
Sample 2 & EAW & 1.49 & & \\
& F10 & 1 & $(0.1 ; 16.9)$ & $P=1.000$ \\
Sample 3 & EAW & 1 & $(1.4 ; 130.2)$ & $P=.003$ \\
& CG+A & 13.6 & & $P=.024$ \\
& F10 & 1 & $(1.0 ; 29.6)$ & $P=.001$ \\
Sample 4* & EAW & 5.55 & $(2.1 ; 68)$ & \\
& CG+A & 12.1 & & $P=.055$ \\
& F10 & 1 & $(0.9 ; 15.7)$ & \\
& EAW & 3.7 & $(2.6 ; 55.1)$ & $P=.001$
\end{tabular}

${ }^{*}$ Odds ratio adjusted for surgery time

$C G+A=$ Chlorhexidine gluconate and ethanol; $F 10=F 10^{\circledR}$ Skin Prep Solution; EAW = Electrochemically activated water

Similar to the analysis of the full data set, there were also no statistical differences in the distributions of skin reactions $(P=.329 ; P=.329 ; P=.118)$ or post-operative infections $(P=.239)$ across the antiseptics. 


\section{DISCUSSION}

Our study showed that significant differences exist between the efficacy of three skin antiseptics in dogs at different stages of a clean surgical procedure. Furthermore, these differences in efficacy were shown to change slightly for different cohorts of bacteria. Careful attention was paid to some of the technical aspects of performing a comparative antiseptic study. Various preconceived principles regarding the risk factors associated with wound contamination and post-operative infections in our study varied from traditional views.

Our surgical skin preparation technique was similar to that of the comparative antiseptic study performed by Lambrechts and others (2004) whereby the initial wash was performed using a neutral detergent solution without specific antimicrobial properties. ${ }^{16}$ The goal behind this was to separate the mechanical effect of skin preparation on reducing bacterial levels from the specific antibacterial effects of the antiseptic solution itself. No prewash sample was taken in our study because of the strong possibility of bacterial overgrowth rendering accurate CFU counting impossible. ${ }^{16}$ This study differs from other antiseptic studies whereby a two hour, intra-operative skin sample was taken from the surgical field of a standardized surgical procedure. The addition of this sample provides valuable information regarding bacterial counts at a fixed time period as opposed to post-operative samples for which the time periods differ significantly. Although this allowed for an increased risk for a break in surgical asepsis which could have influenced the end of surgery CFU counts, specific care was taken not to contaminate the surgical field. These samples were always taken by the same person wearing sterile gloves, scrubs and masks. Only the inner surface of the RODAC plate was pressed against the skin, and if there was any doubt regarding a break in asepsis the dog would be excluded from the study. No cases were however excluded for this reason.

A student ovariohysterectomy model was regarded as an appropriate and relevant procedure to assess the efficacy of the antiseptics. The technical skill of a surgeon is regarded as a critical factor in the maintenance of a healthy local wound environment and has an immense impact on the ability of bacteria to multiply. ${ }^{80}$ By closely observing Halsted's principals of atraumatic, aseptic surgery, bacterial tissue contamination is minimized. ${ }^{19}$ Adherence to Halsted's surgical principles and surgical asepsis are regarded as being poor in the inexperienced surgeon ${ }^{16}$. In our study, final year students performed the surgery, and it can therefore be assumed that bacterial contamination would be higher than when the operation was performed by an experienced surgeon. ${ }^{80}$ 
Similarly, total surgical time for student ovariohysterectomies are longer than when this operation is performed by an experienced veterinarian. ${ }^{81}$ The median total surgical time of 146 minutes however, compared favourably with other studies. ${ }^{16,82-84}$ Surgery time is regarded as one of the most significant operative factors that affect wound infection rates. ${ }^{2,83,84}$ The duration of the operation is directly related to the number of bacteria that gain access to the wound ${ }^{85}$ and also involves more extensive tissue handling that has a negative effect on the local immune resistance of the surgical site. ${ }^{17,86-89}$ For every hour of surgical time the risk of surgical site infection is approximately doubled. ${ }^{17,88,89}$ The increased surgical time by the inexperienced surgeons used in this model should therefore challenge any residual action of the antiseptics and increase the risk of post-operative wound infection. Our study also eliminated the variation of surgical procedures described in similar trials where orthopaedic and neurological procedures were included..$^{18,40}$

An antiseptic contact time of three minutes was used in our study, which was similar to other clinical antiseptic studies. $6,16,18,40$ Increased contact times of chlorhexidine have been shown to decrease the initial bacterial counts. ${ }^{35}$ A recent study by Stinner and others described the time-dependant effects of a chlorhexidine-only surgical preparation. ${ }^{38}$ This study recommended using $4 \%$ chlorhexidine for surgical site preparation and allowing a minimum of two minutes of contact time prior to making the skin incision. ${ }^{38}$ Another author suggested that the contact time for some chlorhexidine and alcohol preparations (2\% chlorhexidine and $70 \%$ isopropyl alcohol) could be as little as 30 seconds. $^{7}$ No clinical studies on contact times are available for F10 or EAW.

The directions of use as detailed on the $\mathrm{F} 10^{\circledR}$ Skin Prep Solution product label were not followed in our research project. The specified directions include an initial wash with $\mathrm{F} 10^{\circledR}$ Antiseptic Liquid Soap followed by three application of $\mathrm{F} 10^{\circledR}$ Skin Prep Solution. Our protocol however, was established to compare all antiseptics on an even platform with the view of assessing CFU counts after a single application of each product.

A contact time of three minutes was regarded as appropriate for our study as well as being a good reflection of the clinical setting. It has been reported that the recommended contact times during the preparation of dogs for surgery are not always followed due to time constraints typically experienced in practice. ${ }^{27}$ Our study, however, differs from most of the other antiseptic trials in that only one antiseptic preparation procedure was performed. ${ }^{16,18,37,40,90}$ The uniform post antiseptic reduction in CFU's of all the products to a median of zero proved that one application of antiseptic only, significantly dropped CFU counts. 
In practice, the skin of a patient is typically scrubbed according to one of a vast array of protocols recommended in human and veterinary literature. ${ }^{5}$ These protocols most commonly include an antiseptic based scrub, of which most contain a surgical detergent with antibacterial properties ${ }^{16}$, alternated with alcohol as the initial preparation in the induction area, and then followed by a sterile scrub procedure in the operating room. ${ }^{5,91}$ By eliminating the antimicrobial agent in the initial wash, we were completely reliant on the mechanical effect of reducing bacterial counts and subsequently, a single application of antiseptic in the operating room. It can therefore be assumed that the initial bacterial load in our research setting would be higher than in a typical clinical setting and that the efficacy of the antiseptic would be tested appropriately. Our results also indicate that a single application of a pre-operative antiseptic solution may be consistent in achieving sufficiently low levels of bacteria and is a topic for future research.

Similar to other studies, the median colony forming units and the level of contamination both followed the expected trajectory with an obvious initial drop in CFU's and bacterial isolates after the application of the antiseptic at the second sampling time. This was followed by a gradual increase in the total CFU counts and number of dogs with positive isolates at the subsequent sampling times. ${ }^{6,16,18,37,40}$ A classification system used to quantify the level of bacterial contamination in our study, was adapted from a recent article by Andrade and others where a survey of intra-operative bacterial contamination in dogs undergoing orthopaedic surgery was performed. ${ }^{92}$ Differing classification systems have been used for comparative antiseptic studies in the past with one author suggesting that the cut off between low and high CFU counts is merely an arbitrary number. ${ }^{37}$

Two of the desirable characteristics of an ideal skin antiseptic are rapid killing capabilities and a persistent or residual lethal effect against bacteria. ${ }^{16}$ These characteristics are measured by recording the bacterial count reductions at set periods in time which may range from seconds to days. The combination of chlorhexidine and alcohol was more effective than F10 and EAW at maintaining zero CFU's or low levels of contamination at the second, third and fourth sampling times. The risk for bacterial contamination was between three and ten fold higher for F10 and EAW, depending on the sampling time compared to $C G+A$. This could be attributed to superior immediate and residual bactericidal properties of chlorhexidine and alcohol and its efficacy in the presence of organic material. ${ }^{36}$ Alcohol, at the correct concentrations, has long been known for its rapid bactericidal effect with short contact times ${ }^{20}$ and the residual effect of chlorhexidine has been well described. ${ }^{31}$ F10 contains alcohol (ethanol) but only at a $20 \%$ concentration. 
This concentration may be inferior at reducing immediate bacterial levels when compared to the $70 \%$ ethanol used in the $C G+A$ preparation as indicated by the significantly higher number of negative cultures at the second sampling time for this antiseptic. Issues such as spectrum of activity, concentration levels, time of action and formulations have been routinely debated in the literature and the use of alcohol has varied widely. ${ }^{44}$ Larson reported that alcohols, when used in appropriate concentrations of between 60 and $90 \%$ provide the most rapid and greatest reduction in microbial counts on the skin. ${ }^{93}$ More research as to the ideal concentration of alcohol in an antiseptic is required.

The high degree of bacterial contamination at samples three and four of the EAW group of antiseptics may be attributed to the fact that contact with organic material, such as blood, has been shown to negatively influence its antimicrobial activity and this questions its use as a surgical antiseptic.

Conversely, high bacterial contamination at the same sampling times of the F10 antiseptic group may be attributed to poor residual activity of the active ingredients of this formulation. QAC are also proven to be inactivated by organic material and soap residues and are generally not regarded as reliable surgical antiseptics. ${ }^{20,94}$ The value that the QAC add to this formulation may be a topic of further research. The residual effect of PHMB has also not been proven in a clinical setting. Fjeld, in a review article of PHMB, suggested that better designed, larger-scale clinical studies of efficacy and safety are needed in order to give recommendations on the use of PHMB on skin, wounds and mucosa. ${ }^{56}$

The bacteria that were cultured during this study are consistent with those cultured from normal skin ${ }^{95}$ and similar to those found in other skin preparation studies. ${ }^{16,18,40}$ Bacteria cultured from healthy skin are called normal inhabitants and are classified as resident or transient depending on their ability to multiply in that environment. ${ }^{95}$ The most prevalent bacteria isolated during our study were Bacillus spp. which are considered to be transient on the skin surface. ${ }^{16}$ Transient organisms are often cultured from the skin but are of no clinical significance unless they become involved in a pathological process as secondary invaders. ${ }^{95}$ Other transient bacteria that were cultured in low numbers in our study included Corynebacterium spp., Pseudomonas spp. and E. coli. These microbes do not multiply on the normal skin of most healthy animals. ${ }^{95}$ 
Staphylococcus pseudintermedius is regarded as the most common Staphylococcus sp. isolated from canines. ${ }^{96}$ This was also reflected in our findings with Staphylococcus pseudintermedius being one of the most prevalent bacteria cultured second to Bacillus spp. Staphylococcus pseudintermedius is a commensal of the mucous membranes and skin of dogs and is considered to be one of the most common bacterial pathogens treated by veterinarians. ${ }^{96,97}$ Studies have reported bacterial colonization rates of $31-68 \%$ on the skin of healthy dogs. ${ }^{1}$ Only a small percentage of dogs develop a clinical infection which typically requires some form of underlying cause such as skin trauma. ${ }^{1}$ Staphylococcus pseudintermedius invades tissues opportunistically and is responsible for a wide range of infectious diseases in dogs such as pyoderma, wound and surgical site infection, septic arthritis, osteomyelitis, liver abcessation, peritonitis urinary tract infections, endocarditis and ocular infections. ${ }^{1,22,23,96}$ Methicillin-resistant Staphylococcus pseudintermedius (MRSP) has emerged worldwide since 2000 and spread in each successive year. ${ }^{1,96,98-100}$ It is considered a serious emerging problem in the veterinary field and one that requires urgent action to control its spread. ${ }^{100}$ Post-operative MRSP infections of the stifle following cranial cruciate ligament surgery (tibial plateau levelling osteotomy) appear to be reported with increased frequency ${ }^{1,22}$ and infection rates in other surgical procedures can be expected to be similar. MRSP can be found in or on clinically healthy dogs and cats ${ }^{1}$ and the reported prevalence of colonization range from $1.5-17 \%$ in dogs $s^{1,101,102}$ One out of 117 dogs $(0.9 \%)$ in our study had a positive culture for MRSP which was lower than published data prevalence, however our report refers to prevalence on surgically prepared skin.

MRSP is an opportunistic pathogen for which colonization does not necessarily lead to disease. It had not been determined whether colonization is an actual risk factor for subsequent development of infection but it is reasonable to assume that colonization poses some degree of risk to an animal. ${ }^{1}$ The specific case in our study that was identified as MRSP had a relatively high initial CFU count (18 CFU's) at the first sampling time, zero CFU at the second sampling time and a low CFU count at the last sampling time (9 CFU's). The dog was not seen for a follow up visit at the hospital but telephonic interview with the owners confirmed an uneventful post-operative recovery without any evidence of infection.

Coagulase negative staphylococci are common commensals of the dog's skin and are often isolated as contaminants but can however, cause disease. ${ }^{1}$ These were the third most common bacteria isolated in our study. Micrococcus spp. were the next most prevalent bacteria isolated and are also considered normal residents on the surface of dog skin ${ }^{95}$ 
They were followed by Corynebacterium spp. as the fifth most prevalent bacteria cultured, which are also transient bacteria on the skin of the dog and are not considered to be clinically significant. ${ }^{95}$ Lastly, the individual Gram negative bacterial species were grouped together and counted as a single entity to form the next most prevalent group. Gram negative bacteria are commonly isolated from normal skin epithelium but many can be pathogenic in dogs and cats and may cause opportunistic infections in immunocompromised animals. ${ }^{95,103}$

The potent cleaning forces of dilution, washing, drying and the desquamation of surface cells are thought to prevent many micro-organisms from colonizing the skin. ${ }^{95}$ Our study confirmed this postulate since no bacterial overgrowth was evident in our post wash samples.

Contact dermatitis can be a significant side effect with the use of some skin antiseptics. ${ }^{18}$ We used similar criteria to those described in other studies to assess skin reactions. ${ }^{16,37}$ Just over a third of the dogs in our study developed cutaneous skin reactions following the initial wash with the neutral detergent. Contact dermatitis has been correlated with a rise in post-surgical wound infections in humans ${ }^{104}$ and similar findings have been suggested in the veterinary literature. ${ }^{18}$ One explanation is that surface bacteria multiply more rapidly on irritated, damaged or diseased skin. ${ }^{105,106}$ Prolonged or repeated washing leads to damage and increased permeability of the stratum corneum which functions as a barrier to toxic agents and bacteria. ${ }^{45}$ Scrubbing causes small excoriations and increases the risk of bacterial colonization of the skin by pathogenic species. ${ }^{107}$ These findings have lead to a distinct trend in surgical hand asepsis amongst veterinary surgeons to move away from the traditional surgical scrub technique to an alcoholic based rub. ${ }^{25,108}$ Verwighen reports that there is increasing evidence that alcoholic rub solutions may be more effective than traditional medicated soaps, and are associated with better tolerance and compliance with surgical hygiene protocols. ${ }^{25,45}$

Another theory is that the seepage of serum from the damaged skin surface inactivates the residual effect of an antiseptic and leads to higher CFU counts. ${ }^{109}$ This would however only be the case in severely diseased skin such as the one that was excluded from our trial. Another unique problem associated with skin irritation is that the pruritis is thought to draw the patient's attention to the surgical site and result in licking and scratching of the wound, thereby increasing the risk of post-operative infections. ${ }^{37,40}$ 
Most of the similar studies had an antiseptic included in the initial presurgical wash. . $^{6,40}$ Our study is the only one to have reported skin reactions after the initial wash with a neutral detergent, and may thereby emphasize the role that washing alone or chemical detergents play in the development of skin reactions. Our study also had a higher prevalence of skin reactions (35\%) when compared to other similar studies ${ }^{6,16,18,40,90}$ This may be attributed to overzealous washing by inexperienced final year students performing the scrub. Because no dogs showed any significant differences in the grading of the cutaneous reactions between the wash and the application of the antiseptic, and the insignificant distribution of the skin reactions across the antiseptics, it is the author's opinion that the skin reactions were caused by the mechanical wash and not the application of the antiseptics. Similar to the findings reported by Osuna in the first part of their experimental trial, there was no correlation between skin reactions and high CFU counts in our study. ${ }^{37}$

The ultimate goal of pre-operative skin preparation and asepsis is the prevention of postoperative wound infection. ${ }^{18}$ A surgical site infection is defined as an infection that occurs anywhere in the operative field within 30 days after surgical intervention. ${ }^{5,19}$ Five percent of dogs in our trial developed post-operative wound infections. This infection rate is comparable to those reported in the veterinary literature, which range from $3.6-5.8 \%$ for patients undergoing clean surgical procedures. ${ }^{2,16,18,19,82,110}$ However, the current literature does not distinguish between the contribution of aseptic technique and post-operative factors towards wound infection. The criteria used to evaluate wound infection in this trial were similar to those of other skin preparation studies and included those dogs that had signs of inflammation. ${ }^{16,18}$ Surgical site infections are most commonly caused by microorganisms introduced into the surgical wound at the time of the operation. ${ }^{5}$ Most of these organisms come from the patient's endogenous flora, but occasionally the pathogenic organism may arise from an exogenous source such as the operation room, surgical equipment or implants, gloves or drugs administered during the operation. ${ }^{111}$ A number of factors such as the degree of bacterial contamination, the virulence of the microbe, duration of surgery, local wound environment and host defence mechanisms have been identified as risk factors for surgical site infections. ${ }^{5,19}$

It is known that all surgical wounds become contaminated by bacteria, even when a strict aseptic operative technique is maintained. ${ }^{92}$ The type of surgical procedure also shows a strong correlation to the degree of bacterial contamination. A risk factor for the development of post-operative infection is determined by classifying operations based on the degree of operative contamination. Numerous studies have reported that the risk for post-operative 
infection is significantly and consistently higher in contaminated and dirty wounds when compared to clean and clean-contaminated wounds. ${ }^{5,19,80,112}$

Infection rate comparisons in clean wounds and clean contaminated wounds are however less conclusive. ${ }^{80,112}$ The student ovariohysterectomies in our trial were classified as clean procedures according to the wound classification system as described by the National Research Council, Division of Medical services ${ }^{5}$ and no peri-operative antibiotics were administered. Therefore antibiosis could not have influenced our intra or post-operative CFU counts or infection rates. Counterintuitively, there was no correlation between the degree of bacterial contamination at the last sampling time and the dogs that developed post-operative infections. Various antiseptic studies have shown differing degrees of microbe reduction but very few have documented any correlation with infection rates. ${ }^{7,112,113}$ Lambrechts and Osuna could also not find any association between post-operative infections and CFU counts in their studies ${ }^{16,40}$ No dogs developed post-operative infections in the Lambrechts study, but these were not recorded in the Osuna study. Stubbs also reported that no dogs with unusually high CFU counts developed wound infections. ${ }^{18}$

The duration of the surgical procedure had no significant effect on the post-operative CFU counts on the skin. Similar findings were reported in the clinical antiseptic trials by Osuna and Lambrechts and appear to contradict some of the older literature where the duration of surgery is reported to directly affect the number of bacteria that gain access to the surgical site. $^{85,114}$ It is however important to realize that these previous studies were performed in very different clinical settings with different outcomes and on wounds with varying degrees of contamination and can therefore not be directly compared. The results of the past and present studies prove that the development of post-operative wound infection is a multifactorial condition that can't be pinpointed to a single incident, factor or micro-organism.

The degree of microbial reduction that is needed after the application of an antiseptic has been debated. $5,115,116$ The presence of bacteria in a surgical wound has however been quoted as the most important factor in the development of post-operative wound infections ${ }^{80}$ and the goal of aseptic skin preparation is to reduce the level of wound contamination to a degree that the patient's defences can control. ${ }^{19}$

A number of recent publications have questioned the methods for testing the efficacy of chlorhexidine gluconate. ${ }^{25,117}$ More specifically, the focus has shifted on whether or not appropriate neutralization agents in the culture media were used in the trials and whether this may have resulted in false positive efficacy assessment of the antiseptic. ${ }^{118,119}$ Authors 
involved in the current debate state that without effective neutralization, certain active ingredients of the antiseptics may continue to reduce the number of surviving bacteria after sampling and may lead to an overestimation of the efficacy of the antiseptic in question. ${ }^{25,117}$ It is however also essential that the neutralizer should not affect the test organisms that are to be cultured. ${ }^{120}$ Kampf has subsequently described protocols to validate neutralization agents and quotes two international test methods (EN 13727 and ASTM 1054-02). ${ }^{119}$

Various compounds are used as neutralizers in different combinations of which polysorbate 80 , saponin, histidine, sodium thiosulphate ether sulphate and lecithin are examples. ${ }^{117,119}$ The neutralizers that were used in our study were lecithin and polysorbate 80 . Lecithin has been proven to neutralize quaternary ammonium compounds, and polysorbate 80 has been shown to neutralize substituted phenolic disinfectants. ${ }^{121}$ Difficulties in neutralizing chlorhexidine gluconate have been documented. ${ }^{118}$ Limited literature is available on the combination of lecithin and polysorbate 80 as the only neutralizing agents, or on the specific concentrations required to as neutralize chlorhexidine, PHMB or EAW. Kampf however, conducted a comparative study in 2005 between two ethanol based hand rubs, of which one contained a chlorhexidine and ethanol solution, where lecithin and polysorbate were the neutralization agents. ${ }^{118}$ Another study assessing the pitfalls of efficacy testing of antiseptics used lecithin polysorbate 80 and histidine as the neutralization agents in the tryptic soy agar and broth. These products were quoted as being valid, effective and nontoxic neutralizing agents following evaluation according to the "standard test methods for evaluation of inactivators of antimicrobial agents". ${ }^{119}$ Kampf has also critically reviewed various antiseptic hand hygiene studies where chlorhexidine gluconate was used and came to the conclusion that, due to the lack of neutralization, these studies were flawed. ${ }^{118,119}$ It is however also important to realize that in these reviews the author is specifically referring to suspension broths and not RODAC plates. ${ }^{118,119}$ The principle of suspension tests is to expose specific test organisms to the antiseptic for a specific exposure time and to measure the mean $\log ^{10}$ reduction that can be achieved within the exposure time. Exact guidelines for the validation of neutralizers used in RODAC plates as in our study, comparing the efficacy of specific antiseptics, are not available and may be an important topic for further research, especially in skin antiseptic comparisons. It may also become essential to develop one neutralizer system that can be used on all the antiseptics in question. Until that point in time, the neutralizers that were used in our study appear to be justifiable and comparable to those used in other antiseptic studies.

Pathogenic bacteria are defined as bacteria which are capable of causing disease. ${ }^{1}$ The pathogenic bacteria that were cultured in this trial included Staphylococcus 
pseudintermedius, Staphylococcus aureus, Corynebacterium spp., Enterococcus spp. and the Gram negative bacteria. ${ }^{1}$ Similar to other antiseptic studies Staphylococcus pseudintermedius was the most prevalent pathogen cultured. ${ }^{16,18.40}$

The concept of repeating the data analysis on the pathogenic bacteria only, is unique to our study and was performed to add to the clinical significance of the relevant antiseptics. However, it is commonly accepted that all facultative bacteria in high enough numbers can cause wound infection.

Similar to the analysis of the full data set, $C G+A$ was superior at maintaining low or zero levels of CFU's when compared to F10 and EAW for pathogens. F10 ${ }^{\circledR}$ Skin Prep Solution however, showed slightly improved results when only the pathogens were analysed. Colony forming unit counts and the level of bacterial contamination were significantly lower for $C G+A$ and $F 10$ when compared to $E A W$ at the second and fourth sampling times. The third sampling time however, revealed significantly lower CFU counts and levels of contamination for $\mathrm{CG}+\mathrm{A}$ when compared to $\mathrm{F} 10$ and $\mathrm{EAW}$.

Electrochemically activated water performed worse in the pathogenic data set than the full data at the second sampling site, with the relative risk for bacterial contamination going up from a 7 to a 13 fold increase. At the same sampling time however, F10 showed an improvement with a 10 fold increased risk for bacterial contamination going down to zero risk. The third sampling time showed a fairly similar relative risk for F10 when comparing the two data sets. Electrochemically activated water again performed worse with a 3 fold relative risk for bacterial contamination going up to a 12 fold increased relative risk for the pathogenic bacteria. The fourth sampling times were fairly similar for F10 but EAW again performed poorly with the relative risk for bacterial contamination increasing from 4 to 12 . These findings therefore confirm that one may expect to see differences in the efficacy of antiseptics when a certain cohort of bacteria are analysed and this may influence the clinical choice of which antiseptic to use.

The combination of chlorhexidine and alcohol was therefore superior in reducing CFU counts and the level of contamination at all sampling times for all isolates and also at the third sampling times for pathogenic bacteria. 


\section{LIMITATIONS}

A limiting factor for the use of EAW is its loss of antimicrobial efficacy over time due to chlorine loss and a decrease in the ORP. Unless a fresh solution of EAW can be supplied and quality control checked it is not possible to keep this variable constant. A decrease in the FAC and the ORP was noted in our trial. These factors may have influenced the colony forming unit counts depending on whether a fresh or older solution was used at the time of sampling.

Skin reactions following the initial wash, after antiseptic application and at the end of surgery were performed by a single observer who was not blinded to the antiseptic that was used. Although similar criteria to other studies were used to assess this factor, the interpretation and grading of skin reactions remains subjective. More objective ways of accessing this parameter may be indicated in future studies.

A number of cases were lost to follow up with many clients returning to their regular vets for suture removal. We had to rely on less objective telephonic interviews with these owners to assess and record post-operative wound infections or wound complications. 


\section{CONCLUSION}

The combination of $2 \%$ chlorhexidine and $70 \%$ alcohol was a statistically significant more effective skin antiseptic at achieving a zero CFU count and low levels of contamination when compared to $\mathrm{F} 10^{\circledR}$ Skin Prep Solution and electrochemically activated water for surgical preparation in dogs undergoing ovariohysterectomy. 


\section{LIST OF REFERENCES}

1. Weese SJ. Staphylococcal Infections. In: Greene CE, ed. Infectious Diseases of the Dog and Cat. $4^{\text {th }}$ ed. St. Louis, MO: Elsevier Saunders; 2012:340-348.

2. Brown DC, Conzemius MG, Shofer F, et al. Epidemiologic evaluation of postoperative wound infections in dogs and cats. J Am Vet Med Assoc. 1997;210:1302-1306.

3. Eugster S, Schawalder P, Gaschen F, et al. A prospective study of postoperative surgical site infections in dogs and cats. Vet Surg. 2004;33:542-550.

4. Dunning D. Surgical wound infections and the use of antimicrobials. In: Slatter DH, ed. Textbook of Small Animal Surgery. $3^{\text {rd }}$ ed. Philadelphia, PA: Saunders; 2003:113-122.

5. Renberg WC. Preparation of the patient, operating team and operating room. In: Tobias KM, Johnston SA, eds. Veterinary Surgery Small Animal. St. Louis, MO: Elsevier Saunders; 2012:164-170.

6. Gibson KL, Donald AW, Hariharan $\mathrm{H}$, et al. Comparison of two pre-surgical skin preparation techniques. Can J Vet Res. 1997;61:154-156.

7. Bhavan KP, Warren DK. Surgical preparation solutions and preoperative skin disinfection. J Hand Surg Am. 2009;34:940-941.

8. Alexander JW, Fischer JE, Boyajian M, et al. The influence of hair-removal methods on wound infections. Arch Surg. 1983;118:347-352.

9. Shmon C. Assessment and preparation of the surgical patient and the operating team. In: Slatter DH, ed. Textbook of Small Animal Surgery. $3^{\text {rd }}$ ed. Philadelphia, PA: Saunders; 2003:162-178.

10. Ayliffe GA, Bridges K, Lilly HA, et al. Comparison of two methods for assessing the removal of total organisms and pathogens from the skin. $J$ Hyg (Lond). 1975;75:259274.

11. Ayliffe GA. Surgical scrub and skin disinfection. Infect Control. 1984;5:23-27.

12. Dineen P. An evaluation of the duration of the surgical scrub. Surg Gynecol Obstet. 1969;129:1181-1184.

13. Galle PC, Homesley HD, Rhyne AL. Reassessment of the surgical scrub. Surg Gynecol Obstet. 1978;147:215-218. 
14. Kundsin RB, Walter CW. The surgical scrub-practical consideration. Arch Surg. 1973;107:75-77.

15. O'Shaughnessy M, O'Malley VP, Corbett G, et al. Optimum duration of surgical scrubtime. Br J Surg. 1991;78:685-686.

16. Lambrechts NE, Hurter K, Picard JA, et al. A prospective comparison between stabilized glutaraldehyde and chlorhexidine gluconate for preoperative skin antisepsis in dogs. Vet Surg. 2004;33:636-643.

17. Brown DC. Wound infections and antimicrobial use. In: Tobias KM, Johnston SA, eds. Veterinary Surgery Small Animal. St. Louis, MO: Elsevier Saunders; 2012:135-145.

18. Stubbs WP, Bellah JR, Vermaas-Hekman D, et al. Chlorhexidine gluconate versus chloroxylenol for preoperative skin preparation in dogs. Vet Surg. 1996;25:487-494.

19. Cockshutt J. Principles of surgical asepsis. In: Slatter DH, ed. Textbook of Small Animal Surgery. $3^{\text {rd }}$ ed. Philadelphia, PA: Saunders; 2003:149-155.

20. Boothe HW. Antiseptics and disinfectants. Vet Clin North Am Small Anim Pract. 1998;28:233-248.

21. Lemarie RJ, Hosgood G. Antiseptics and disinfectants in small animal practice. Comp Cont Educ Pract Vet 1995;17:1339-1352.

22. Weese JS, Faires M, Brisson BA, et al. Infection with methicillin-resistant Staphylococcus pseudintermedius masquerading as cefoxitin susceptible in a dog. $J$ Am Vet Med Assoc. 2009;235:1064-1066.

23. van Duijkeren E, Catry B, Greko C, et al. Review on methicillin-resistant Staphylococcus pseudintermedius. J Antimicrob Chemother. 2011;66:2705-2714.

24. Cloete $T$, Thantsha $M$, Maluleke $M$, et al. The antimicrobial mechanism of electrochemically activated water against Pseudomonas aeruginosa and Escherichia coli as determined by SDS-PAGE analysis. J Appl Microbiol. 2009;107:379-384.

25. Verwilghen D, Kampf G, Doyle AJ. Antibacterial Efficacy of Several Surgical Hand Preparation Products Used by Veterinary Students. Vet Surg. 2016;45:1118-1119.

26. Block SS. Historical review. In: Block SS, ed. Disinfection, sterilization, and preservation. $5^{\text {th }}$ ed. Philadelphia, PA: Lippincott Williams \& Wilkins; 2001:3-19. 
27. Evans LK, Knowles TG, Werrett G, et al. The efficacy of chlorhexidine gluconate in canine skin preparation - practice survey and clinical trials. J Small Anim Pract. 2009;50:458-465.

28. Hibbard JS, Mulberry GK, Brady AR. A clinical study comparing the skin antisepsis and safety of ChloraPrep, $70 \%$ isopropyl alcohol, and $2 \%$ aqueous chlorhexidine. J Infus Nurs. 2002;25:244-249.

29. Hibbard JS. Analyses comparing the antimicrobial activity and safety of current antiseptic agents: a review. J Infus Nurs. 2005;28:194-207.

30. Denton GW. Chlorhexidine. In: Block SS, ed. Disinfection, sterilization and preservation. $4^{\text {th }}$ ed. Philadelphia, PA: Lea \& Febiger; 1991:274-289.

31. Lim KS, Kam PC. Chlorhexidine-pharmacology and clinical applications. Anaesth Intensive Care. 2008;36:502-512.

32. Davies GE, Francis J, Martin AR, et al. 1:6-Di-4'-chlorophenyldiguanidohexane (hibitane); laboratory investigation of a new antibacterial agent of high potency. $\mathrm{Br} J$ Pharmacol Chemother. 1954;9:192-196.

33. Shaker L, Russell A, Furr J. Aspects of the action of chlorhexidine on bacterial spores. Int J Pharm. 1986;34:51-56.

34. DeBaun B. Evaluation of the antimicrobial properties of an alcohol-free $2 \%$ chlorhexidine gluconate solution. AORN J. 2008;87:925-933.

35. Denton GW. Chlorhexidine. In: Block SS, ed. Disinfection, sterilization, and preservation. $5^{\text {th }}$ ed. Philadelphia, PA: Lippincott Williams \& Wilkins; 2001:321-336.

36. Sanchez IR, Nusbaum KE, Swaim SF, et al. Chlorhexidine diacetate and povidoneiodine cytotoxicity to canine embryonic fibroblasts and Staphylococcus aureus. Vet Surg. 1988;17:182-185.

37. Osuna DJ, DeYoung DJ, Walker RL. Comparison of three skin preparation techniques in the dog. Part 1: Experimental trial. Vet Surg. 1990;19:14-19.

38. Stinner DJ, Krueger CA, Masini BD, et al. Time-dependent effect of chlorhexidine surgical prep. J Hosp Infect. 2011;79:313-316.

39. Larson E. Guideline for use of topical antimicrobial agents. Am J Infect Control. 1988;16:253-266. 
40. Osuna DJ, DeYoung DJ, Walker RL. Comparison of Three Skin Preparation Techniques Part 2: Clinical Trial in 100 Dogs. Vet Surg. 1990;19:20-23.

41. Pereira LJ, Lee GM, Wade KJ. An evaluation of five protocols for surgical handwashing in relation to skin condition and microbial counts. J Hosp Infect. 1997;36:49-65.

42. Helgeland K, Heyden G, Rölla G. Effect of chlorhexidine on animal cells in vitro. Eur J Oral Sci. 1971;79:209-215.

43. Rosenberg A, Alatary SD, Peterson AF. Safety and efficacy of the antiseptic chlorhexidine gluconate. Surg Gynecol Obstet. 1976;143:789-792.

44. Ali Y, Dolan MJ, Fendler EJ, et al. Alcohols. In: Block SS, ed. Disinfection, sterilization, and preservation. $5^{\text {th }}$ ed. Philadelphia, PA: Lippincott Williams \& Wilkins; 2001:229253.

45. Verwilghen D, Grulke S, Kampf G. Presurgical hand antisepsis: concepts and current habits of veterinary surgeons. Vet Surg. 2011;40:515-521.

46. Amber E, Henderson R, Swaim S, et al. A comparison of antimicrobial efficacy and tissue reaction of four antiseptics on canine wounds. Vet Surg. 1983; 12: 63-68.

47. Rochat MC, Mann FA, Berg JN. Evaluation of a one-step surgical preparation technique in dogs. J Am Vet Med Assoc. 1993;203:392-395.

48. Romatowski J. Prevention and control of surgical wound infection. J Am Vet Med Assoc. 1989;194:107-114.

49. Gilbert P, Moore LE. Cationic antiseptics: diversity of action under a common epithet. $J$ Appl Microbiol. 2005;99:703-715.

50. Hubner NO, Kramer A. Review on the efficacy, safety and clinical applications of polihexanide, a modern wound antiseptic. Skin Pharmacol Physiol 2010;23:17-27.

51. Rosin M, Welk A, Bernhardt O, et al. Effect of a polyhexamethylene biguanide mouthrinse on bacterial counts and plaque. J Clin Periodontol. 2001;28:1121-1126.

52. Koburger T, Müller G, Eisenbeiss W, et al. Microbicidal activity of polihexanide. GMS Hyg Infect Control 2007;2:1-4.

53. Müller G, Kramer A. Biocompatibility index of antiseptic agents by parallel assessment of antimicrobial activity and cellular cytotoxicity. $J$ Antimicrob Chemother. 2008;61:1281-1287. 
54. Koburger T, Hübner NO, Braun M, et al. Standardized comparison of antiseptic efficacy of triclosan, PVP-iodine, octenidine dihydrochloride, polyhexanide and chlorhexidine digluconate. J Antimicrob Chemother. 2010;65:1712-1719.

55. Banovic F, Bozic F, Lemo N. In vitro comparison of the effectiveness of polihexanide and chlorhexidine against canine isolates of Staphylococcus pseudintermedius, Pseudomonas aeruginosa and Malassezia pachydermatis. Vet Dermatol. 2013;24:409-413.

56. Fjeld H, Lingaas E. Polyhexanide-safety and efficacy as an antiseptic. Tidsskr Nor Laegeforen. 2016;136:707-711.

57. Bakhir VM. Electrochemical activation: Theory and practice. Paper presented at: $1^{\text {st }}$ International Symposium on Electrochemical Activation; 1997; Moscow.

58. Leonav BI. Electrochemical activation of water and aqueous solutions: Past, present and future. Paper presented at: $1^{\text {st }}$ International Symposium on Electrochemical Activation; 1997; Moscow.

59. Marais JT, Brözel VS. Electro-chemically activated water in dental unit water lines. $\mathrm{Br}$ Dent J. 1999;187:154-158.

60. Annandale $\mathrm{CH}$, Schulman ML, Kirkpatrick RD. The use of electrochemically activated saline as a uterine instillation in pony mares. J S Afr Vet Assoc. 2008;79:36-38.

61. Al-Haq MI, Sugiyama J, Isobe S. Applications of electrolyzed water in agriculture \& food industries. Food Sci Technol Res. 2005;11:135-150.

62. Hricova D, Stephan R, Zweifel C. Electrolyzed water and its application in the food industry. J Food Prot. 2008;71:1934-1947.

63. Marais JT, Williams WP. Antimicrobial effectiveness of electro-chemically activated water as an endodontic irrigation solution. Int Endod J. 2001;34:237-243.

64. Deza MA, Araujo M, Garrido MJ. Inactivation of Escherichia coli, Listeria monocytogenes, Pseudomonas aeruginosa and Staphylococcus aureus on stainless steel and glass surfaces by neutral electrolysed water. Lett Appl Microbiol. 2005;40:341-346.

65. Park $\mathrm{H}$, Hung YC, Chung D. Effects of chlorine and $\mathrm{pH}$ on efficacy of electrolyzed water for inactivating Escherichia coli $\mathrm{O} 157: \mathrm{H} 7$ and Listeria monocytogenes. Int $J$ Food Microbiol. 2004;91:13-18. 
66. Koseki S, Yoshida K, Isobe S, et al. Decontamination of lettuce using acidic electrolyzed water. J Food Prot. 2001;64:652-658.

67. Sakarya S, Gunay N, Karakulak M, et al. Hypochlorous Acid: an ideal wound care agent with powerful microbicidal, antibiofilm, and wound healing potency. Wounds. 2014;26:342-350.

68. Liao L. The generation and inactivation mechanism of oxidation-reduction potential of electrolyzed oxidizing water. J Food Eng. 2007;78:1326-1332.

69. Len SV, Hung YC, Chung D, et al. Effects of storage conditions and pH on chlorine loss in electrolyzed oxidizing (EO) water. J Agric Food Chem. 2002;50:209-212.

70. Ayebah B, Hung YC, Frank JF. Enhancing the bactericidal effect of electrolyzed water on Listeria monocytogenes biofilms formed on stainless steel. $J$ Food Prot. 2005;68:1375-1380.

71. Fabrizio KA, Cutter CN. Stability of electrolyzed oxidizing water and its efficacy against cell suspensions of Salmonella typhimurium and Listeria monocytogenes. J Food Prot. 2003;66:1379-1384.

72. Park $\mathrm{H}$, Hung $\mathrm{Y}$, Kim C. Effectiveness of electrolyzed water as a sanitizer for treating different surfaces. J Food Prot. 2002;65:1276-1280.

73. Horiba N, Hiratsuka K, Onoe T, et al. Bactericidal effect of electrolyzed neutral water on bacteria isolated from infected root canals. Oral Surg Oral Med Oral Pathol Oral Radiol Endod. 1999;87:83-87.

74. Wang L, Bassiri M, Najafi R, et al. Hypochlorous acid as a potential wound care agent: part I. Stabilized hypochlorous acid: a component of the inorganic armamentarium of innate immunity. J Burns Wounds 2007;6:65-79.

75. Gottardi W. lodine and lodine Compounds. In: Block SS, ed. Disinfection, sterilization, and preservation. $5^{\text {th }}$ ed. Philadelphia, PA: Lippincott Williams \& Wilkins; 2001:159183.

76. Weber DJ, Rutala WA. Use of metals as microbicides in preventing infection in healthcare. In: Block SS, ed. Disinfection, sterilization, and preservation. $5^{\text {th }}$ ed. Philadelphia, PA: Lippincott Williams \& Wilkins; 2001:415-430.

77. O'Toole MT. Mosby's medical dictionary. $9^{\text {th }}$ ed. St. Louis, MO: Elsevier Mosby;2013:2426. 
78. Rossmoore HW. Nitrogen compounds. In: Block SS, ed. Disinfection, sterilization, and preservation. $5^{\text {th }}$ ed. Philadelphia: Lippincott Williams \& Wilkins; 2001:383-413.

79. Lubbe AM, Henton MM. Sterilisation of surgical instruments with formaldehyde gas. Vet Rec. 1997;140:450-453.

80. Smeak D, Olmstead M. Infections in clean wounds: the roles of the surgeon, environment, and host. Comp Cont Educ Pract. 1984;7:629-634.

81. Walsh DA, Osburn BI, Schumacher RL. Defining the attributes expected of graduating veterinary medical students, part 2: External evaluation and outcomes assessment. $J$ Vet Med Educ. 2002;29:36-42.

82. Kennedy KC, Tamburello KR, Hardie RJ. Peri-operative morbidity associated with ovariohysterectomy performed as part of a third-year veterinary surgical-training program. J Vet Med Educ. 2011;38:408-413.

83. Johnson JA, Murtaugh RJ. Preventing and treating nosocomial infection. Part II. Wound, blood, and gastrointestinal infections. Comp Cont Educ Pract. 1997;19:693-703.

84. Sawyer RG, Pruett TL. Wound infections. Surg Clin North Am. 1994;74:519-536.

85. Cruse PJ, Foord R. The epidemiology of wound infection: a 10-year prospective study of 62,939 wounds. Surg Clin North Am. 1980;60:27-40.

86. Al-Niaimi A, Safdar N. Supplemental perioperative oxygen for reducing surgical site infection: a meta-analysis. J Eval Clin Pract. 2009;15:360-365.

87. Brand J, Kirchner H, Poppe C, et al. The effects of general anesthesia on human peripheral immune cell distribution and cytokine production. Clin Immunol Immunopathol. 1997;83:190-194.

88. Eugster S, Schawalder P, Gaschen F, et al. A prospective study of postoperative surgical site infections in dogs and cats. Vet Surg. 2004;33:542-550.

89. Nicholson M, Beal M, Shofer F, et al. Epidemiologic evaluation of postoperative wound infection in clean-contaminated wounds: a retrospective study of 239 dogs and cats. Vet Surg.2002;31: 577-581.

90. Wilson D, Hartmann F, Carter V, et al. Comparison of three preoperative skin preparation techniques in ponies. Equine Vet Edu. 2011;23:462-465. 
91. Guzel A, Ozekinci T, Ozkan U, et al. Evaluation of the skin flora after chlorhexidine and povidone-iodine preparation in neurosurgical practice. Surg Neurol. 2009 ;71:207-210.

92. Andrade N, Schmiedt CW, Cornell K, et al. Survey of intraoperative bacterial contamination in dogs undergoing elective orthopedic surgery. Vet Surg. 2016;45:214222.

93. Larson EL. APIC guidelines for handwashing and hand antisepsis in health care settings. Am J Infect Control. 1995;23:251-269.

94. Terleckyj B, Elsinger EC, Axler DA. Antiseptics and disinfectants: Current issues. J Am Podiatr Med Assoc. 1995;85:439-445.

95. Campbell KL, Griffin CE, Miller WH. Bacterial skin diseases. In: Campbell KL, Griffin CE, Miller WH, eds. Muller and Kirk's Small Animal Dermatology. $7^{\text {th }}$ ed. St. Louis, MO: Elsevier Mosby; 2013:184-222.

96. Sykes JE. Staphylococcus Infections. In: Sykes J, ed. Canine and Feline Infectious Diseases. St. Louis, MO: Elsevier Saunders; 2014:347-354.

97. Markey BK, Leonard FC, Archambault M, Cullinane A, et al. Staphylococcus species. In: Markey BK, ed. Clinical Veterinary Microbiology. $2^{\text {nd }}$ ed. Edinburgh, UK: Elsevier Mosby; 2013:105-121.

98. Meucci V, Vanni M, Guardabassi L, et al. Evaluation of methicillin resistance in Staphylococcus intermedius isolated from dogs. Vet Res Commun. 2010;34:79-82.

99. Perreten V, Kadlec K, Schwarz S, et al. Clonal spread of methicillin-resistant Staphylococcus pseudintermedius in Europe and North America: an international multicentre study. J Antimicrob Chemother. 2010;65:1145-1154.

100. Gronlund-Andersson U, Finn M, Kadlec K, et al. Methicillin-resistant Staphylococcus pseudintermedius: An emerging companion animal health problem. Paper presented at: $2^{\text {nd }}$ ASM-ESCMID Conference on Methicillin-resistant Staphylococci in Animals; 2001; Washington.

101. Epstein CR, Yam WC, Peiris JS, et al. Methicillin-resistant commensal staphylococci in healthy dogs as a potential zoonotic reservoir for community-acquired antibiotic resistance. Infect Genet and Evol. 2009;9:283-285. 
102. Griffeth GC, Morris DO, Abraham JL, et al. Screening for skin carriage of methicillinresistant coagulase-positive staphylococci and Staphylococcus schleiferi in dogs with healthy and inflamed skin. Vet Dermatol. 2008;19:142-149.

103. Koenig A. Staphylococcal infections. In: Greene CE, ed. Infectious Diseases of the Dog and Cat. $4^{\text {th }}$ ed. St. Louis, MO: Elsevier Saunders; 2012:349-359.

104. Rodeheaver G, Bellamy W, Kody M, et al. Bactericidal activity and toxicity of iodinecontaining solutions in wounds. Arch Surg. 1982;117:181-186.

105. Seropian R, Reynolds BM. Wound infections after preoperative depilatory versus razor preparation. Am J Surg. 1971;121:251-254.

106. Ihrke PJ, Schwartzman RM, McGinley K, et al. Microbiology of normal and seborrheic canine skin. Am J Vet Res. 1978;39:1487-1489.

107. Larson EL, Hughes CAN, Pyrek JD, et al. Changes in bacterial flora associated with skin damage on hands of health care personnel. Am J Infect Control. 1998;26:513-521.

108. Verwilghen DR, Mainil J, Mastrocicco E, et al. Surgical hand antisepsis in veterinary practice: evaluation of soap scrubs and alcohol based rub techniques. Vet $\mathrm{J}$. 2011;190:372-377.

109. Connell JF, Rousselot LM. Povidone-iodine: extensive surgical evaluation of a new antiseptic agent. Am J Surg. 1964;108:849-855.

110. Vasseur PB, Levy J, Dowd E, et al. Surgical wound infection rates in dogs and cats data from a teaching hospital. Vet Surg. 1988;17:60-64.

111. Kirby JP, Mazuski JE. Prevention of surgical site infection. Surg Clin North Am. 2009;89:365-389.

112. Lee JT. Contemporary wound infection surveillance issues. New Horiz. 1998;6:20-29.

113. Smylie HG, Logie JR, Smith G. From Phisohex to Hibiscrub. Br Med L. 1973;4:586589.

114. Ireifej S, Marino DJ, Loughin CA, et al. Risk factors and clinical relevance of positive intraoperative bacterial cultures in dogs with total hip replacement. Vet Surg. 2012;41:63-68.

115. Ayliffe G. The effect of antibacterial agents on the flora of the skin. $J$ Hosp Infect. 1980;1:111-124. 
116. Price PB. The bacteriology of normal skin; a new quantitative test applied to a study of the bacterial flora and the disinfectant action of mechanical cleansing. $J$ Infect Dis. $1938 ; 301-318$

117. Reichel M, Heisig P, Kampf G. Pitfalls in efficacy testing-how important is the validation of neutralization of chlorhexidine digluconate? Ann Clin Microbiol Antimicrob. 2008;7:20-25.

118. Kampf G, Shaffer M, Hunte C. Insufficient neutralization in testing a chlorhexidinecontaining ethanol-based hand rub can result in a false positive efficacy assessment. BMC Infect Dis. 2005;5:48-55.

119. Kampf G. What is left to justify the use of chlorhexidine in hand hygiene? J Hosp Infect. 2008;70:27-34.

120. Sheikh W. Development and validation of a neutralizer system for in vitro evaluation of some antiseptics. Antimicrob Agents Chemother. 1981;19:429-434.

121. Zimbro MJ, Power DA, Miller SM, et al. In: Manual of Microbiological Culture Medium. $2^{\text {nd }}$ ed. Sparks, MD: Becton, Dickson and Company; 2009:571-573. 


\subsection{ANNEXURE A: Animal ethics committee approval form}

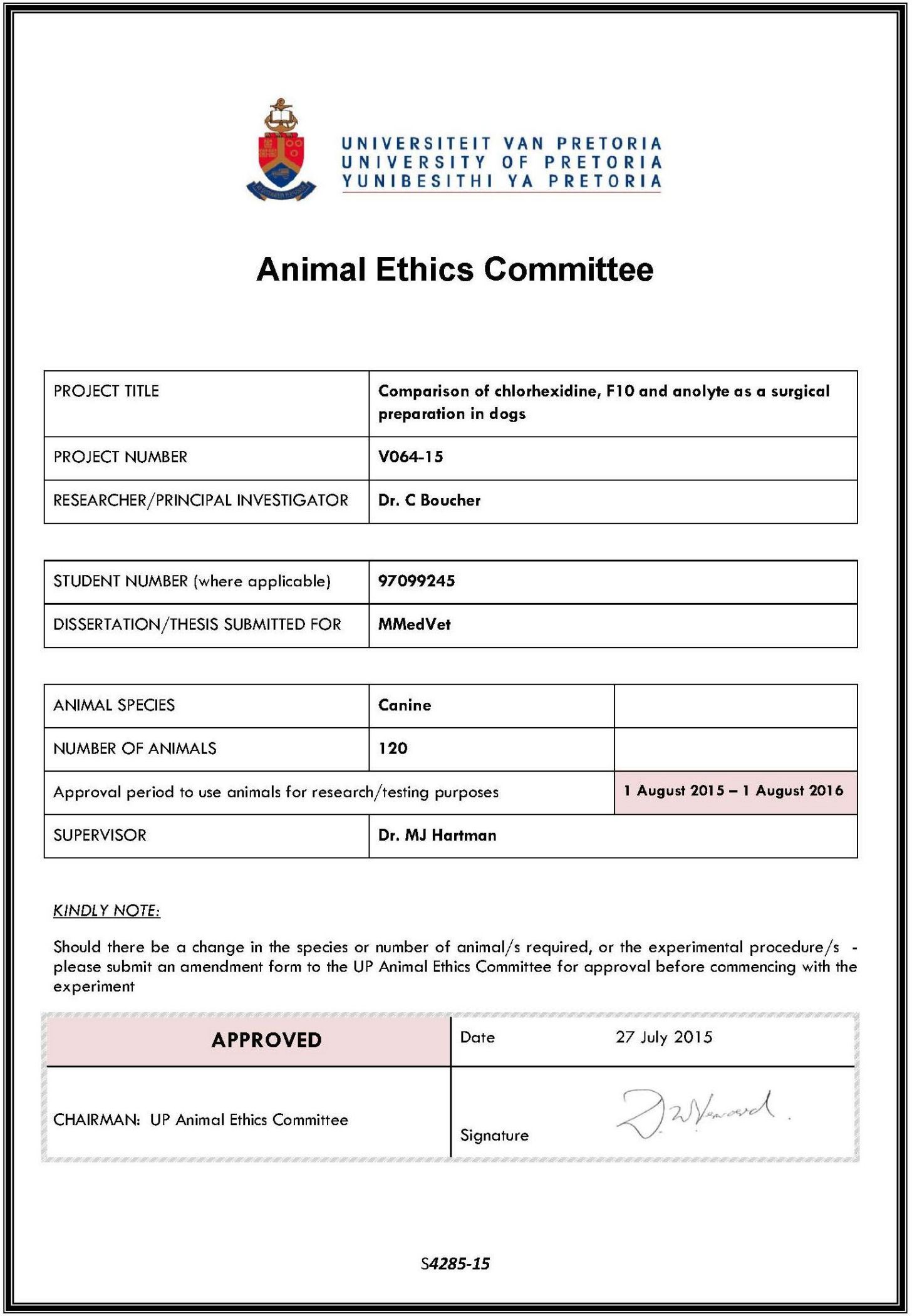


9.2 ANNEXURE B: Data collection sheet

\begin{tabular}{|c|c|}
\hline Study No: & \\
\hline UVIS Patient ID: & \\
\hline UVIS Client ID: & \\
\hline Date: & \\
\hline Weight: & \\
\hline Age: & \\
\hline Breed: & \\
\hline Anaesthetic protocol: & \\
\hline Student spay & $1^{\text {st }} \quad 2^{\text {nd }} \quad 3^{\text {rd }}$ \\
\hline Clipper injuries: & YES $\quad$ NO \\
\hline Antiseptic solution: & $\begin{array}{lll}1 & 2 & 3\end{array}$ \\
\hline Time when wash started: & \\
\hline Time when wash completed: & \\
\hline $1^{\text {st }}$ swab ID: & \\
\hline Time of $1^{\text {st }}$ swab: & \\
\hline $2^{\text {nd }}$ swab ID: & \\
\hline Time of $2^{\text {nd }}$ swab: & \\
\hline
\end{tabular}




\begin{tabular}{|l|l|}
\hline Skin reaction post antisepsis: & YES NO \\
\hline Surgery starting time: & \\
\hline $3^{\text {rd }}$ swab ID: & \\
\hline Time of $3^{\text {rd }}$ swab: & \\
\hline Surgery completion time: & \\
\hline $4^{\text {th }}$ swab ID: & \\
\hline Time of $4^{\text {th }}$ swab: & YES \\
\hline Skin reaction post sx: & NO \\
\hline Skin reaction 24 hours: & YES \\
\hline Comments: & \\
\hline
\end{tabular}

Dr C Boucher. Small Animal Surgery. Room 4-49. Tel: 012-5298135 
9.3 ANNEXURE C: RODAC plate label

\begin{tabular}{|c|c|c|c|}
\hline \multicolumn{4}{|l|}{ Study No: } \\
\hline \multicolumn{4}{|l|}{ UVIS Patient ID: } \\
\hline \multicolumn{4}{|l|}{ UVIS Client ID: } \\
\hline \multicolumn{4}{|l|}{ Date: } \\
\hline Antiseptic solution & 1 & 2 & 3 \\
\hline RODAC plate ID & & & \\
\hline
\end{tabular}

Dr C Boucher. Small Animal Surgery. Room 4-49. Tel: 012-5298135 


\subsection{ANNEXURE D: Informed consent forms}

I hereby grant permission for the above animal to be admitted to the OVAH for the investigation/treatment

of OVARIOHYSTERECTOMY and accept/consent to the following:

1. Where deemed necessary and appropriate by the veterinarian:

a. Performance of various procedures and tests, including surgical intervention

b. Administration of sedative, local and general anaesthetic agents

c. Administration of drugs or medications including those approved for use in humans or another species.

2. That I will not remove my animal from its stable or cage in OVAH until a duly authorized person from OVAH has given permission.

3. Storage of my animal's medical records, including photographic images, and the usage thereof for training purposes and/or publication.

4. Use of my animal for supervised student training purposes.

5. Use of diagnostic samples for training and/or in research projects.

6. A post mortem examination in the event of the death of my animal (due to elective euthanasia, or as a result of a terminal disease) both for student training purposes, as well as to aid in the diagnosis and treatment of a similar condition in other animals.

7. That euthanasia may, after verbal permission from me, be performed for either humane reasons, or in compliance with State Veterinary regulations.

8. That personal property is left with my animal entirely at my own risk.

9. Diagnostic testing of my apparently healthy animal, and/or appropriate treatment of my clinically affected animal as part of the management of a contagious disease within the OVAH.

10. That all drugs, procedures, tests and surgical interventions carry risk and that the success of any medical or surgical treatment cannot be guaranteed.

11. That my animal can form part of a research project whereby three modern surgical preparations will be compared to each other.

Furthermore, I agree to the estimated costs of treatment for the above animal, and understand that:

1. This is a provisional estimate only, and that actual treatment may exceed this estimate.

2. My consent to additional costs shall be obtained, if at all practically possible, prior to them being incurred.

3. This estimate does not take into account any potential complication or cost thereof.

4. This estimate does not cover follow-up and/or future visits or long-term chronic medication.

5. Full payment is required upon collection of the animal from the OVAH.

Should the animal become deceased while hospitalized in the OVAH, full payment will be required upon notification thereof.

Provisional estimate between $\mathrm{R}$.

and $\mathrm{R}$ (including VAT)

Owner/Agent (names and surname)

Owner/Agent signature. Date.

Daytime contact number. Cell number

Clinician signature. 


\subsection{ANNEXURE E: Budget/Resources}

EXPENSES:

\begin{tabular}{|c|c|}
\hline ITEM & COST \\
\hline Overheads (telephone, internet, photocopies) & R3000 \\
\hline RODAC plates $(500 \times$ R180) & R90 000 \\
\hline Laboratory report fees $(120 \times \mathrm{R} 25)$ & R3000 \\
\hline F10 (40 x R37.50) & R1500 \\
\hline Chlorhexidine (40 x R40) & R1600 \\
\hline Anolyte (40 x R36) & R1440 \\
\hline Sterile water (240 x R13.85) & R3324 \\
\hline Alcohol ethoxylate $(120 \times \mathrm{R} 35)$ & R4200 \\
\hline Latex gloves $(240 \times \mathrm{R} 0.80)$ & R 192 \\
\hline Oster clipper blade \#40 (2 x R768) & R 1536 \\
\hline Gauze swabs (1200 x R0.34) & $\mathrm{R} 408$ \\
\hline Face masks (240 x R2) & $\mathrm{R} 480$ \\
\hline Theatre overshoes $(480 \times \mathrm{R} 1)$ & $\mathrm{R} 480$ \\
\hline Surgeons caps $(120 \times \mathrm{R} 2)$ & R240 \\
\hline
\end{tabular}

\section{Total R111 400}

\section{INCOME:}

\begin{tabular}{|l|l|}
\hline SOURCE & AMOUNT \\
\hline CACS Research Fund & R40 000 \\
\hline South African Veterinary Foundation & R30 000 \\
\hline Prof. Kirberger Research Fund & R22 000 \\
\hline Prof. Hartman Research Fund & R20 000 \\
\hline
\end{tabular}

Total R112000 


\subsection{ANNEXURE F: Copyright certificate}

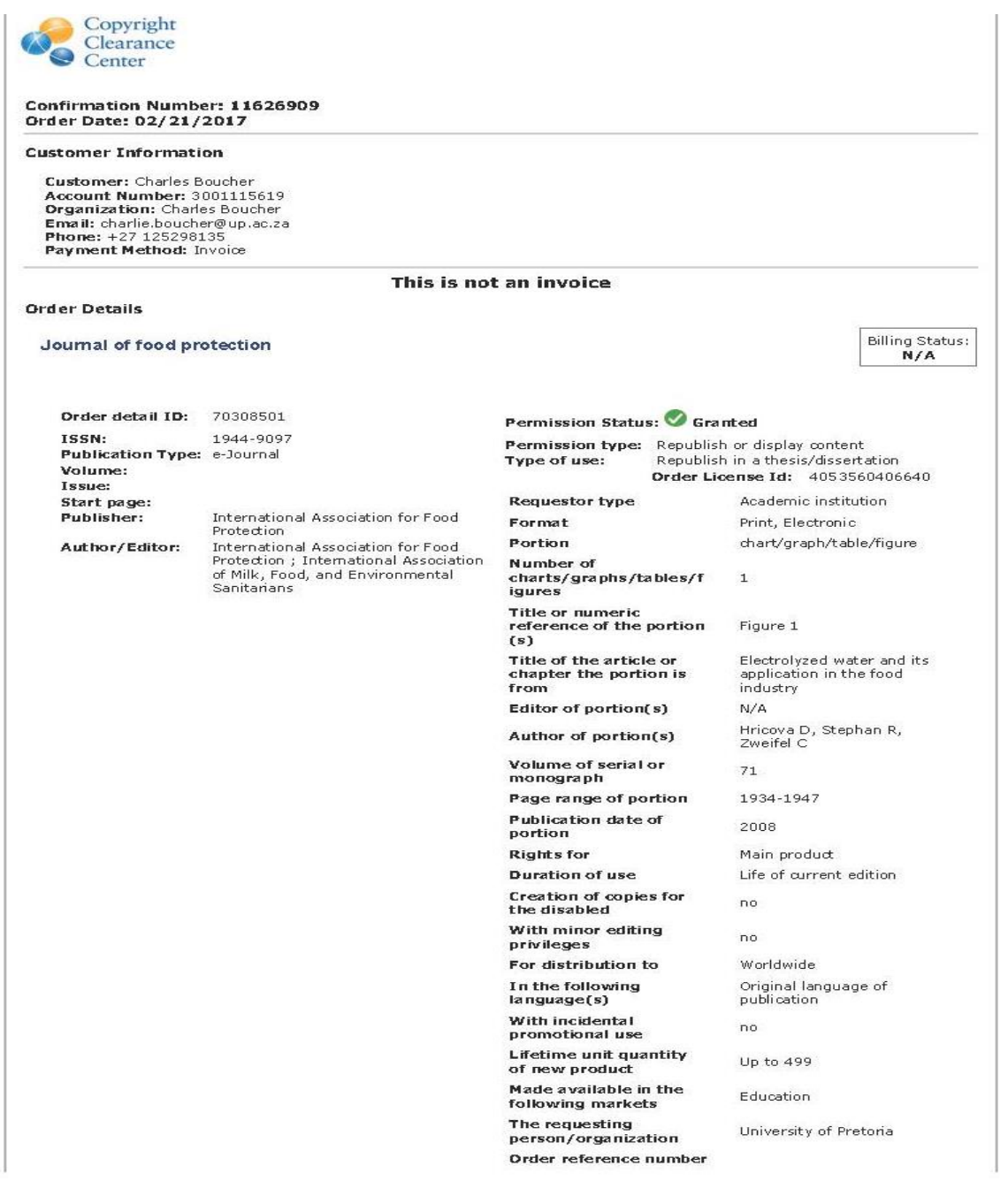

\begin{tabular}{|c|c|}
\hline Author/Editor & Charles Boucher \\
\hline $\begin{array}{l}\text { The standard identifier } \\
\text { of New Work }\end{array}$ & Antiseptic \\
\hline The proposed price & N/A \\
\hline Title of New Work & $\begin{array}{l}\text { Comparison of three } \\
\text { antiseptics as a surgical } \\
\text { skin preparation in dogs }\end{array}$ \\
\hline Publisher of New Work & University of Pretoria \\
\hline $\begin{array}{l}\text { Expected publication } \\
\text { date }\end{array}$ & Sep 2017 \\
\hline Estimated size ( $p$ & 80 \\
\hline
\end{tabular}

Note: This item was invoiced separately through our RightsLink service. More info 


\subsection{ANNEXURE G: Raw datasheet}

\begin{tabular}{|c|c|c|c|c|c|c|c|c|c|c|c|c|c|c|c|c|c|c|c|c|c|c|c|c|c|}
\hline $\begin{array}{c}\begin{array}{c}\text { Projeot } \\
\text { no }\end{array} \\
\end{array}$ & Date & $\begin{array}{l}\text { Fatient } \\
\text { Fieference }\end{array}$ & Student & DogBreed & \begin{tabular}{|l} 
Dog \\
weight \\
Kag)
\end{tabular} \mid & $\begin{array}{c}\text { Spay } \\
\text { no }\end{array}$ & Antiseptic & $\left|\begin{array}{l}\text { Duration } \\
\text { of wash } \\
\text { (min) }\end{array}\right|$ & 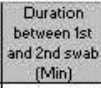 & \begin{tabular}{|c|} 
Skin \\
reacion \\
post \\
wash \\
wast
\end{tabular} & \begin{tabular}{|c|} 
Skin \\
reacotion \\
post \\
antisepsis
\end{tabular} & $\begin{array}{l}\text { Surgery } \\
\text { time } \\
\text { (Minutes) }\end{array}$ & & SAMPLE1 & & SAMPLE 2 & & SAMPLE 3 & & SAMPLE 4 & & AIRI CONTROL & $\left|\begin{array}{c}\text { Skin } \\
\text { reaction } \\
\text { posis: } \\
\text { [Yisi }\end{array}\right|$ & $\begin{array}{l}\text { Post operative } \\
\text { infeotion (YMN) }\end{array}$ & Comments \\
\hline & & & & & & & & & & & & & $\begin{array}{c}\text { Numb } \\
\text { ef } \\
\text { CFU }\end{array}$ & Bacteriallo & \begin{tabular}{|l} 
Numb \\
ef \\
CFU
\end{tabular} & Bacterial10 & $\mid \begin{array}{c}\text { Numb } \\
\text { e } \\
\text { CFU }\end{array}$ & BacterialID & \begin{tabular}{|c|} 
Num \\
ber \\
CFU
\end{tabular} & Bacteriallo & \begin{tabular}{|c|} 
Num \\
bef \\
CFu
\end{tabular} & Bacterial10 & & & \\
\hline 1 & 2015,090103 & 2940415 & Jearine Gibb & Border Calle & 15,4 & 2 & $\mathrm{~F} 10$ & 8 & 10 & No & No & 160 & 13 & Staphylocococus $\mathrm{sp}$ & 1 & $\begin{array}{l}\text { Staphylococous } \\
\text { pseudintermedius }\end{array}$ & 0 & No growen & 0 & No growen & 0 & No growen & No & No & $\begin{array}{l}\text { Telephonic contact. No } \\
\text { complications }\end{array}$ \\
\hline & & & & & & & & & & & & & 1 & Bacilus sp & 1 & Actinetobacater sp & & & & & & & & & \\
\hline 2 & 2015090,03 & 2940715 & Mathew Huckle & Jack Rusell Temer & 6,4 & 2 & Chlomexidine & 7 & 8 & No & No & 120 & 2 & Bacilus sp & 10 & No growen & 0 & No growth & 1 & Baclus sp & 0 & No growten & No & No & $\begin{array}{l}\text { Telephonic contact. № } \\
\text { complications }\end{array}$ \\
\hline & & & & & & & & & & & & & 3 & Micrococous sp & & & & & & & & & & & \\
\hline & & & & & & & & & & & & & \begin{tabular}{|l|}
1 \\
6
\end{tabular} & \begin{tabular}{|l|} 
Bacilus cereus \\
Streptomyces
\end{tabular} & & & & & & & 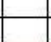 & & & & \\
\hline & & & & & & & & & & & & & & & & & & & & & & & & & \\
\hline 3 & $2015090 / 03$ & 2940615 & Fred le Roux & Border Colle & 15,6 & 2 & Anolye & 8 & 10 & No & No & 135 & 8 & \begin{tabular}{|l} 
Staphylococous \\
psevdontermedus
\end{tabular} & 0 & No growen & 0 & No growen & 1 & $\begin{array}{l}\text { Staphylococous } \\
\text { psendontermetus }\end{array}$ & 0 & No growth & No & No & Heavy ick burden. \\
\hline & & & & & & & & & & & & & & & & & & & & & & & & & $\begin{array}{l}\text { Telephonic contact. No } \\
\text { comolications }\end{array}$ \\
\hline 4 & 2015090,08 & 2941415 & Ben Jacobs & Border Collie & 20 & 1 & Chlomexidine & 7 & 12 & Mid & Mid & 124 & 3 & Bacilus sp Isolate 1 & 1 & Bacllus sp Isolate 3 & 1 & Bacilus sp Isolate 1 & 1 & Baclius sp Isolate 2 & 1 & $\begin{array}{l}\text { Staphyloococous } \\
\text { oseudointermedus }\end{array}$ & Mid & No & \\
\hline & & & & & & & & & & & & & 2 & Bacilus sp lsolate 2 & & & & & 1 & Bacilus sp Isolate 4 & $\frac{1}{1}$ & \begin{tabular}{|l|} 
Microcococus sp \\
Baclus sp l solate 5 \\
\end{tabular} & & & \\
\hline & & & & & & & & & & & $-5+2>$ & & + & 5 & & & 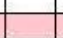 & & 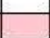 & & 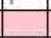 & Bacilus sp isolie 5 & & & \\
\hline 5 & 201509908 & 3061115 & Danny de Vres & Bassen Hound & 21,2 & 1 & Anolye & 8 & 10 & No & No & 161 & 1 & $\begin{array}{l}\text { Staphylococous } \\
\text { pseudontermedius }\end{array}$ & 1 & Bacllus sp & 0 & No growh & 1 & Corynebactenum sp & 1 & $\begin{array}{l}\begin{array}{l}\text { Staphylooocous } \\
\text { oseudointermedus }\end{array} \\
\end{array}$ & No & $\begin{array}{l}\text { Lost to followt } \\
\text { up }\end{array}$ & \\
\hline & & & & & & & & & & & & & & & & & & & 1 & Weeksella virosa & 1 & Micrococous sp & & & \\
\hline & & & & & & & & & & & & & 1 & & & & 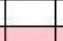 & & $T_{0}+2$ & & 1 & Bacilus sp Isolate 5 & & & \\
\hline 6 & $2015: 109117$ & 3116615 & Justin Grace & Shar-Pei & 14,2 & 2 & $\mathrm{~F} 10$ & 5 & 12 & No & No & 132 & 20 & 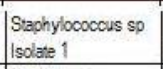 & 0 & No growen & 7 & $\mid \begin{array}{l}\text { Staphylococous sp } \\
\text { Isolate } 1\end{array}$ & 2 & $\begin{array}{l}\text { Staphylococous sp } \\
\text { Isolatie } 1\end{array}$ & 2 & $\begin{array}{l}\text { Mixed cuthre } \\
\text { Bacilus sp }\end{array}$ & No & No & Telephonic contact \\
\hline & & & & & & & & & & & & & 3 & Bacilus sp & & & & & & & 1 & Microcococus sp & & & \\
\hline & & & & & & & & & & & & & & & & & & & & & 2 & $\begin{array}{l}\text { Staphylococous sp- } \\
\text { Isolate 2 }\end{array}$ & & & \\
\hline 7 & $2015 / 09 / 22$ & 3137915 & Tanin Wells & Spaniel & 12 & 1 & $\mathrm{~F} 10$ & 5 & 9 & \begin{tabular}{|l} 
Mid \\
along \\
midine
\end{tabular} & Mid & 142 & 1 & Bacilus cereus & 10 & No grown & 0 & No growth & 1 & Corynebactenum sp & 3 & $\begin{array}{l}\text { Staphylococous } \\
\text { oseudontermedius }\end{array}$ & Mid & Noo & Telephonic contact \\
\hline & & & & & & & & & & & & & 1 & Bacilus sp lsolate 1 & & & & & & & 2 & Bacilius sp Isolitie 2 & & & \\
\hline & & & & & & & & & & & & & & & & & & & & & 1 & Acinetobacter sp & & & \\
\hline & & & & & & & & & & & & & $\mathrm{L}-2+$ & & & & & & & & 2 & Micrococous sp & & & \\
\hline 8 & 2015:09:23 & 3140415 & Noluhando Nolushe & Jack Russel| Temriet| & 6,4 & 3 & F10 & 5 & 7 & No & No & 126 & 35 & $\begin{array}{l}\text { Staphyloococous } \\
\text { sseudointermedius }\end{array}$ & 1 & Baclilus sp Isoltst 1 & 1 & $\begin{array}{l}\text { Staphylocococous } \\
\text { pseudointermedius }\end{array}$ & 1 & Bacilus sp Isolate 1 & 1 & Becilus sp Isolite 3 & | No & No & Telephonic contact \\
\hline & & & & & & & & & & & & & 9 & Baclius sp Isolate 1 & & & & & & & 1 & $\begin{array}{l}\text { Staphylococcus } \\
\text { epidermidis }\end{array}$ & & & \\
\hline & & & & & & & & & & & & & 1 & Bacilus sp lsolate 2 & & & & & & & 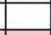 & & & & \\
\hline 9 & $2015 / 109: 23$ & 3143015 & Thapelo Makae & Dachshund & 9,6 & 3 & Chlomexidine & 4 & 16 & No & No & 110 & 2 & Baclilus sp lsolate 1 & 10 & No growen & 10 & No grown & 10 & No grown & 1 & Bacilus sp Isolate 3 & N No & No & Telephonic contact \\
\hline & & & & & & & & & & & & & & & & & & & & & 1 & $\begin{array}{l}\text { Staphylococous } \\
\text { epidermids }\end{array}$ & & & \\
\hline 10 & $20151 / 09: 23$ & 1985814 & Khelekani Lukhele & Mn Schnauzer & 14 & 3 & Andyle & 11 & 12 & No & No & 250 & 5 & Bacilus sp Isolate 1 & 0 & No growem & 1 & Eschenichia colk & 1 & Escherichia coli & 1 & Bacilus sp Isolate 3 & No & No & \begin{tabular}{|l} 
Mid post operative \\
brisisg. No post \\
operative infecson. \\
Telephonic contact
\end{tabular} \\
\hline & & & & & & & & & & & & & 2 & Bacilus sp Isolate 2 & & & & & & & 1 & \begin{tabular}{|l|}
$\begin{array}{l}\text { Staphylococous } \\
\text { epidermidis }\end{array}$ \\
\end{tabular} & & & \\
\hline & & & & & & & & & & & & & & & & & & & & & & & & & \\
\hline
\end{tabular}




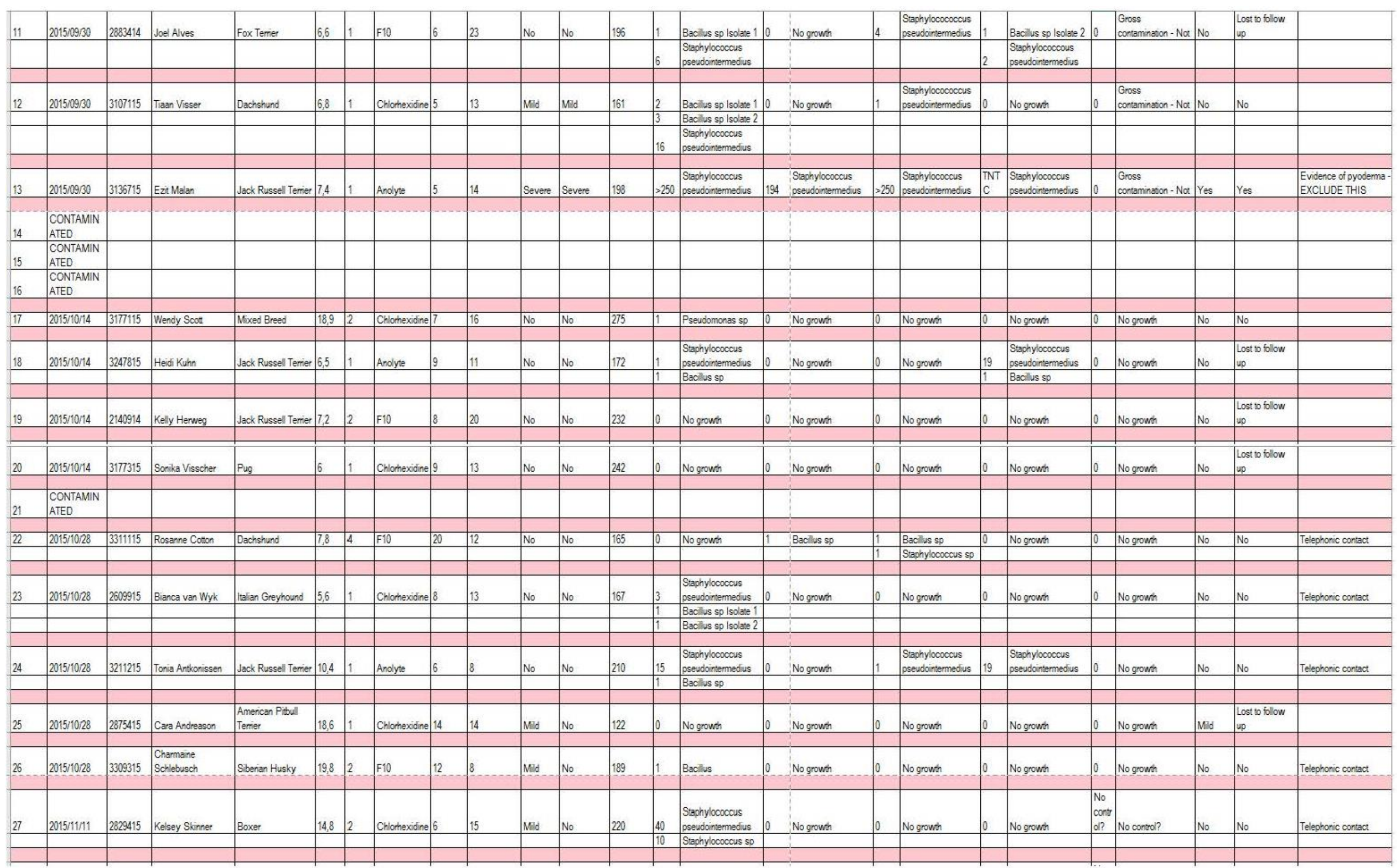




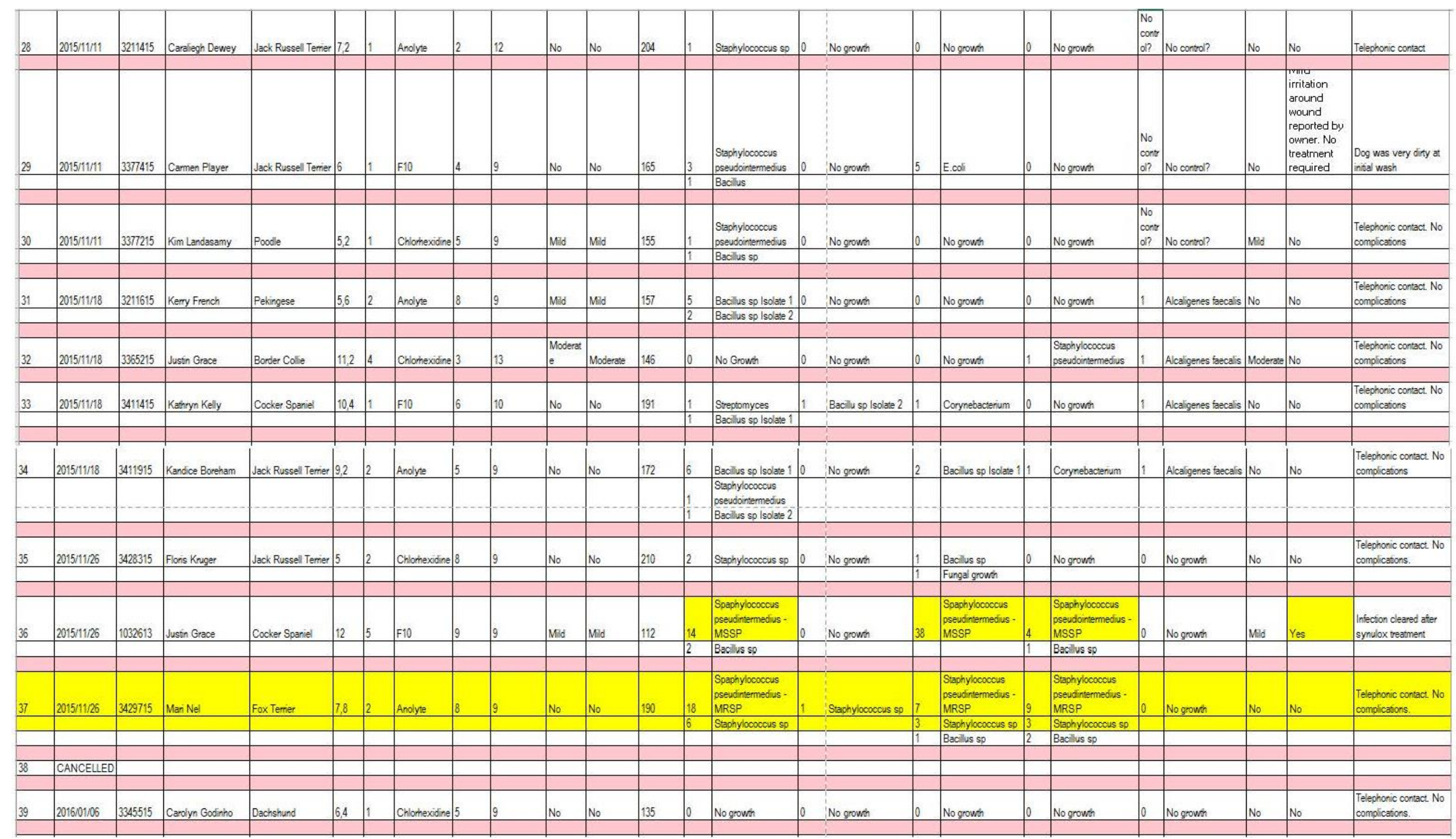




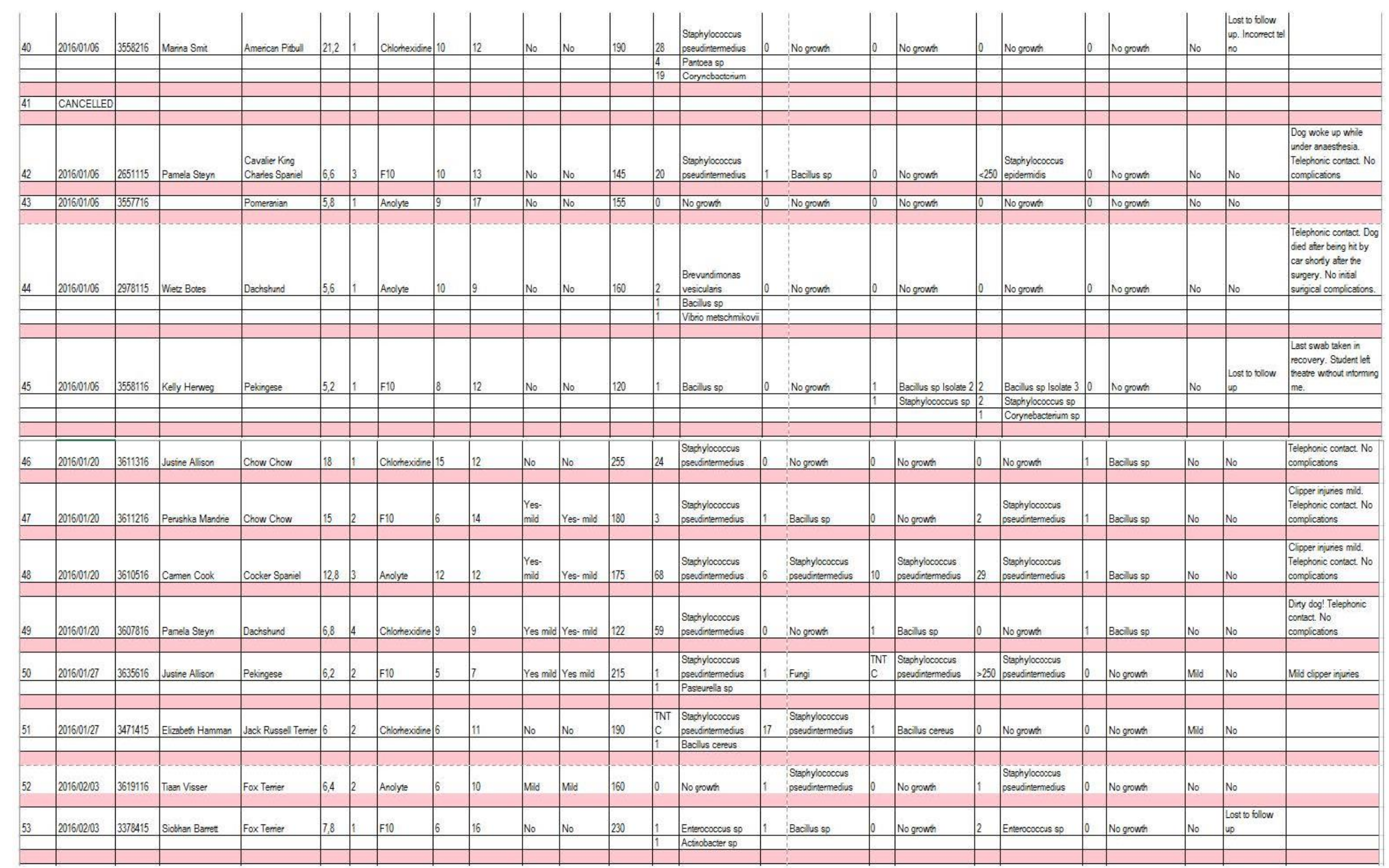




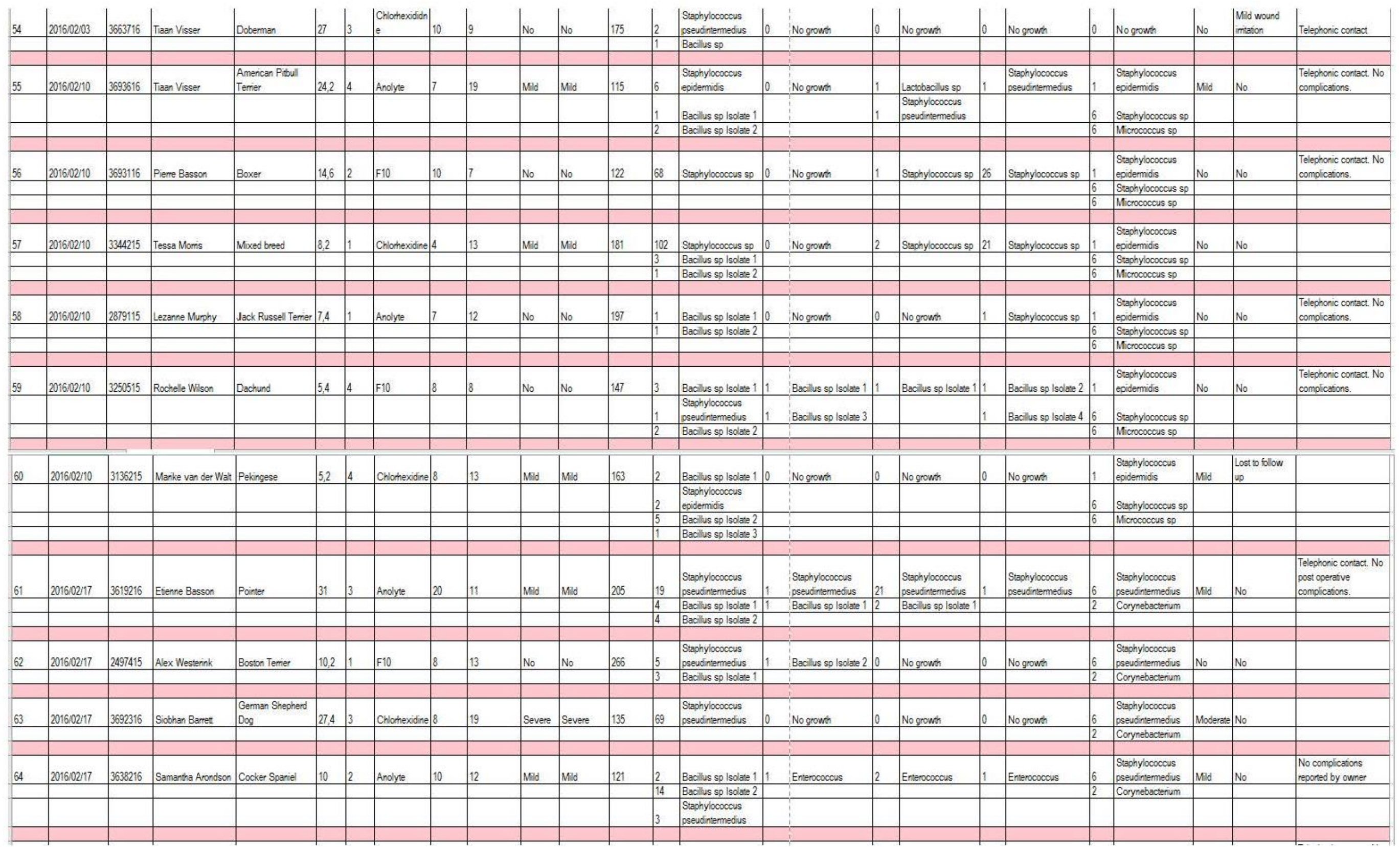




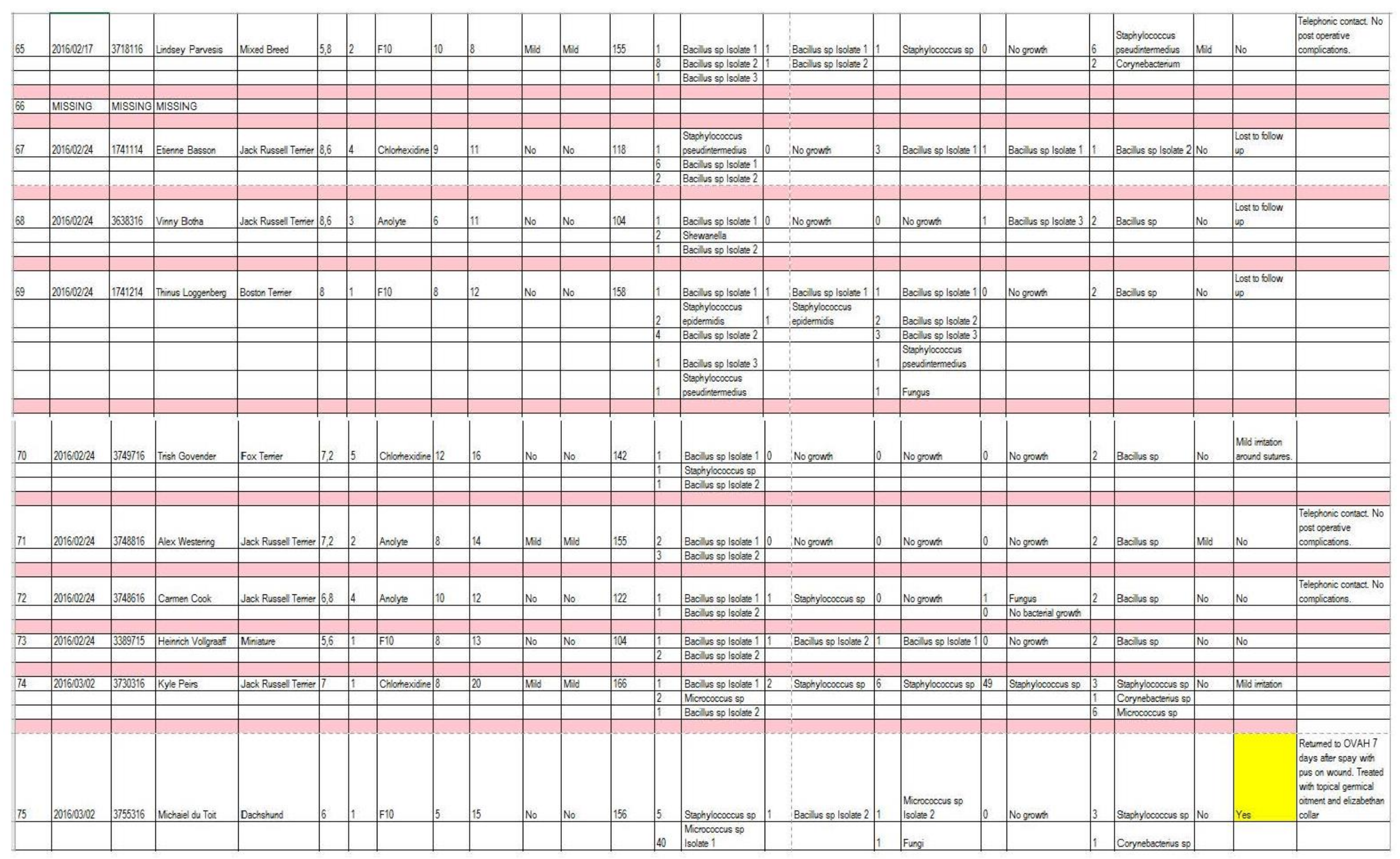




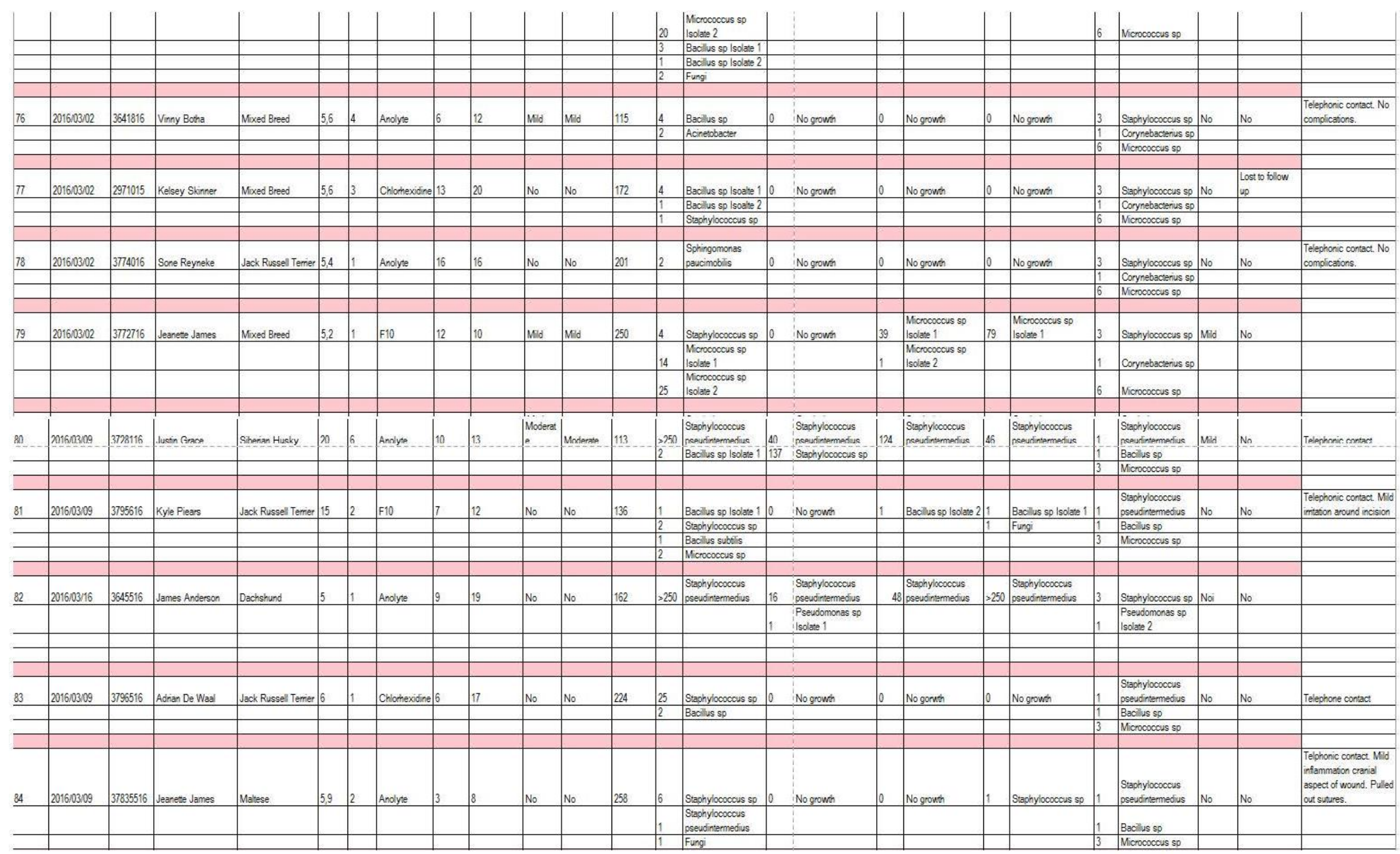




\begin{tabular}{|c|c|c|c|c|c|c|c|c|c|c|c|c|c|c|c|c|c|c|c|c|c|c|c|c|c|}
\hline & & & & & & & & & & & & & 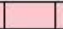 & & & 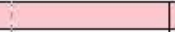 & -5 & & 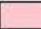 & & & & & & \\
\hline 85 & $2016: 03,09$ & 3797316 & Jaryd Thorpe & Yorkshire Temer & 5 & 1 & F10 & 10 & 14 & No & No & 234 & 1 & Baclius sp Isolate 1 & 0 & No growth & 0 & No grown & 2 & Micrococcus sp & 1 & 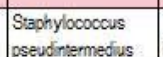 & Noo & No & Telechonic contact \\
\hline & & & & & & & & & & & & & 1 & Bacilus sp Isolatie 2 & & & & & & & 1 & Bacilus sp & & & \\
\hline & & & & & & & & & & & & & 1 & Bacilus sp Isolate 3 & & 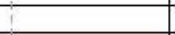 & & & & & 3 & Micrococcus sp & & & \\
\hline & & & & & & - & & 5 & & & & & & & & 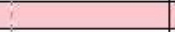 & - & & 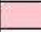 & & 工 & & & & \\
\hline 86 & 20161030309 & 3797416 & Tasmeen Anhony & Doberman Pinscher & 4,8 & 1 & Chlamexione & 6 & 14 & No & No & 136 & 1 & Staphylococous sp & 0 & No growth & 0 & No growh & 0 & No growh & 1 & $\begin{array}{l}\text { Staphylocococus } \\
\text { pseudintermedius }\end{array}$ & No & No & Telephonic contisct \\
\hline & & & & & & & & & & & & & 4 & \begin{tabular}{|l|} 
Staphyliocococus \\
pseudintemedius
\end{tabular} & & & & & & & 1 & Bacilus sp & & & \\
\hline & -- & -. & & & $-\cdots$ & $\cdots$ & &.- & & $\cdots$ & $\cdots$ & $\ldots$ & $\frac{1}{1}$ & Bacilus sp Isolate 1 & & & 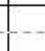 & $\ldots$ & 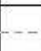 & $\ldots$ & 3 & Microcococus so & $\ldots$ & $\ldots$ & $\ldots$ \\
\hline & & & & & & & & & & & & & & Dacicus spo isolate 2 & & 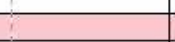 & & & & & & & & & \\
\hline 87 & $2016 / 03 / 16$ & 1217714 & Kirsten Colins & Pekingese & 7,8 & 2 & Chlomexidine & 6 & 12 & Mid & Mid & 155 & $=250$ & \begin{tabular}{|l|} 
Staphyliococous \\
pseudintemedius
\end{tabular} & 0 & No growh & 0 & No growh & 3 & $\begin{array}{l}\text { Staphylocococus } \\
\text { pseudintermedus }\end{array}$ & 3 & Staphylooccous sp & Mild & Lost to contact & \\
\hline & & & & & & & & & & & & & (a & & 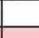 & $i$ & - & & $\square$ & & 1 & \begin{tabular}{|l|} 
Pseudomonas sp \\
\end{tabular} & & & \\
\hline 88 & $2016103 / 16$ & 3645416 & Barent Jacobs & Dachund & 6,4 & 3 & $\mathrm{~F} 10$ & 6 & 16 & No & No & 111 & 1 & Becilus sp & 0 & No grown & 0 & No grown & 0 & No growh & 3 & Staphyliococous sp & No & No & $\begin{array}{l}\text { Telephonic contact. № } \\
\text { complicatons. }\end{array}$ \\
\hline & & & & & & & & & & & & & 1 & Staphyliococous sp & & & & & & & 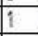 & \begin{tabular}{|l|} 
Pseudomonas sp \\
\end{tabular} & & & \\
\hline & & & & & & & & & & & & & 4 & $\begin{array}{l}\text { Staphylocococus } \\
\text { pseudintermedus }\end{array}$ & & & & & & & & & & & \\
\hline & & & & & & & & & & & & & & & & & & & & & & & & & \\
\hline 89 & $2016103 / 23$ & 3838016 & Ben Jacobs & Jack Russell Temer & 7,6 & 4 & $F 10$ & 6 & 19 & No & No & 105 & 0 & No growen & 0 & No growh & 0 & No growen & 3 & $\begin{array}{l}\text { Staphylococous } \\
\text { pseudintermedvis }\end{array}$ & 1 & Microcococussp & № & \begin{tabular}{|l} 
Lost to followi \\
up
\end{tabular} & \\
\hline & & & & & & & & & & & & & & & & 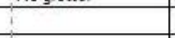 & & & & & 1 & Corynebacterium & & & \\
\hline & & & & & & & & & & & & & _ & & E- & 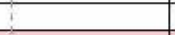 & & & & & 1 & Unidentfed yeast & & & \\
\hline & & & & & & & & & & & & & E & & & 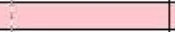 & 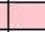 & & $\square$ & 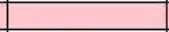 & 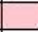 & & & 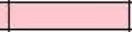 & \\
\hline 90 & $2016103 / 23$ & 3838516 & Tonia Artionissen & Basset Hound & 12,4 & 3 & Anolyte & 12 & 15 & No & No & 122 & 108 & $\begin{array}{l}\text { Staphyliococous } \\
\text { pseudintermedus }\end{array}$ & 2 & $\begin{array}{l}\text { Staphylococous } \\
\text { pseudintermedus }\end{array}$ & 7 & $\begin{array}{l}\text { Staphylocococus } \\
\text { pseudintermedius }\end{array}$ & 7 & $\begin{array}{l}\text { Staphylocococus } \\
\text { pseudintermedus }\end{array}$ & 1 & Micrococcussp & No & No & \\
\hline & & & & & & & & & & & & & 2 & Bacilus sp & & & & & & & 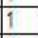 & Corynebacienum & & & \\
\hline & & & & & & & & & & & & & & & & 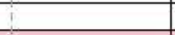 & & & & & 1 & Unidenffed yeast & & & \\
\hline & & & & & & & & & & & & & & & & & & & & & & & & & \\
\hline 91 & $2016003 / 23$ & 3838716 & Poul Reynolds & Yorkshire Temer & 5,4 & 1 & Chlomexidine & 6 & 10 & No & No & 100 & 15 & $\begin{array}{l}\text { Staphylococous } \\
\text { pseudintermedus }\end{array}$ & 0 & No grovito & 0 & No growth & 0 & No growth & 1 & Micrococous sp & No & No & $\begin{array}{l}\text { Pulled out sutures. No } \\
\text { nnecton }\end{array}$ \\
\hline & & & & & & & & & & & & & 2 & Staphylococous sp & & & & & & & 1 & Corynebacterium & & & \\
\hline & & & & & & & & & & & & & 6 & Corynebactenum & & $i$ & & & & & 1 & Unidenffed yeast & & & \\
\hline & & & & & & & & & & & & & 1 & Bacilus $\mathrm{sp}$ & & i & & & & & & & & & \\
\hline & & & & & & & & & & & & & & & & & & & & & 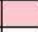 & & & & \\
\hline 92 & $2016 / 04 / 16$ & 3882916 & Kelsey Trasschler & Yorkshire Temer & 5 & 1 & Anolyte & 9 & 20 & Mid & Mid & 110 & 1 & $\begin{array}{l}\text { Staphylococous } \\
\text { epidermids }\end{array}$ & 0 & No growín & 0 & No growth & 1 & Corynebacternum sp & 1 & Micrococcus sp & No & No & $\begin{array}{l}\text { Telephonic contact. № } \\
\text { compicications. }\end{array}$ \\
\hline 93 & $2016 / 04 / 16$ & 3426615 & Michelle Weshof & Mixed Breed & 16,6 & 2 & $\mathrm{~F} 10$ & 12 & 17 & No & No & 186 & 4 & Baclius sp Isolate 1 & 2 & Bacllus sp Isolate 1 & 2 & Bacllus sp Isolatie 1 & 1 & Baclus sp Isolate 1 & 1 & Micrococcus sp & Noo & No & $\begin{array}{l} \\
\text { Telephonic contact. № } \\
\text { comolications. }\end{array}$ \\
\hline & & & & & & & & & & & & & 1 & Bacilus sp Isolate 2 & & & & & 1 & Staphylocococus sp & & & & & \\
\hline & & & & & & & & & & & & & 2 & Bacilus sp Isolate 3 & & $i$ & & & & & & & & & \\
\hline & & & & & & & & & & & & & & & & it & & & & & & & & & \\
\hline 94 & $2016 / 04 / 16$ & 3882016 & Orsilia Smit & Jack Russell Temer & 8,2 & 1 & Chlomexidine. & 4 & 22 & No & No & 131 & 1 & Bacilus sp Isolate 1 & 0 & No grown & 0 & No growth & 1 & \begin{tabular}{|l}
$\begin{array}{l}\text { Baclus species } \\
\text { isolate } 2\end{array}$ \\
\end{tabular} & 1 & Micrococcus sp & No & No & $\begin{array}{l}\text { Telephonic contact. № } \\
\text { complications. }\end{array}$ \\
\hline 95 & $2016,04 / 16$ & 38311116 & Juie Sianley & Jack Russell Temer & 7 & 1 & Anolye & 6 & 15 & Mid & Mild & 145 & 2 & $\begin{array}{l}\text { Staphylococous } \\
\text { osendintemedtus } \\
\text { MSSP) }\end{array}$ & 1 & $\begin{array}{l}\text { Staphylococous } \\
\text { epidernidis }\end{array}$ & 1 & $\begin{array}{l}\text { Staphylococous } \\
\text { pseudintermedus }\end{array}$ & 1 & $\begin{array}{l}\text { Staphylococous } \\
\text { epidermidis }\end{array}$ & 1 & Micrococcus sp & Mild & No & $\begin{array}{l}\text { Telephonic contract. NNo } \\
\text { compicictions. }\end{array}$ \\
\hline & & & & , & & & & & & & & & 6 & $\begin{array}{l}\text { Staphylocococus } \\
\text { epidermils }\end{array}$ & & & 1 & Carynebacterium sp & & & & & & & \\
\hline & & & & & & & & & & & & & 1 & Bacilus sp & & & & & & & & & & & \\
\hline & & & & & & & & & & & & & & & & & & & & & & & & & \\
\hline
\end{tabular}




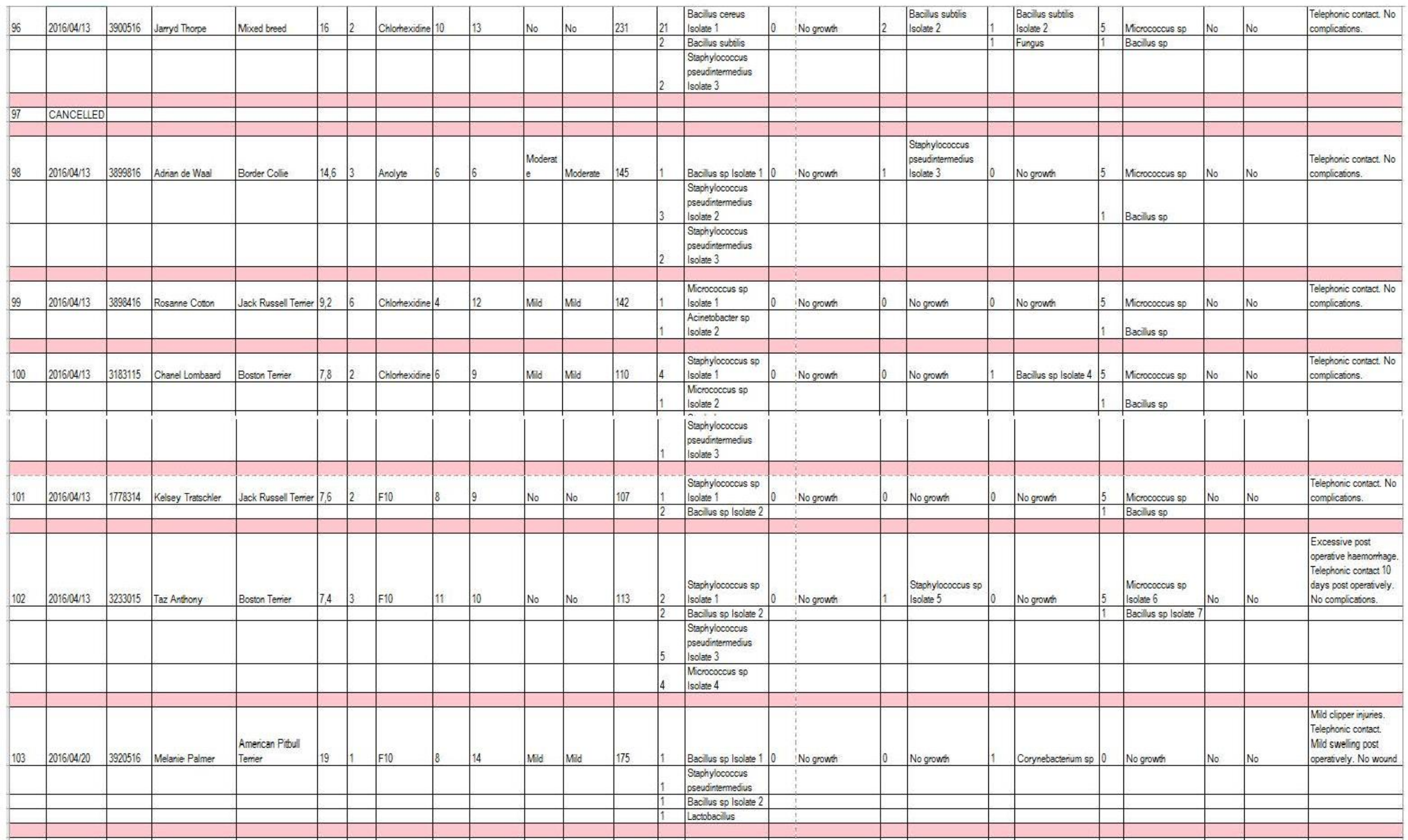




\begin{tabular}{|c|c|c|c|c|c|c|c|c|c|c|c|c|c|c|c|c|c|c|c|c|c|c|c|c|c|}
\hline 104 & $201604 / 20$ & 3557016 & Rosar Bnggemann & Mreed breed & 22 & 3 & Anolyte & 14 & 19 & No & No & 116 & 2 & Baclus sp Isolate 1 & 2 & $\begin{array}{l}\text { Staphyloococus } \\
\text { spseudintermedus }\end{array}$ & 0 & No grown & 2 & Bacilus sp Isolate 2 & 0 & No grown & No & No & \begin{tabular}{|l} 
Telephonic contiact. No \\
complicatons.
\end{tabular} \\
\hline & & & & & & & & & & & & & 1 & $\begin{array}{l}\text { Staphylococous } \\
\text { pseudintermedius }\end{array}$ & & & & & & & & & & & \\
\hline 105 & $2016,04 / 20$ & 3922216 & Nick Temlet & Sibenan Husky & 22,4 & 2 & Andyse & 10 & 25 & No & No & 112 & 1 & Bacilus cereus & 0 & No growh & 1 & Corynebactenum sp & 2 & $\begin{array}{l}\text { Staphylococous } \\
\text { pseudintermedius }\end{array}$ & 0 & No growen & No & No & $\begin{array}{l}\text { Telephone contact. } \\
\text { Wound looking good. } \\
\text { Sight imation over } \\
\text { shaved porions of } \\
\text { abdomen. }\end{array}$ \\
\hline & & & & & & & & & & & & & 1 & Corynebacterium sp & & & & & 2 & $\begin{array}{l}\text { Malassezia } \\
\text { pachydermats }\end{array}$ & & & & & \\
\hline & & & & & & & & & & & & & 2 & $\begin{array}{l}\text { Staphylocococus } \\
\text { pseudintermedus }\end{array}$ & & & & & & & & & & & \\
\hline 106 & $2016,04 / 20$ & 3921516 & Man Huckle & Bonder Calle & 29,2 & 5 & $F 10$ & 12 & 25 & Mid & Mid & 158 & 0 & No grown & 1 & Bacilus sp Isolate 1 & 1 & Bacilus sp isolate 2 & 1 & Bacilus sp Isolate 1 & 0 & No growen & No & No & $\begin{array}{l}\text { Telephonic contact. Noo } \\
\text { complicafons. }\end{array}$ \\
\hline & & & & & & & & & & & & & & & & & & & 1 & Bacilus sp Isolate 2 & & to & & & \\
\hline 107 & $2016104 / 29$ & 3949516 & Rosal Bruggeman & Jack Russell Temer & 8,6 & 4 & Chlomexidine & 7 & 18 & Severe & Severe & 113 & 4 & Bacilus sp Isolate 1 & 0 & No grown & 0 & No growen & 1 & Baclus so isolate 1 & $\begin{array}{lll}1 & \end{array}$ & Micrococcus sp & Moderate & No & $\begin{array}{l}\text { Telephoric contact. № } \\
\text { compications. }\end{array}$ \\
\hline & & & & & & & & & & & & & 3 & \begin{tabular}{|l|} 
Staphylococous \\
pseudintermedus
\end{tabular} & & & & & & & 1 & Staphylococous sp & & & \\
\hline & & & & & & & & & & & & & 2 & Bacilus sp Isolate 2 & & & & & & & 1 & Fungi & & & \\
\hline 108 & $201604 / 29$ & 3951016 & Jufie Stanley & Pekingese & 4,8 & 2 & Anolyte & 6 & 12 & No & No & 106 & 1 & Bacilus sp & 0 & No growen & 2 & Staphylocococous sp & 17 & Staphyliococous sp & 1 & Micrococcus sp & No & No & $\begin{array}{l}\text { Telephonic contact. № } \\
\text { complications. }\end{array}$ \\
\hline & & & & & & & & & & & & & & & & & & & & & Tr & Staphylococous sp & & & \\
\hline & & & & & & & & & & & & & & & & & & & & & 1 & Fungi & & & \\
\hline & & & & & & & & & & & & & 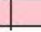 & & & & & & & & 1 & & & & \\
\hline 109 & $2016104 / 29$ & 3951316 & Rudel Zovusky & Jack Russell Temer & 8 & 2 & $F 10$ & 8 & 8 & Noo & No & 135 & 0 & No grown & 8 & Staphylocococus sp & 6 & Staphylococous sp & 2 & Staphyliococous sp & 1 & \begin{tabular}{|l} 
Micrococcous sp \\
\end{tabular} & No & No & $\begin{array}{l}\text { Telephonic contact. No } \\
\text { complicatons. All fne } \\
\text { when sutures were } \\
\text { removed }\end{array}$ \\
\hline & & & & & & & & & & & & & & & 1 & Yeast & & & & & 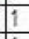 & Staphylocococus sp & & & \\
\hline & & & & & & & & & & - & & & & & & & & & & & 1 & Fungi & & & \\
\hline 110 & $201604 / 29$ & 3068315 & Melarie Palmer & Jack Russell Temier & 8,6 & 2 & Chlomexidine & 10 & 10 & Noo & No & $\mid 112$ & 1 & Staphylocococus sp & 0 & No growth & 0 & No growth & 0 & No growth & 1 & Micrococous sp & No & & Lost to follow up \\
\hline & & & & & & & & & & & & & 1 & \begin{tabular}{|l|} 
Bacilus sp \\
\end{tabular} & & & & & & & 1 & Staphylocococus sp & & & \\
\hline & & & & & & & & & & & & & 3 & $\begin{array}{l}\text { Staphylococous } \\
\text { pseudintermedius }\end{array}$ & & & & & & & 1 & Fungi & & & \\
\hline & & & & & & & & & & & & & & & & & & & & & & & & & \\
\hline 111 & CANCELLED & & & & & & & & & & & & & & & & & & & & & & & & $\begin{array}{l}\text { Resprataby distess - } \\
\text { OVH cancelled }\end{array}$ \\
\hline & & & & & & & & & & & & & & & & & & & & & & & & & \\
\hline 112 & 201605504 & 3968216 & \begin{tabular}{|l|} 
Annemieke van \\
Maas
\end{tabular} & Mxed breed & 8,4 & 3 & Andyle & 11 & 16 & Mid & Mid & 120 & 1 & \begin{tabular}{|l|} 
Staphylococcus \\
pseudintermedus
\end{tabular} & 0 & No growth & 0 & No growth & 0 & No growh & 2 & Baclus sp & Mid & No & $\begin{array}{l}\text { Telephonic contact - No } \\
\text { complicstons }\end{array}$ \\
\hline & & & & & & & & & & & & & 4 & Enterococuccus sp & & & & & & & 1 & Eschenchia & & & \\
\hline 113 & 2016:05:04 & 3033315 & Kristen Colins & Matese & 4,5 & 2 & Chlomexidine & 9 & 15 & No & No & 145 & 1 & $\begin{array}{l}\text { Rhizobium } \\
\text { radiobacter }\end{array}$ & 0 & No growth & 0 & No growh & 0 & No growh & 2 & Baclius sp & No & No & $\begin{array}{l}\text { Telephonic contact - No } \\
\text { complicatons }\end{array}$ \\
\hline & & & & & & & & & & & & & & & & & & & & & 1 & Eschenchia & & & \\
\hline 114 & 201605504 & 3033215 & Orsilla Smit & Matese & 4,5 & 3 & $F 10$ & 8 & 17 & Mid & Mid & 104 & 0 & No growen & 0 & No growth & 0 & No grown & 1 & Micrococous & 2 & Baclus sp & Mid & No & $\begin{array}{l}\text { Telephonic contact-No } \\
\text { complicstons. No } \\
\text { complicatons at sure } \\
\text { removal }\end{array}$ \\
\hline & & & & & & & & & & & & & & & & & & & & & 1 & Eschenchis & & & \\
\hline & & & & & & & & & & & & & & & & & & & & & & & & & \\
\hline
\end{tabular}




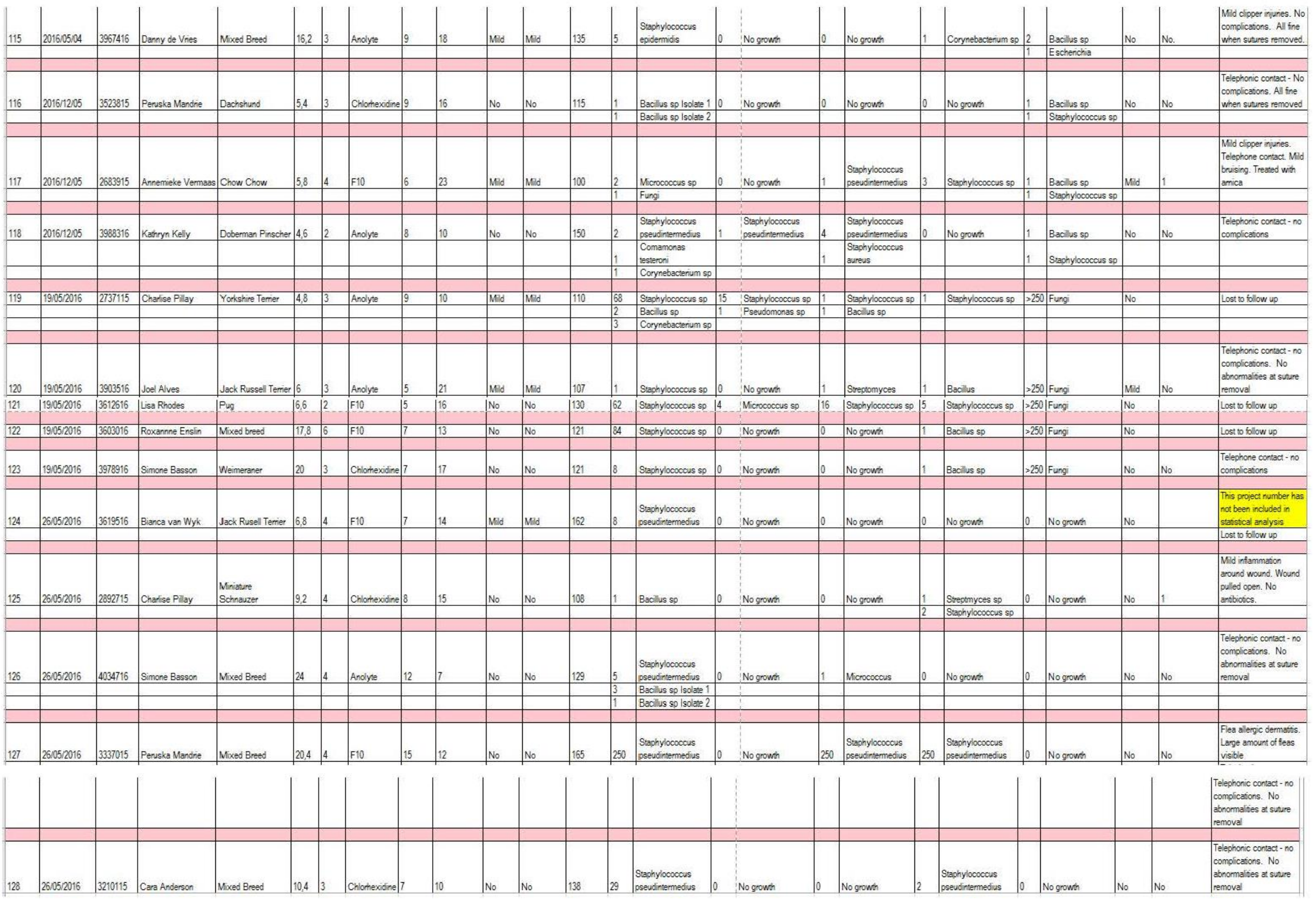

